\title{
Optimal intervention in the sickness absence process to prevent disability
}

Citation for published version (APA):

Joling, C. (2004). Optimal intervention in the sickness absence process to prevent disability. [Doctoral Thesis, Maastricht University]. Universiteit Maastricht. https://doi.org/10.26481/dis.20041119cj

Document status and date:

Published: 01/01/2004

DOI:

10.26481/dis.20041119cj

Document Version:

Publisher's PDF, also known as Version of record

\section{Please check the document version of this publication:}

- A submitted manuscript is the version of the article upon submission and before peer-review. There can be important differences between the submitted version and the official published version of record.

People interested in the research are advised to contact the author for the final version of the publication, or visit the DOI to the publisher's website.

- The final author version and the galley proof are versions of the publication after peer review.

- The final published version features the final layout of the paper including the volume, issue and page numbers.

Link to publication

\footnotetext{
General rights rights.

- You may freely distribute the URL identifying the publication in the public portal. please follow below link for the End User Agreement:

www.umlib.nl/taverne-license

Take down policy

If you believe that this document breaches copyright please contact us at:

repository@maastrichtuniversity.nl

providing details and we will investigate your claim.
}

Copyright and moral rights for the publications made accessible in the public portal are retained by the authors and/or other copyright owners and it is a condition of accessing publications that users recognise and abide by the legal requirements associated with these

- Users may download and print one copy of any publication from the public portal for the purpose of private study or research.

- You may not further distribute the material or use it for any profit-making activity or commercial gain

If the publication is distributed under the terms of Article $25 \mathrm{fa}$ of the Dutch Copyright Act, indicated by the "Taverne" license above, 
Optimal intervention in the sickness absence process to prevent disability 
Production: PrintPartners Ipskamp, Enschede, the Netherlands.

Lay-out: BiFab, Bianca Fraats

Cover design: BiFab, Bianca Fraats

ISBN 90-9018654-9

Copyright ${ }^{\odot}$ 2004, Catelijne Joling 


\title{
Optimal intervention in the sickness absence process to prevent disability
}

\author{
PROEFSCHRIFT \\ ter verkrijging van de graad van doctor \\ aan de Universiteit Maastricht, \\ op gezag van de Rector Magnificus, \\ Prof. mr. G.P.M.F. Mols, \\ volgens het besluit van het College van Decanen, \\ in het openbaar te verdedigen \\ op vrijdag 19 november 2004 om 14.00 uur \\ door
} Catelijne Ingold Joling 


\section{Promotor:}

Prof. dr. W. Groot

\section{Copromotor:}

Dr. P.P.M. Janssen

Beoordelingscommissie:

Prof. dr. M.P.F. Berger (voorzitter)

Prof. dr. J.T.M. van Eijk

Prof. dr. Ph. de Jong (Universiteit van Amsterdam)

N. Krause, MD, PhD, MPH (University of California Berkeley/San Francisco)

Prof. dr. C. de Neubourg 


\section{Contents}

Chapter $1:$ Introduction

The problem of incapacity for work

Social security in the Netherlands

The 1980s

The 1990s

As from the late $90 \mathrm{~s}$

The disability problem in numbers

Previous research on intervention in the sickness absence process to prevent disability

Aim of this study

The data

British data

Dutch data

Outline of this thesis

References

Chapter 2: A study of physiotherapy interventions for people with musculoskeletal complaints

Abstract

Introduction

Limitations of previous research

Biases and state dependence 
Aim of this study

Determinants of the probability of receiving an intervention

Research questions

Method

Design

Sample

Instruments 46

Analytical framework 46

Results 49

Descriptives 49

Estimation results for the probability of receiving an intervention 49

Estimation results for the probability of recovery

Discussion

Determinants of the probability of receiving a physiotherapy intervention

Determinants of the probability of recovery

Conclusions

References

Appendix

Chapter 3 : The timing of an intervention by the occupational physician

Abstract

Introduction

Predictors of the hazard rate

Duration

Other predictors 
Methods

Design

Sample

Instruments

Analyses

75

Results

Preliminary results 76

Parameter estimates 78

Expected duration

Discussion

Effect of duration

Effect of other predictors

Conclusions

References

Chapter $4:$ Modelling return-to-work intervention strategies

Abstract

Introduction

The modelling framework

Intervention

Predictors of the probability of intervention

Predictors of RTW

Methods

Design 
Results

Relationship between the probability of intervention and RTW

Relationship between the timing of the intervention and the timing of RTW

Discussion

Relationship between the probability of intervention and RTW

Whom to target?

The relationship between the timing of the intervention and the timing of RTW 116

Conclusions

References

Chapter 5 : How can we optimize Disability Management intervention strategies?

Abstract

Introduction

Duration dependence during the return to work process

Methods

Design

Sample and instruments

Analyses

Goodness-of-fit measures

Unobserved heterogeneity

Results 
Effect of the intervention on the RTW rate

Effect of worker characteristics on the RTW rate

Discussion and conclusions

References

Chapter 6: General Discussion

Introduction

Main Findings

Strengths and weaknesses

Level of analysis

Conceptualization of intervention in the sickness absence process

The risk of model misspecification

Policy implications

References

Samenvatting (Summary in Dutch) 

Chapter 1

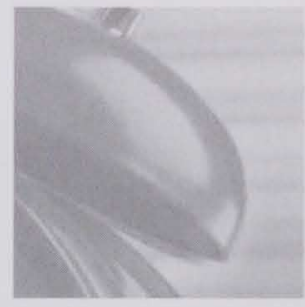

Introduction 
12 Chapter 1 


\section{The problem of incapacity for work}

In many European and North American countries incapacity for work is a major socio-economic problem ${ }^{1-3}$. In the Netherlands, over the last decades, an alarming number of workers has entered the disability benefit system. The number of disability benefit claims that were granted increased from 474,8 thousand in 1976 to almost one million in 2002 4, 5 . These nearly one million claimants make up no less than $14 \%$ of the working population ${ }^{5}$. In 2003, the number of disability beneficiaries slightly decreased ${ }^{6}$.

Incapacity for work is a problem that affects many aspects of society. Its financial and social consequences not only reach into workplaces and homes but also into hospitals, courts, and the local community ${ }^{7}$. Considering these far-reaching consequences, it is not surprising that the interest in work retention and return to work (RTW) has increased substantially over the last couple of years. In the Netherlands, over the last decades, many changes were implemented in the social security structure and administration practice in order to control the problem of work incapacity. To return absent workers back to the workplace, interventions take place during sickness absence. In this study we discuss important aspects of intervention strategies, with the aim to optimize intervention strategies for sick workers to prevent disability. To provide a framework in which this study can be placed, we will first briefly explain the social security system in the Netherlands, and the ideas behind some major amendments in the social security structure over the last decades, in section 2. In section 3, we describe the major trends in inflow and outflow of the disability benefit system over the last decades. We will see that, judging by the more or less stable inflow and outflow risks of the disability benefit system between 1976 and 2002, the legislative changes did not have much of an effect on the risk of incapacity for work. After twenty years of continuous adaptations of the social security system, work incapacity remains a major problem. Policymakers apparently do not have enough grip on the matter. In section 4, we will go into the issue of intervention in the sickness absence process to prevent disability, from a research perspective. From problems that were encountered in previous research we move on to the aim of this study in section 5 . 
$14 \mid$ Chapter 1

\section{Social security in the Netherlands}

In the 1950s, 60s and 70s, social security arrangements in the Netherlands were extended in several ways. Before that time, the Netherlands had an employeebased insurance system, covering just the "risque professionel" of workers. From the $50 \mathrm{~s}$ on, arrangements were extended to non-workers by introducing social insurances and social services ${ }^{8}$. Social security arrangements became more or less universal, covering both workers and non-workers, the risque professionel and the risque social ${ }^{4,8}$. With this system, the Dutch were unique in the world. However, expenses on social security increased rapidly. After a period of economic decline in the 70s, it was realized that this system was not tenable in the form in which it had been designed. The social security arrangements attracted an unexpected high number of claimants, which led to problems of affordability and control ${ }^{8}$. Consequently, from the 80 s on, the social security system has been subject of continuous reorganization and economization ${ }^{8}$.

\section{The $1980 \mathrm{~s}$}

In the 80 s, problems with social security were merely defined in terms of affordability $^{8}$. Arrangements became too expensive since a rapidly increasing number of people applied for social benefits. Reasons for this increase were the economic recession in the early 1980s, changing work and living patterns (e.g., individualization, emancipation, changes in household composition, an increase in (female) labor market participation, and changing labor relations) and a changing attitude of individuals and organizations towards the use of social security arrangements ${ }^{8}$. Until the mid 80 s, the disability benefit system was particularly used as a solution for the social consequences of the restructuring of the Dutch economy ${ }^{4}$. Work incapacity was seen as a solution to a problem, instead as a problem in itself ${ }^{4}$. The disability benefit system was especially used as a rather generous early retirement arrangement for older workers, who were not able to meet the increasing productivity demands ${ }^{4}$, or who were made redundant in (industrial sector) jobs for which demand was declining. 
In 1987, important changes in the social security system were implemented ${ }^{a}$ to restrain the rising expenditures ${ }^{8,9}$. The mean benefit level was cut back, and arrangements became more selective in order to control the number of claimants ${ }^{8}$. To control the inflow into the disability benefit system and the disability benefit duration, the eligibility criteria were restricted ${ }^{9}$. In the Netherlands, work incapacity is defined by a loss of earning capacity. The 'degree of disability' that is used to determine benefit levels, is determined by the loss of earning capacity as a result of the disability. The loss of earning capacity is determined by comparing a worker's former earnings to those of jobs that the worker could still fulfil with his ${ }^{b}$ disability ('suitable jobs'). Before 1987, claimants who were only partially disabled were frequently granted total disability benefits ${ }^{8}$. This was intended as a compensation for their lower chances on the labor market because of their partial disabilityc. This measure led to a higher inflow and a lower outflow of the disability benefit system, however, and was therefore abolished in $1987^{9}$. The eligibility criteria were further restricted in 1987 by making the decision about the degree of work disability a theoretical one, and by broadening the definition of suitable jobs ${ }^{9}$. The benefit decision was no longer based on a worker's actual job opportunities. The result of the restriction of the eligibility criteria was that absent workers' remaining earning capacity was enhanced and workers became less eligible for disability benefits. Another change that was implemented in 1987 was that work capacity was determined more formally by using a checklist ${ }^{d} 9$.

Between 1985 and 1990, the disability benefit system was especially used by workers who could not cope with the increasing (psychological) work demands and with the changing nature of the labor ${ }^{4}$. This were increasingly women and younger men. Many women who were then just starting to participate in the labor market encountered problems combining their work with their family role, e.g., the care for children at home ${ }^{4}$.

\section{The $1990 \mathrm{~s}$}

In the 90s the perception of the problem shifted from an affordability issue towards a question of control ${ }^{8}$. Consequently, the measures that were taken in the $90 \mathrm{~s}$ to

\footnotetext{
a "Stelselherziening van 1987".

"Where it says "he/his", can also be read "she/her".

c "Verdiscontering van de werkloosheid".

d "Functie Informatie Systeem (FIS)".
} 
restrain social security costs were of a different nature than those taken in the $80 \mathrm{~s}$. Inflow and outflow of the social security arrangements became a key issue in social security policy. The main question in the 90 s was how to control the use of the social service and arrangements. To decrease the number of claimants, the Dutch government has pursued an "activation policy" since the beginning of the $90 \mathrm{~s}^{8}$. This policy has a strong behavioral emphasis, and enforces more responsibility on individual workers and employers ${ }^{8}$. The government aimed to guide the behavior and actions of individual workers and organizations, but also the actions of those that implemented the policy. The administration practice was thought to be reprehensible ${ }^{8}$. The idea arose that this behavior could be guided by providing more incentives and disincentives. In legislation that followed, disincentives to claim disability benefits and incentives to return to work were built in, and personal responsibility was emphasized ${ }^{e}$. Employers, workers and those implementing the policy were activated through financial incentives. Employers were obliged to facilitate a return to work of sick workers. They were also forced to pursue a health and safety policy and became responsible for sickness absence management and sickness absence certification of their workers. In 1994, indeed, a reduction in sickness absence was observed ${ }^{10}$.

By a further restriction of the eligibility criteria and applying behavioral incentives (e.g., revising the administration structure and increasing own risks), the government intended to decrease the sickness and disability benefit claims ${ }^{8}$. In $1996^{f}$ and $1998^{g}$, a far-reaching privatization of the sickness and disability risk followed ${ }^{8}$. Employers became responsible for the income of their workers during the first year of absence. The financial incentives for prevention and reintegration, however, proved to be too small to decrease the volume of disability beneficiaries ${ }^{10}$. For workers, the financial incentives to return to work (i.e. cutback in the benefit level) were undone by collective labor agreements that supplemented their sickness benefit of $70 \%$ of their former wage to a $100 \%{ }^{10}$. The intended behavioral change was not obtained ${ }^{10}$.

All in all, the continuous economization and the radical changes in the eligibility criteria have changed the nature of disability and restrained the financial burden of

e TAV (1992), TBA (1993), TZ/Arbo (1994).

${ }^{i}$ Wulbz.

s Pemba. 
the disability benefit system (as we will see in the next section). As yet, the activation policy has, however, not been able to break the habit of medicalizing socio-economic problems, and solving them through the disability benefit system ${ }^{4}$. Important means to bring about a behavioral change, i.e. financial incentives, were introduced but minimized at the same time. The measures that were taken since 1992 did not result in an enduring long-term turnaround ${ }^{10}$. We can conclude that the context of disability and RTW has not changed much between 1990 and 2000 . The actual effects of the social security policy on the number of claimants, and the inflow and outflow of the disability benefit system over time, are discussed in the next section. The disability risk shows a diverging trend over time ${ }^{4,10}$. Especially women and youngsters are falling behind because they have a higher disability risk.

The radical policy measures in the 90 s interrupted the diverging trend, but did not stop it ${ }^{4}$. The second half of the $90 \mathrm{~s}$, the feminization and rejuvenation of the disability risk became even stronger ${ }^{4}$. The focus of attention shifted towards the sickness absence period ${ }^{h}$. The idea was that a more intensive management of the sickness absence process could decrease the disability risk.

\section{As from the late 90s}

The idea of intensive management of the sickness absence process, has found increasing support from the late 90s. From English-speaking countries like Canada and the United States, so-called Disability Management (DM) practices came across. DM is an integral approach aimed at work retention and return to work " Key principles of this approach are prevention and early intervention in the sickness absence process ${ }^{11-13}$. On the one hand, DM strategies aim to prevent sickness absence. On the other hand, once workers are absent, they are supported to return to work as soon as possible.

In the Netherlands, the integral DM approach is still in its infancy, though separate interventions aimed at work retention and RTW have been part of the sickness and disability management practices. The significance of prevention and reintegration efforts by workers and employers was confirmed by a law that came into force in 1998'. This law aimed to protect the health and safety of workers. Employers were

$\mathrm{h}$ The sickness absence period in the Netherlands consists of the first 52 weeks of absence.

i Arbowet (1998). 
officially required to pursue a sickness and disability prevention policy. They had to take on an occupational health service, an advisory body, that could assist them with the recognition of health and safety risks in the workplace and support the management of sickness absence. Flanking measures, aimed at minimizing the sickness absence duration of absent workers, provided positive incentives to accelerate the return to work, and imposed sanctions to workers and employers who put forward insufficient RTW efforts ${ }^{j}$ or put too many workers in disability. There has been an ongoing privatization of institutional responsibilities for sickness absence and disability. Private insurers took over a large part of the former public sickness benefit insurance ${ }^{14}$. However, as with the financial privatization, the institutional privatization (occupational health services, private insurers and reintegration agencies) did not immediately lead to behavioral changes ${ }^{14}$. The need for early and efficient intervention is nowadays stressed, and responsibilities of workers and employers are accentuated. Views on prevention and early RTW are slowly changing. However, behavior of employers still seems to be more reactive, i.e. coping with high levels or long periods of sickness absence as they occur, than pro-active ${ }^{14}$. Full wage replacement during the first year of absence is still standard practice, as is the practice of supplementing the disability benefit ${ }^{14}$. We will now turn to the effects of the changes in the social security structure and legislation on the composition of the disabled population. Were the intended effects achieved?

\section{The disability problem in numbers}

Whether the changes in the disability benefit system led to the effects that were intended can be judged by the number of claimants and the inflow and outflow numbers over the years. Trends of the past 25 years were extensively described by Aarts, de Jong and Van der Veen ${ }^{4}$. We will confine ourselves here to describing some major trends, and refer to Aarts et al for a complete overview.

Over the past three decades, the absolute number of disability benefit claims has more than doubled (475.000 in $1976-993.000$ in 2002) ${ }^{4,5}$. From 1976 up to 
1993, the number of claims grew steadily. Due to the radical changes that were implemented through the disability legislation in 1994, a temporary reduction in the number of claims occurred. This decline did however not persist, and after 1997 the absolute number of claimants again increased. When we look the proportional increase of the disabled population, numbers are less dramatick, but we still see an increase. The number of disabled workers as a percentage of the insured population' increased from $6.1 \%$ in 1975 to $11.4 \%$ in 1990 , then decreased to $9.7 \%$ in 1996 , became $9.9 \%$ in 1999 , and $10 \%$ in 2002 4. .

When the disability problem is viewed in terms of the financial burden upon society, we can see that the social security expenditures as a percentage of the Gross Domestic Product (GDP) in the year 2002 were approximately the same as they were in 1975 . In 1975 , social security expenditures took up $2.4 \%$ of the GDP. In 1980 this increased to $3.9 \%$, while a further increase was noted in 1984: $4.2 \%$. After that, a decrease set in, and in the year 1999 expenditures were back at the $2.6 \%$ level $4,5,15$. Three years later, in 2002, this was still the same ${ }^{5,15}$. Until 1993, the lower expenditure rate was related to a cutback in the mean benefit level. After 1993, the number of claims dropped as well. After 1996 the lowering of the financial pressure was mainly due to the large increase of the GDP. Social security expenditures in 1999 were exactly the same as in 1976: $2.6 \%$ of the $\mathrm{GDP}^{4}$. So with twice the number of claimants, the financial burden has remained the same. In this respect, the continuous economization and the radical changes in the access criteria of the disability benefit system aimed at cost containment were successful ${ }^{4}$. On balance, the benefit dependency ${ }^{m}$ did not change either between in 1980 and 2000. After an initial increase in the mid 80s, and a benefit dependency of 0,42 in 1985, in 2000 a number 0,28 benefits per labor income was noted ${ }^{4}$. The benefit dependency rate was by 2000 back at the level of 1980 .

An important trend in disability benefit numbers is the increase of the number of women in the system. In 1976, 25\% of the claimants were women. This proportion increased to $41 \%$ by $1999{ }^{4}$. In part, this is caused by the increased labor market participation of women. However, since the second half of the 80s, women also have a greater disability risk than men (in all age groups) ${ }^{8}$. With the

$k$ This is related to the fact that the insured population has increased over the years (Aarts, de Jong \& vd Veen, 2002).

'Insured population: part of the labor force that is insured for disability benefits ("WAO").

${ }^{m}$ Benefit dependency: number of benefit incomes / number of labor incomes. 
increase of the number of women in the system, from the beginning of the ' $90 \mathrm{~s} \mathrm{a}$ rejuvenation occurred as well. This increase in the number of youngsters was not so much due to a change in the proportional increase of youngsters, but rather due to the development of the age-specific disability risk ${ }^{8}$. Furthermore, from the beginning of the 80 s, the proportion of claimants with a psychological diagnosis increased from $20 \%$ to $33 \%$ in $1999^{4}$.

The dynamics of the disability problem are reflected in the inflow and outflow numbers. The probability of entering disability (i.e. inflow or disability risk) decreased from 1980 to 1987 ( $2.1 \%$ to $1.5 \%$ respectively), increased to $2.0 \%$ in 1990, and then decreased in 1995 to $1.1 \%{ }^{4}$ (also see the Appendix). After 1995 we see an upward trend again, especially for women. The inflow risk for women was $1.9 \%$ in $2002{ }^{5}$. Inflow probabilities for men dropped in the second half of the 90s. In 2002, men had a disability risk of $1.2 \%{ }^{5}$. Moreover, the inflow risk of youngsters increased over the years, while that of older workers decreased. Figure 1 shows the inflow trends of the disability benefit system from 1976 to 2002 .

Figure 1. Inflow of the Disability Benefit System: number of new granted disability benefits (WAO/WAZMAJONG) as a percentage of the working population of the previous year (source: UWV ${ }^{5}$ ).

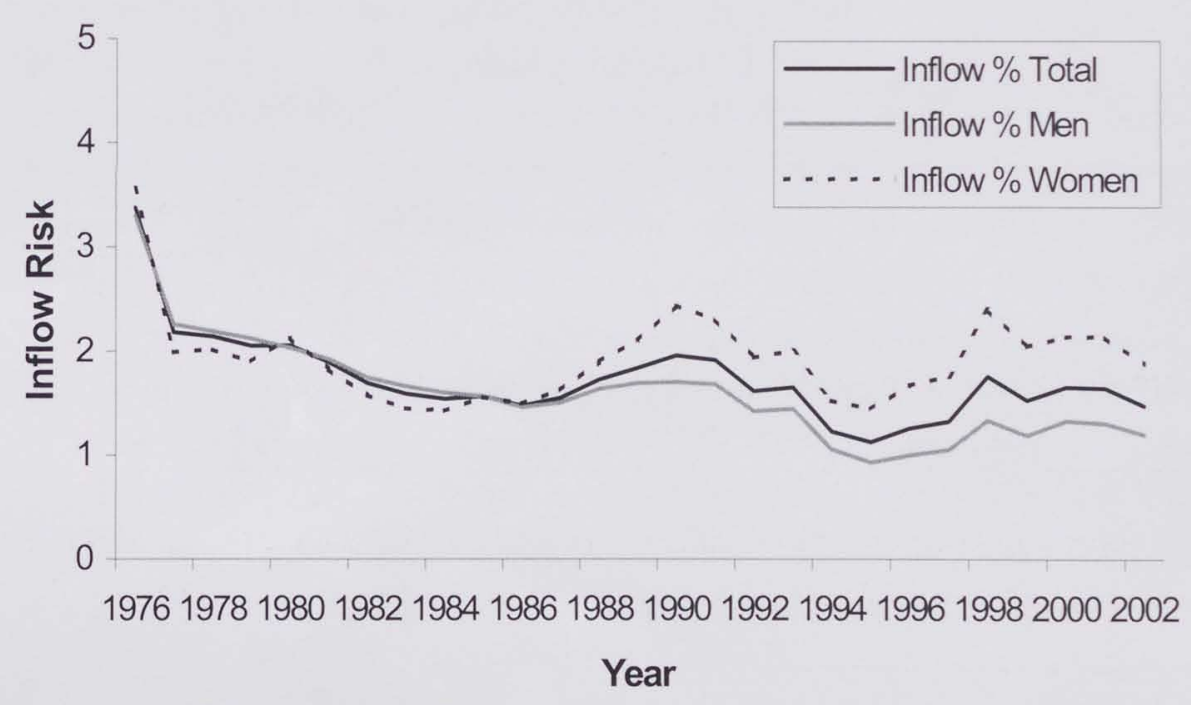


In sum, in all age groups, and for men and women, the inflow risk decreased from 1980-1986, increased from 1986-1990, decreased between 1990-1995 and increased again after that.

The outflow concerns disability benefit claims that are ended because of recovery, old-age pension or death. In 1976 , for $7.8 \%$ of all people in the disability benefit system benefits ended. In 1995, this was the case for $11 \%$ of the claimants, and in 1998 for $10.3 \%{ }^{8}$. Fluctuations in the general outflow trend are mainly determined by fluctuations in the probability of recovery ${ }^{n}$. For men, the probability of recovery fluctuates around 3\%, for women around $5 \%{ }^{4}$. The positive difference in recovery probabilities between women and men is somewhat distorted by the fact that female disabled workers are on average younger than male disabled workers ${ }^{4}$. When women and men of the same age groups are compared, it appears that women still have a somewhat higher probability of recovery. This does however not compensate for their higher inflow risk ${ }^{4}$.

Figure 2. Outflow of the Disability Benefit System: number of ended disability benefits (WAO/WAZ/WAJONG) on a yearly basis as a percentage of the total number of benefits (ongoing + ending benefits) that were granted during that period. (source: UWV ${ }^{5}$ ).

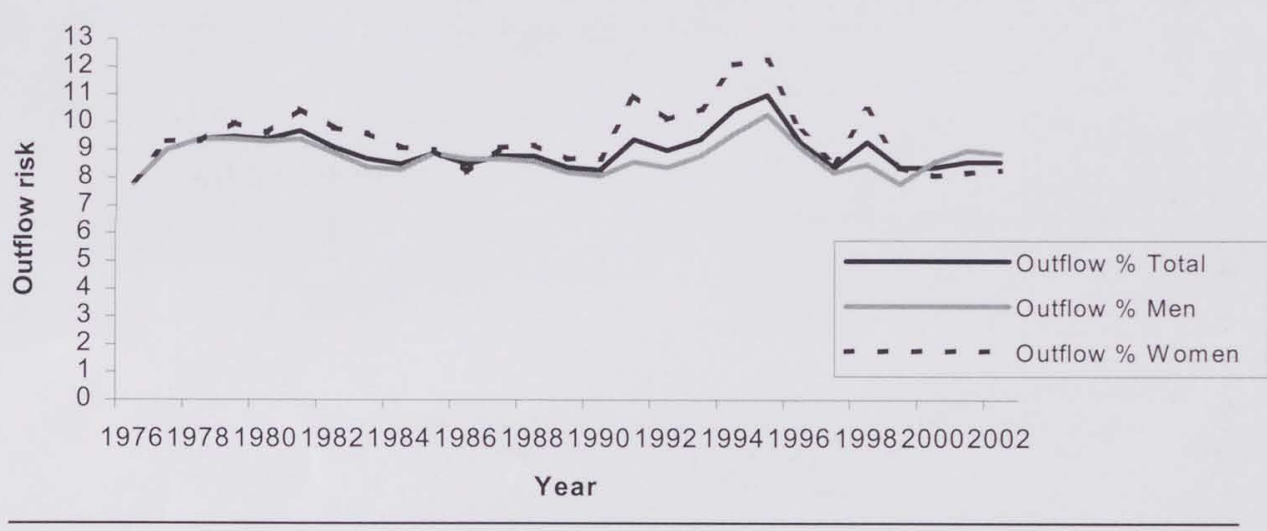

The sickness absence percentage ${ }^{\circ}$ can give us an idea about the sickness absence duration over the years. Figure 3 shows the sickness absence percentage of the

${ }^{n}$ Probability of recovery: mean chance of all claimants that their disability benefit is ended because they have recovered from their complaints.

- Sickness absence percentage: number of sicklisted days as a percentage of the total number of working days in a year. 
22 Chapter 1

private sector and the public sector over the last couple of years. We can see that, while the sickness absence percentage of public sector organizations was traditionally higher than that of the private sector, by 2002 they had almost reached the same level $(5.6 \%$ for governmental organizations; $5.4 \%$ for the private sector). We do, however, not see a positive effect of the explicit attempts to decrease the sickness absence duration in the late 1990s. In fact, both sectors show an increasing sickness absence percentage in that period. Since 1999, the sickness absence percentage of the private sector has stabilized at $5.4 \%$. Statistics on the sickness absence duration are scarce, but the available information indicates that it lengthened between 1992 and $2002^{16}$. The average sickness absence duration ${ }^{p}$ of civil servants was approximately 11 days in 1992, while in 2002 an average of 17 days was reported ${ }^{16}$.

Figure 3. Sickness absence percentage: number of sick listed days as a percentage of the total number of working days in a year, of public sector organizations and the private sector (source: CBS / Statistics Netherlands ${ }^{17}$ )

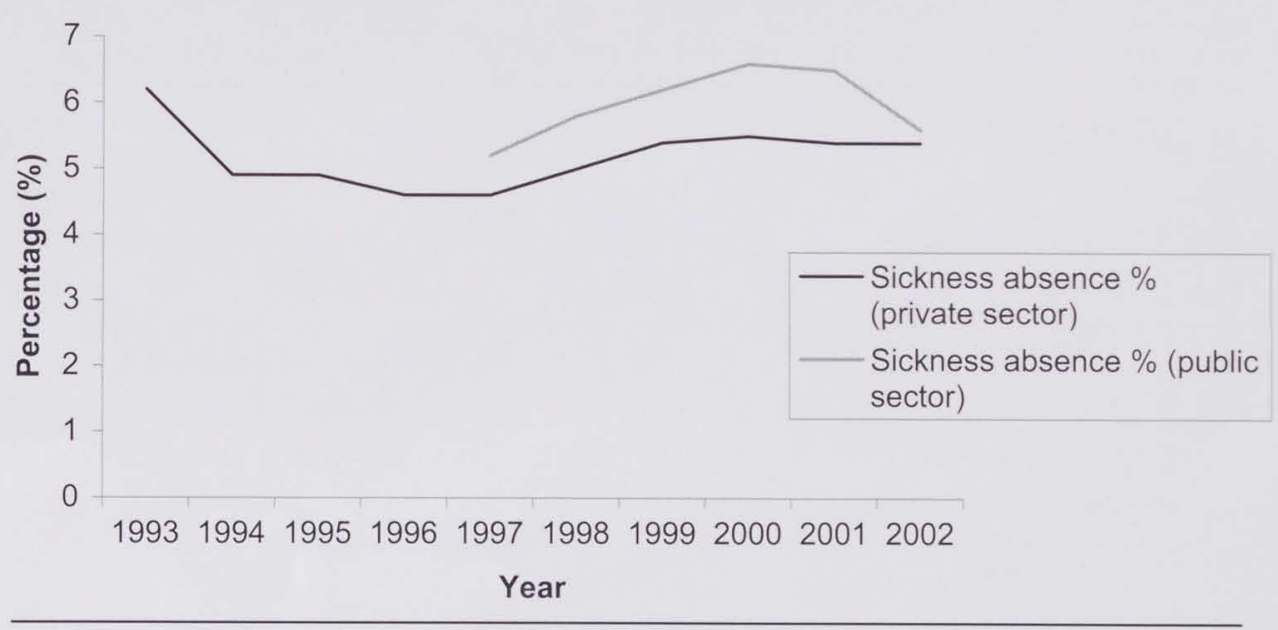

In short, the inflow risk into disability at the end of the twentieth century was about the same as it was in 1980, the outflow nowadays remains low, and the number of people in the disability benefit system is ever increasing. The sickness

P Average sickness absence duration: sum of durations of absence divided by the number of absent cases in a time period. 
absence duration does not seem to be shortened. Over one million people entered the disability benefit system. It is apparent that this is not desirable, neither for the individuals nor for society. For both parties, high costs are involved. We can conclude that it appears that the activation policy of the Dutch government in general, and the disability prevention and RTW interventions that relate to this policy in particular, have not had the desired effects, at least at macro level ${ }^{q}$. The effectiveness of interventions at macro level is, however, determined by many factors. It is possible that the interventions did have an effect at the individual level. There could be individual differences in RTW behavior. We will go into this further in the next section.

\section{Previous research on intervention in the sickness absence process to prevent disability}

Though we see that there is an urge to return sick workers back to work, experience has shown it is not easy. The RTW process is shaped by individual, organizational, social and economic factors, which may be variable and are likely to interact ${ }^{18-22}$. During sickness absence, interventions take place to accelerate or facilitate the return to work. Formally speaking, interventions are behaviors that inject into ongoing social processes of a system ${ }^{23}$. They intervene in interactions between individuals, in procedures, strategies and policies guiding the system, and in the attitude of people towards work, the organization, authority and social values ${ }^{23}$. In short, an intervention can be defined as an action in response to the particular situation facing an individual ${ }^{24}$. This could be, for instance, a call of a sick worker by an occupational physician, or physical therapy for an absent worker with low back pain.

The effectiveness of many interventions during sickness absence, however, falls short of expectations'. Studies have not managed to disentangle the exact mechanisms behind successful interventions. On the one hand this is related to methodological problems, namely problems related to the study designs, as a

\footnotetext{
q We note that the measures that were taken could have offset possible negative effects of the aging population, the work intensification, and the changing nature of the work.

' See Chapter 4 for a further review of this issue.
} 
consequence of which solid statements on the effectiveness could not be made (cf. ${ }^{25}$ ). On the other hand, it is due to the great heterogeneity of interventions that take place during sickness absence. These are combined in many different "intervention packages" (e.g., multidisciplinary interventions), and it is difficult to separate the effectiveness of each single intervention ${ }^{26}$. As a result of this, it remains unclear as to which interventions work, and under which conditions.

Methodological problems are related to the fact that in the field of sickness absence, a randomized controlled trial (RCT, or experiment), which is commonly seen as the most appropriate design to study the effectiveness of interventions ${ }^{27-29}$, is not always possible. There are, for example, legal requirements that make certain interventions compulsory for everyone. Moreover, it is often considered not ethical to exclude people in a control group from an intervention that is likely to benefit their health or their work status ${ }^{30}$. Consequently, experiments are scarce and we have to resort to non-experimental designs in studying the effectiveness of interventions. This implies, however, that we have to be aware of possible validity problems ${ }^{31}$. An important issue in this respect is the selection of people for interventions. With Disability Management (DM) interventions, not all sick workers have the same chance of receiving a particular intervention. Instead, a worker's characteristics, characteristics of his working and living situation and the phase of complaints or stage of absence he $e^{t}$ appears to be in, may determine this chance ${ }^{32}$. This selection affects the outcome of the intervention. The question is, who is selected for a particular intervention?

During sickness absence, interventions are applied with the aim to return the worker to the workplace. The decision to initiate an intervention is likely to be affected by the prospects of RTW. It could for example be the case, that especially workers with bad prospects of RTW are chosen (first), or on the contrary, that they are left waiting. In any case, some absent workers are left waiting and this, in turn, could affect the probability that they return to work. It is observed that the longer someone is absent, the lower his chance of returning to work ${ }^{11,13,33}$. This is called "negative duration dependence". With this negative duration dependence, it is advisable that one intervenes early in the sickness absence process in order to

s The following chapters provide a further review of the methodological problems encountered and provide alternative analytical strategies.

"Where it says "he/his", can also be read "she/her". 
increase the chance of RTW (the 'early intervention' principle of DM strategies) ${ }^{12}$ ${ }^{13}$. This is not so obvious, however. The role of duration in sickness absence is far from clear-cut. While intervening late in the sickness absence process can increase the chance that workers take on the sick role ${ }^{32}$, early intervention can also aggravate the situation ${ }^{32}$ and lead to high and needless costs. Early intervention might be less effective if you also help people who can help themselves and do not need help from others. Duration dependence can be positive or negative, constant or variable over time, as well as constant or variable across workers ${ }^{34}$. The presence and type of duration dependence and the interaction between the timing of interventions and the probability of RTW have hardly been investigated. The shape of the RTW probability function over time, i.e. the possibility of variable duration dependence during sickness absence, has been subject of only one study in the past ${ }^{34}$. This study indicated that, indeed, the shape of the RTW probability function differs between different types of workers ${ }^{34}$. This has important consequences for intervention strategies. Variable duration dependence would imply that intervention strategies may have to differ between different types of workers, for example, between men and women, or people with different previous absence records ${ }^{34}$.

Summarizing, there is an obvious need for more effective intervention strategies to prevent disability and promote RTW. Important aspects of interventions that take place in a non-experimental context are selection and timing. Furthermore, the elapsed duration in sickness absence plays an important role in the effectiveness of interventions. The presence and type of duration dependence in sickness absence have yet to be clarified.

\section{Aim of this study}

Designing an optimal intervention strategy for sick workers implies making decisions about what kind of intervention is undertaken for whom and when. Up to now, there is limited knowledge upon which these decisions can be made. This study aims to provide more insight into the selection and timing aspects of intervention strategies, which are frequently disregarded in studies on the effectiveness, but can play a major role in the outcome. We address the following issues: (a) who is selected for an intervention (selection processes); (b) when does 
this intervention take place (timing); and (c) what is the effect of this selection and timing on the probability of return to work?

Studying these issues can help us answer policy questions about the use of interventions in a population. Analyses at population level can provide a general picture of relationships that exist between aspects of intervention strategies that determine the effectiveness of these interventions (like selection and timing), and RTW. It can help us optimize intervention strategies for sick workers to prevent disability in the future. The results can be used to target interventions more effectively. By identifying worker characteristics with a negative or positive duration dependence and investigating patterns in selection and return to work probabilities, for example, the timing of interventions can be improved ${ }^{34}$.

We aim to generate relevant empirical evidence regarding the role of time or duration in sickness absence, that can serve as a link in a chain of reasoning about causal mechanisms ( $\left(\mathrm{cf}^{31}\right.$ ). Our (observational) design does not allow for a direct demonstration of causal processes. Yet, Blossfeld and Rohwer argue that observational event history data can provide useful information about causal mechanisms ${ }^{31}$. In this view, causality is seen a generative process ${ }^{31}$. Causal inference has various temporal features. The most obvious representation of a causal relationship is in terms of variables that change their values in time. Causal statements relate to changes in two or more variables. A change in variable $X$ at time $t$ might be a cause of a change in variable $Y$ at a later point in time. In other words, there is a time ordering between causes and effects. The causes must precede the effects in time. The time ordering is a necessary but not sufficient condition for causal inferences. There needs to be a delay between the timing of the cause and the beginning of the unfolding effect. There might be different shapes of how the causal effect unfolds over time ${ }^{31}$.

In this study, Intervention and RTW are conceptualized as being a change of state, i.e. a transition from having received 'no intervention' to 'intervention', and from not working to working, for an individual in a particular time period. A transition or hazard rate (the dependent variable in event history analysis) can give a timerelated description of how the process of intervention or RTW evolves over time. As a 'causal' effect, the changes in one or more variables $X$ in the past, may lead to a change in the hazard rate $(Y)$ in the future, which in turn describe the propensity that the units under study will change in some presupposed state space (e.g., from not working to working) ${ }^{31}$. We do not speak of an 'effect' in the classical sense, 
like with a randomized controlled trial (RCT). At every point in time, the hazard rate can be made dependent upon what happened in the past, but not upon what happens in the future ${ }^{31}$.

In this study, an intervention is defined as an action in response to the particular situation facing an individual ${ }^{24}$. The study population comprises all workers that are absent from work. We study several interventions that take place during the first year of absence. The modelling framework is depicted in figure 4 . The following steps are taken. First, we investigate the predictors of the chance that someone is selected for an intervention (arrow 1 in figure 4). Secondly, we investigate the influence of the intervention and other predictors on the probability of return to work (arrow 2). Thirdly, the possibility of interdependence between the intervention and the return to work is investigated (bilateral arrow 3). The reason for this is that with return-to-work interventions, it is possible that the probability of receiving an intervention is determined by the probability of return to work, and the other way around. Finally, the presence and type of duration dependence in sickness absence is studied (arrows 4). The framework from figure 4 is discussed in parts in successive chapters.

Figure 4. Modelling framework (the numbers relate to the research questions explained in the text)

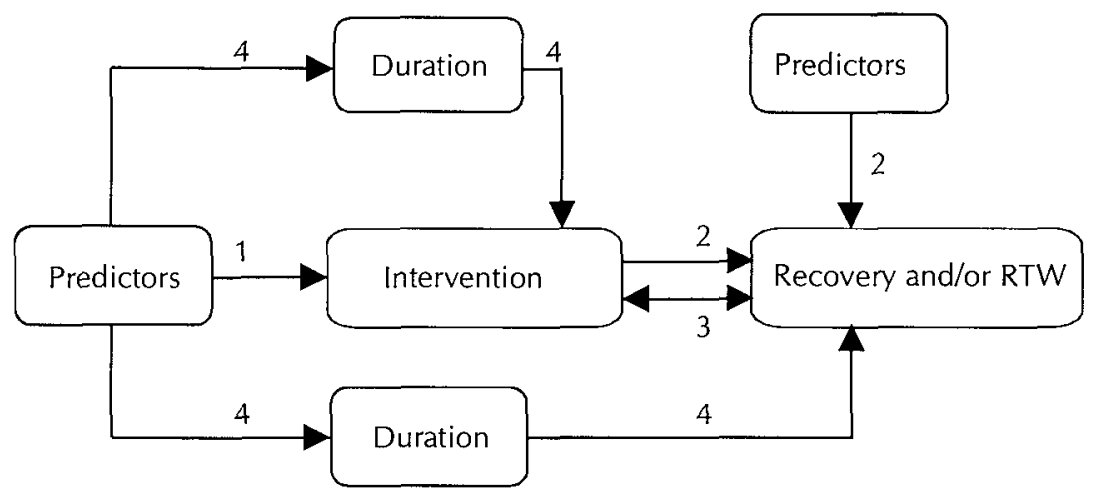

To model the process of intervention and return to work, both univariate and bivariate logit, probit and hazard models are used. These models enable us to study selection processes, the effect of duration and the possibility of 
$28 \mid$ Chapter 1

interdependence between the intervention and the return to work. Our study also serves a methodological aim. We explore the utility of the above mentioned econometric and event history models in this research area. To answer our research questions, secondary data are used from two major surveys, one in the United Kingdom (British Household Panel Survey (BHPS) ${ }^{35}$, and one in the Netherlands (Project Evaluatie Stelselherziening, 1991-1994) ${ }^{9}$.

\section{The data}

\section{British data}

For Chapter 2, we used data from the British Household Panel Survey (BHPS) ${ }^{36}$. This is an annual survey of each adult $(16+)$ member of a nationally representative sample of more than 5,500 households (or 10,300 individuals) in Great Britain ${ }^{35}$. It was set up with the aim to develop a further understanding of social and economic change at the individual and household level in Britain. The BHPS consists of multiple waves. In successive waves, the same individuals were reinterviewed. If they split off from the original household, all adult members of the new household were also interviewed. A study by Lynn et al showed that the panel was indeed found to be representative of the British population at each point in time ${ }^{37}$. Major topics of the survey are household organization, the labor market, income and wealth, housing, health, and socio-economic values. In our study, the BHPS data are used to study the effect of physiotherapy interventions for workers with musculoskeletal complaints on recovery. Five waves of the BHPS (1994/1995 - 1998/1999) are used for the analyses. An extensive study of the quality of the BHPS data was published by Lynn et al ${ }^{37}$. For the present study it is important to note that there are no indications of a selective non-response in the five waves that were used in our study. The response rates were around $90 \%$.

\section{Dutch data}

For Chapters 3, 4 and 5, data were used from a major longitudinal survey on work incapacity and return to work in the Netherlands (Project Evaluatie Stelselherziening (PES), 1991-1994) ${ }^{9}$. The PES study was performed to evaluate the effects of the changes that were implemented in the social security structure in the Netherlands in 1987 (see section 2). It concerns the situation of long-term 
absent workers (i.e. possible disability benefit claimants). These workers were asked retrospective questions about their health, health history, employment situation before and after their sickness absence, return to work, their perception of the situation and their financial situation during the first year of absence. Workers were interviewed three times. The first measurement took place after approximately 11 months of illness or absence. Then they were followed-up after 1,5 years and again after 2,5 years. For the present study, the first measurement was used (October - November 1991). In this data we look at selection processes with an intervention by the occupational physician, the relationship between the probability of intervention by the occupational physician and the probability of RTW, and the effect of duration of sickness absence on both probability functions. As is often the case with this type of studies, some selectivity occurred in the response. Molenaar-Cox et al ${ }^{9}$ performed an extensive non-response study. The passive authorization procedure for participation in the study resulted in some significant response effects. This means that some groups were over-represented in the file of respondents that could be approached for the first interview. This concerns men, people in the age of 35-44 years, workers that were (partially) disabled, and people with musculoskeletal complaints. Workers that were not considered disabled under Dutch law participated less, probably because they were less committed to the study ${ }^{9}$. At the first interview, people in the ages between 35-64 years, workers from some geographical regions in the Netherlands, workers that were (partially) disabled, and workers with musculoskeletal or cardiovascular complaints, were slightly over-represented ${ }^{9}$.

\section{Outline of this thesis}

In the following chapters, the framework depicted in figure 4 is elaborated upon. Chapter 2 presents a study of physiotherapy interventions for people with musculoskeletal complaints. We discuss the probability that someone visits a physiotherapist, and look at the probability of recovery of people that received physiotherapy. In Chapter 3 we discuss the role of duration in the probability that sick workers are selected for an intervention by the occupational physician. It is investigated whether the relatively high inflow risk into disability for women, compared to that for men, is reflected in a disadvantage in the chance of being 
$30 \mid$ Chapter 1

called by the occupational physician during sickness absence. In Chapter 4 the relationship between the probability of receiving an intervention by the occupational physician and the probability of RTW of sick workers is analyzed. In Chapter 5 we investigate the presence and type of duration dependence in sickness absence. This thesis is concluded with a general discussion on the contribution of this study to our knowledge about and insight in the impact of interventions on sickness absence. 


\section{References}

1. Einerhand MGK, Knol G, Prins R, Veerman TJ. Sickness and invalidity arrangements. Facts and figures from six European countries. Den Haag: Ministerie van Sociale Zaken en Werkgelegenheid; 1995.

2. Vos EL, de, Wevers CWJ. Aan de slag met een arbeidshandicap: internationale ervaringen: Landelijk Instituut Sociale Verzekeringen; 1998.

3. Shrey DE, Hursh $\mathrm{CH}$. Workplace Disability Management: International Trends and Perspectives. Journal of Occupational Rehabilitation. 1999;9(1):45-59.

4. Aarts L, Jong Pd, Veen Rvd. Met de beste bedoelingen. WAO 1975-1999: trends, onderzoek en beleid. Den Haag: Elsevier Bedrijfsinformatie; 2002.

5. UWV. Kroniek van de Sociale Verzekeringen 2003. Amsterdam: Uitvoering Werknemersverzekeringen; 2003.

6. UWV. Maandoverzicht arbeidsongeschiktheidsuitkeringen (voorlopige cijfers). Januari $t / m$ december 2003. Amsterdam: Uitvoering Werknemersverzekeringen; 2003.

7. Dembe AE. The Social Consequences of Occupational Injuries and IIInesses. American Journal of Industrial Medicine. 2001;40:403-417.

8. Trommel W, Veen Rvd. De herverdeelde samenleving. Ontwikkeling en herziening van de Nederlandse verzorgingsstaat. Amsterdam: Amsterdam University Press; 1999.

9. Molenaar-Cox PGM, Fiseler JG, Stelt HGvd, Smaal M, Kers WC. Databoek PES3. Amsterdam: GAK/GMD; 1995.

10. Veerman TJ, Besseling JJM. Prikkels en privatisering: integrerende rapportage evaluatie wetgeving rond ziekteverzuim, WAO en reïntegratie. 's-Gravenhage: Ministerie van Sociale Zaken en Werkgelegenheid; 2001.

11. Akabas $\mathrm{SH}$, Gates LB, Galvin DE. Disability Management. A Complete System To Reduce Costs, Increase Productivity, Meet Employee Needs, And Ensure Legal Compliance. New York: AMACOM; 1992.

12. Shrey DE, Lacerte $M$. Principles and Practices of Disability Management in Industry. Florida: CRC Press LLC; 1997.

13. Shrey DE. Worksite disability management model for effective return-to-work planning. Occupational Medicine: state of the art reviews. 2000;15(4):789-801.

14. Veerman T, Andriessen S. Financiële prikkels leiden tot actiever verzuimbeleid. Arbeidsomstandigheden. 1996;72(2):73-75.

15. CBS. Macro-economie, Lopende prijzen mln euro. In.: Centraal Bureau voor de Statistiek, Voorburg/Heerlen; 2004.

16. CBS / Statistics Netherlands. Ziekteverzuim overheid. Heerlen: Statistics Netherlands; 2004. 
$32 \mid$ Chapter 1

17. CBS / Statistics Netherlands. Sickness Absence Private Sector. Heerlen: Statistics Netherlands; 2004.

18. Smulders PGW, Veerman TJ. Handboek Ziekteverzuim. Gids voor de bedrijfspraktijk. Den Haag: Delwel; 1990.

19. Franche RL, Krause N. Readiness for Return to Work Following Injury or Illness: Conceptualizing the Interpersonal Impact of Health Care, Workplace, and Insurance Factors. Journal of Occupational Rehabilitation. 2002;12(4):233-256.

20. Habeck RV, Hunt HA, Tol Bv. Workplace factors associated with preventing and managing work disability. Rehabilitation Counseling Bulletin. 1998:Counseling-Bulletin.

21. Krause N, Frank JW, Dasinger LK, Sullivan TJ, Sinclair SJ. Determinants of Duration of Disability and Return-to-Work After Work-Related Injury and Illness: Challenges for Future Research. American Journal of Industrial Medicine. 2001;40:464-484.

22. Vallacher RR, Nowak A, editors. Dynamical Systems in Social Psychology. London: Academic Press, Inc; 1994.

23. Buijs J. Innovatie en interventie. Deventer: Kluwer; 1984.

24. Bloch FS, Prins R. Who Returns to Work and Why? A six-Country study on Work Incapacity \& Reintegration. New Brunswick NJ: Transaction Publishers; 2001.

25. Karjalainen $K$, Malmivaara A, Tulder MWv, Roine $R$, Jauhiainen $M$, Hurri $H$, et al. Multidisciplinary Biopsychosocial Rehabilitation for Subacute Low Back Pain among Working Age Adults. The Cochrane Library. 2003(1).

26. Beek AJvd, Frings-Dresen MHW, Elders LAM. Effectiviteit van werkaanpassingen bij werkhervatting na klachten aan het bewegingsapparaat. TBV. 2000;8(5):137-143.

27. Bouter LM, Dongen MCJMv. Epidemiologisch onderzoek. Opzet en interpretatie. Houten: Bohn Stafleu van Loghum; 1991.

28. Swanborn PG. Evalueren. Het ontwerpen, begeleiden en evalueren van interventies: een methodische basis voor evaluatie-onderzoek. Amsterdam: Boom; 1999.

29. Staal JB, Hlobil H, Tulder MWV, Köke AJA, Smid T, Mechelen WV. Return-to-Work Interventions for Low Back Pain. A Descriptive Review of Contents and Concepts of Working Mechanisms. Sports Medicine. 2002;32(4):251-276.

30. Rosenbaum PR. Observational Studies. 2nd ed. New York: Springer-Verlag; 2002.

31. Blossfeld HP, Röwer G. Techniques of event history modeling: new approaches to causal analysis. 2nd ed. Mahwah, NJ: Lawrence Erlbaum; 2002.

32. Frank J, Sinclair S, Hogg Johnson S, Shannon H, Bombardier C, Beaton D, et al. Preventing disability from work-related low-back pain. New evidence gives new hope-if we can just get all the players onside. CMAJ. 1998;158(12):1625-31.

33. Crook J, Moldofsky $\mathrm{H}$. The probability of recovery and return to work from disability as a function of time. Quality of Life Research. 1994;3(suppl. 1):s97-s109. 
34. Butler RJ, Baldwin ML, Johnson WG. The effects of worker heterogeneity on duration dependence: low-back claims in workers compensation. The Review of Economics and Statistics. 2001;83(4):708-716.

35. ISER. British Houshold Panel Survey. In.: Institute for Social and Economic Research; 1999-2001.

36. Taylor MF, Brice J, Buck N, Prentice-Lane E, editors. British Household Panel Survey User Manual Volume A: Introduction, Technical Report and Appendices. Colchester: University of Essex; 1999.

37. Lynn P, Buck N, Burton J, Laurie H. Quality Profile. British Household Panel Survey. Waves 1 to 10: 1991-2000. Essex: Institute for Social and Economic Research, University of Essex; 2003. 
34 Chapter 1 


\section{Chapter 2}

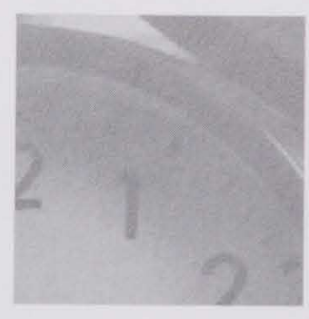

\section{A study of physiotherapy interventions for people with musculoskeletal complaints}

Published as:

Joling C, Groot W, Janssen PPM. Taking a new course in research on the effectiveness of interventions. A study of physiotherapy interventions for people with musculoskeletal complaints. International Journal of Rehabilitation Research $2002 ; 25(1): 33-46$. 
36 Chapter 2 


\begin{abstract}
Physiotherapy is a commonly employed intervention for people with musculoskeletal complaints. However, due to (methodological) limitations in previous research, the effectiveness of physiotherapy interventions has not yet been proven. The aim of the present study is twofold. First we try to solve some of the methodological problems, of which the most important are selection and endogeneity biases and state dependence. Secondly, the effect of a physiotherapy intervention on recovery from musculoskeletal complaints is investigated. The probability of receiving a physiotherapy intervention is estimated, as well as the probability of recovery as a result of this intervention. A longitudinal design is used. Analyses are performed using secondary data at population level. The analytical framework is provided by a Markov model. We use a logit model to estimate transition probabilities of this Markov model. Results show that experience with physiotherapy in the past is an important predictor for receiving physiotherapy in the future. Other predictors of the probability of receiving an intervention are also identified. Furthermore, results indicate that the effect of a physiotherapy intervention on recovery is negative. It is concluded that both the latter effect and the effect of the intervention experience can partly be explained by medicalization, in spite of a presence of 'severe' cases in the intervention group.
\end{abstract}


$38 \mid$ Chapter 2 


\section{Introduction}

Musculoskeletal complaints are one of the most common causes of absence from work ${ }^{1-4}$. Of all musculoskeletal complaints, the most widespread in occupational populations is low back pain ${ }^{5,6}$, followed by neck and shoulder complaints ${ }^{7}$. Studies indicate that $60-85 \%$ of the general population in Western societies will experience low back pain during adult life ${ }^{8-11}$. Physiotherapy is a commonly employed paramedical intervention for people with musculoskeletal complaints ${ }^{1 .}$ ${ }^{11-13}$. It has been estimated that approximately $10-50 \%$ of the people with low back pain receive physiotherapy ${ }^{9}$. In Great Britain, some 1.3 million people with low back pain are treated by physiotherapists each year ${ }^{9}$. Although physiotherapy is frequently applied, its effectiveness is disputed ${ }^{14}$. In some studies, indications of beneficial effects upon the health status of individuals are found ${ }^{15,16}$, whereas other studies find little or no effect ${ }^{14,17}$. In any case, hard evidence on the effectiveness of physiotherapy is lacking. This can be partly ascribed to limitations that occurred in the traditional experimental and cross-sectional research. Studies on the effectiveness of physiotherapy encounter many methodological problems 7 ${ }^{18}$. In general, these problems are related to the study design, the wide variation in interventions, in outcome measures and in the timing of the outcome assessment ${ }^{7}$. Consequently, causal statements regarding the effectiveness are difficult to make and results may be biased. The knowledge on effectiveness of physiotherapy interventions therefore remains scarce. Obviously, the lack of knowledge creates a need to investigate alternative ways of studying effectiveness of interventions. In this paper we address some of the problems that are met in previous research and offer an alternative method of studying effectiveness, derived from econometric theory.

\section{Limitations of previous research}

There are several reasons for the fact that little can be said about the effectiveness of physiotherapy interventions for people with musculoskeletal complaints. The most important reasons addressed here are biases, state dependence and causality problems that are found in previous studies. 
$40 \mid$ Chapter 2

\section{Biases and state dependence}

Limitations of previous research on interventions are particularly related to selectivity and endogeneity issues. Selectivity and endogeneity lead to biased results. A selection bias can occur due to selectivity in the application of interventions: not everyone with musculoskeletal complaints has the same probability of receiving an intervention. Instead, this probability seems to depend on a worker's characteristics and characteristics of the initial situation he appears to be in $\left(\mathrm{cf}^{13}{ }^{13}\right.$. The influence of these characteristics remains unclear however, and accordingly it is unknown which individuals are more likely to receive an intervention than others. It is often observed that individual experiences in the past influence the experience of the event in the future (state dependence) ${ }^{19,20}$. There are two possible explanations for the occurrence of state dependence. One explanation is that as a consequence of experiencing an event, preferences or constraints relevant to future choices are altered, and a genuine behavioral effect is reached ('true' state dependence) ${ }^{19}$. The second explanation is that individuals may differ in their propensity to experience the event, due to differences in certain unmeasured variables ('spurious' state dependence) ${ }^{19}$. In that case, previous experience is a determinant of future experience because it is a proxy for temporally persistent unobservables that determine choices ${ }^{20}$. Anyway, the people that receive a physiotherapy intervention are not a random sample of the people with musculoskeletal complaints, but a selected group of people with a high likelihood of having received treatment in the past. It is important to disentangle the effects of true and spurious state dependence when the effect of an intervention is evaluated. This can be done by using methods that control for unobserved heterogeneity ${ }^{21}$.

Besides selection bias and state dependence, endogeneity bias is also present in previous research on interventions. Endogeneity bias is caused by the joint causal relationship between intervention and recovery. That is, an intervention seems to affect the probability of recovery and the potential for recovery determines the probability of receiving an intervention. In other words, a simultaneous relation exists between intervention and recovery. Both the endogeneity bias and the selection bias described above can lead to an over- or underestimation of the effect of the intervention, and need therefore be avoided. A selection bias is inherent in traditional experimental research, because of self selection by the individuals or sample selection decisions by researchers ${ }^{22}$. Furthermore experimental research 
generally has short follow-up durations (ranging from several weeks to several months), which do not provide a clear picture of the course of the complaints over time. Cross-sectional research, which is also frequently performed, prohibits this by definition. As a consequence, the temporal sequence of cause and effect remains unknown. Moreover, cross-sectional research is also greatly susceptible to (selection) bias ${ }^{23}$.

\section{Chain of events}

Besides the biases we described above, which occur in research on interventions in general, we signal some other methodological problems in research on interventions for musculoskeletal problems in particular. These are related to assumptions made about the chain of events and the course and severity of complaints. When investigating musculoskeletal complaints, many researchers assume a straightforward chain of events. In that case the complaints are followed by sickness absence, while recovery and return to work are seen as identical. Recovery is used as an operationalization of return to work, or the other way around (return to work is operationalized by recovery) cf.15, 17, 24. This reasoning seems to be inconsistent. The chain of events frequently follows the pattern described above, but there are some exceptions. It is known, for example, that not every worker automatically returns to work once he/she has recovered (so called avoidable absence), while there are also workers who start working though they have not yet completely recovered. To assume that recovery and return to work are identical is therefore not correct. These two outcome measures need to be studied separately. This study will focus on recovery. The course of the complaints and severity form additional problems. Musculoskeletal diseases, especially low back pain, often have a recurrent course ${ }^{10,17,25,26}$. The complaints can recur, or complete recovery can fail to occur regardless of the intervention. The complaints can also be chronic. The physiotherapy circuit consists of different types of patients, all of them responding differently to treatment. Patients with acute severe complaints will for example experience a different effect than people with chronic complaints, or people with minor complaints. In other words, interventions will be more or less effective for different types of patients. Variables related to the severity of the complaints therefore need to be controlled for in the analyses. 
42 Chapter 2

\section{Aim of this study}

The aim of the present study is twofold. First we try to solve some methodological problems of previous research, of which the selectivity problem is the most important. The selectivity problem is dealt with by estimating the probability of receiving an intervention. Second, the effect of a physiotherapy treatment on recovery from musculoskeletal complaints is investigated. The simultaneous relation between intervention and recovery asks for a simultaneous equation model. We control for experience with physiotherapy in the past. By using longitudinal data, we are enabled to establish a temporal relationship. Data are analyzed at population level, by comparing people that did receive a physiotherapy treatment to people who did not, on two outcome measures. A Markov chain model is used to analyze the data. Markov models are discrete-state, discrete-time models that specify the probability distribution of a transition from one state of affairs to another ${ }^{27}$. In our model, a finite number of health states is defined, namely 'intervention' and 'no intervention' (first equation) and 'recovery' and 'no recovery' (second equation), describing the situation in which individuals are found. The probability that an individual is in one of these states can then be estimated. Estimates of contributions of other variables can be made as well. In a Markov model, the probability of transition to a future state is dependent on the present state, but not on history prior to the present state ("Markov Property"). This modelling makes it possible to estimate the actual effect of the intervention more precisely (see analyses section for a more extensive description).

\section{Determinants of the probability of receiving an intervention}

In order to estimate the probability of receiving an intervention, factors of influence on this probability need to be identified. In this paragraph, a short summary of possible determinants is given. As we mentioned above, the application of interventions is subject of a certain amount of selectivity. Little is known about this phenomenon. Whether someone receives a physiotherapy intervention or not is the result of a decision made by a general practitioner or another health service professional ${ }^{28}$ and/or the person himself/herself. Individual experiences with the intervention in the past are known to be an important predictor for future behavior ${ }^{19,29,30}$ and therefore of influence on the decision to 
visit a physiotherapist. Several personal and job characteristics are likely to influence the decision to visit a physiotherapist.

Some insight in the contributing factors is provided by load-capacity models and labor market theories. The labor market position of the worker is important when the intervention runs through the firm ${ }^{13}$. Labor market position appears to depend mostly on sex, length of job tenure and nationality ${ }^{13}$. Furthermore it seems that education level is associated with the probability of receiving an intervention ${ }^{13,30}$, while occupation, industry and firm size are correlated with the prevalence of interventions within firms ${ }^{13}$. In general, agricultural, fishery, craft and machine workers experience fewer interventions. In construction, agriculture, fishing and manufacturing industries, also relatively little interventions take place. We have to wonder to what extent these general trends are reflected in the probability of receiving physiotherapy interventions. Gründemann and Nijboer also show that firm size could be of influence on the prevalence of interventions, although this relationship is not quite clear ${ }^{13}$. Besides these factors, other factors can be hypothesized to be of influence on the probability of receiving and intervention as well. The decision to visit a physiotherapist is likely to depend on the standard of local medical and transport services. The availability of therapists in the region and the accessibility (i.e. can someone easily reach a physiotherapists practice) need therefore be taken into account. Factors of influence on the probability of receiving an intervention are summarized in table 1.

\section{Research questions}

Considering the selectivity problem described in paragraph 2, the first question we examine is which factors determine whether workers receive a physiotherapy intervention when having musculoskeletal complaints. Several factors found in the literature serve as explanatory variables in the relationship between intervention and recovery. An overview is depicted in table 1 . From this table, hypotheses regarding the association (positive or negative) between these factors and the intervention and recovery variables can be deduced. Higher probabilities of receiving an intervention are expected for females, people working in larger firms, availability and accessibility of a physiotherapist and high educational qualifications. People that have received physiotherapy in the past are also 
$44 \mid$ Chapter 2

hypothesized to have higher probabilities of receiving an intervention. Lower probabilities of receiving an intervention are expected for immigrants, agricultural, fishery, craft and machine workers and workers in construction and manufacturing industries. After the probability of receiving an intervention is investigated, the effect of the intervention itself on recovery can be studied.

Table 1. Prognostic factors for intervention and recovery ${ }^{a}$

\begin{tabular}{lcc}
\hline Factor & Intervention & Recovery \\
\hline Sex: female & + & - \\
Job tenure: longer & + & \\
Nationality: immigrant status & + & \\
Educational level: higher & + \\
Occupation: agricultural, fishery, craft and machine workers & - \\
Firm size: larger & $+/-$ & - \\
Sector: construction, agriculture, fishing and manufacturing industries & \\
Past experience of pain problem & $+/-$ \\
Past experience of intervention & + \\
Availability of physiotherapist & + \\
Accessibility of physiotherapist & & - \\
Emotional distress: high level & \\
Coping capacity: poor & \\
Somatization & & - \\
Psychological distress & \\
Diagnosis: lack of & & - \\
Pain intensity: severe & & - \\
Initial subjective disability: high & & - \\
Age: older & & - \\
Number of cigarettes smoked: high & & - \\
Pelf-rated health status: poor & \\
\hline
\end{tabular}

The second question is therefore: to what extent does a physiotherapy intervention explain the probability of recovery of people with musculoskeletal complaints, and to what extent do other factors? The probability of recovery is hypothesized to become lower when there is a past experience with a pain problem, when people

a This list of determinants is not exhaustive. A number of other factors have been identified or hypothezised to be of influence, e.g., factors related to the fit between a worker and his job, as well as ergonomic and organizational factors. 
are smoking or when other health problems besides musculoskeletal complaints exist.

\section{Method}

\section{Design}

A longitudinal design is used. Analyses are performed using secondary data at population level. The data used are those of the British Household Panel Survey (BHPS) ${ }^{31}$. This is a longitudinal study of individuals of some 5,500 households and 10,300 individuals (wave 1) drawn from 250 different areas of Great Britain ${ }^{31}$. The BHPS is a household-based survey, in which every adult member (aged 16 years and older) of the households sampled is interviewed each year. Five waves (1994/1995-1998/1999) of the BHPS are used for the analyses. More information about the survey can be found in Taylor ${ }^{32}$.

\section{$\underline{\text { Sample }}$}

Two selection criteria were used; we selected those people who were employed and had musculoskeletal complaints the year before the interview (that is, they reported to have complaints at the time of the previous interview). Musculoskeletal complaints are operationalized as having problems or disability connected with: arms, legs, hands, feet, back, or neck (including arthritis and rheumatism). After this selection, a sample of 2793 observations was obtained for the analyses: 1196 males and 1597 females aged between 17 to 81 years. Mean age of the people in the sample was 45 (exact: 45.01) years. Of the selected observations 375 had received a physiotherapy treatment during the year after they reported complaints. Recovery (meaning the individual reported to be free of complaints at the time of interview) occurred for 1004 observations, whereas the remaining 1789 were still having complaints at the time of the interview in the subsequent yearb.

${ }^{b}$ Of the people that received physiotherapy, $20.4 \%$ recovered in the subsequent year. Of the people that did not receive physiotherapy for their musculoskeletal problems, $21.3 \%$ recovered. 
$46 \mid$ Chapter 2

\section{Instruments}

The data are obtained by means of a questionnaire. Major topics of this questionnaire involve household organization, the labor market, income and wealth, housing, health and socio-economic values. The dependent variables are "intervention" and "recovery". The explanatory variables used are those which we found in the literature, and which were present in the survey. Explanatory variables used in the equations are (see appendix for an operationalization of these variables):

- For "intervention": age, sex, immigrant status, educational qualifications, firm size, occupation, sector, physiotherapy density, pay, intervention experience and chronicity of complaints.

- For "recovery": probability of receiving intervention, age, sex, immigrant status, educational qualifications, firm size, occupation, sector, pay, chronicity of complaints, and other health problems concerning sight, hearing, skin conditions/allergy, chest/breathing, heart/blood pressure, stomach or digestion, diabetes, anxiety or depression, alcohol/drugs, epilepsy, migraine or other.

We control for chronicity of complaints in order to diminish a possible selection effect caused by the presence of 'severe' cases in the intervention group.

\section{Analytical framework}

The analytical framework is provided by a Markov (chain) model. Markov models are discrete-state, discrete-time models. This is an appropriate framework since we have binary dependent variables. The Markov model specifies a stochastic process with the so-called "Markov property". It consists of a sequence of random variables taking values in a state space. The value of $Y_{j}(t)$ denotes the state of the system at time $t$ :

$Y^{i}{ }_{j}(t)=1$ if the $/$ th person is in state $j$ at time $t$.

The probability distribution of $Y^{i}{ }_{j}(t)$ is specified as a function of $Y^{i}{ }_{k}(s)$, as well as of exogenous variables ${ }^{27}$, where $k=1,2, \ldots M$ and $s=t-1, t-2 \ldots$.

The discrete-time Markov property says that the conditional distribution of the "future" given the "past", depends on the past only through $Y_{j}(t-1)$. In first 
order Markov models, the distribution of $Y^{i}{ }_{j}(t)$ depends on $Y^{i}{ }_{k}(t-1)$ but not on $Y^{i}{ }_{k}(t-2), Y_{k}^{i}(t-3), \ldots$.

$P^{i}{ }_{j k}(t)$ is the probability that an individual $i$ is in state $\mathrm{k}$ at time $t$ given that he/she was in state $j$ at time ( $t-1$ ) (Markov Property) ${ }^{33}$. By defining the different states and calculating transition probabilities, the probability of receiving an intervention can be estimated. Transition probabilities are defined by:

$P^{i}{ }_{j k}(t)=$ prob $[/$ th person has recovered at time $\mathrm{t}$ given that he had musculoskeletal complaints at time $t$ - 1] ("recovery").

We use a logit model to estimate the transition probabilities of the Markov chain. We postulate the following equation for the probability of recovery:

$P^{i}{ }_{1}(t)=\frac{\exp (x \beta)}{1+\exp (x \beta)}$

Where $x$ is a vector of individual characteristics with associated coefficients $\beta$.

For the probability of receiving an intervention $P^{i}{ }_{2}(t)$ we estimate:

$$
P^{i}{ }_{2}(t)=\frac{\exp (y \alpha)}{1+\exp (y \alpha)}
$$

Where $y$ is a vector of individual characteristics with associated coefficients $\alpha$.

Since we have binary dependent variables and the linearity constraints of OLS regression are violated, logit models are proven to be appropriate ${ }^{34}$. The logit model directly estimates the probabilities of an event occurring, which is having received an intervention or being recovered. An effect is to be interpreted as a change in outcome resulting from a change in an independent variable, holding all other variables constant ${ }^{34}$.

It can be argued that 'intervention' is not exogenous with respect to recovery. As we described before, this may lead to an endogeneity bias. If intervention is not an exogenous variable in the recovery equation, use of an instrumenting variable (IV) technique is warranted ${ }^{35}$. The $\mathrm{N}$ technique is used to eliminate the endogeneity bias and the measurement error in the recovery variable. It is a generally accepted 
alternative for OLS ${ }^{35-37}$, whereby consistent estimates of the structural effect, for instance of the intervention on recovery, can be obtained. For a proper IV, at least some of the instruments must be highly correlated with the intervention variable, but must be uncorrelated with the error term of the recovery equation. Instrumental quality, validity and relevance are examined. Instrumental quality is ensured if there is a strong correlation between the instruments and the intervention variable ${ }^{35}$. Validity of the instruments is ascertained if the instruments affect recovery through the intervention variable only. An IV procedure is relevant if any endogeneity in the intervention variable has a significant effect on the recovery parameter ${ }^{35,38}$. This is checked by means of a Hausman test ${ }^{38}$.

By regressing the intervention variable on the explanatory variables, instruments for "intervention" are identified and predicted values for the probability of receiving an intervention are obtained. Subsequently, this predicted probability of receiving an intervention is used as an explanatory variable in the recovery equation. Corrections are made for chronicity and the effect of an experience with such an intervention in the past, but the model is also estimated without these controls. For each person it is examined if he or she has complaints at time $t$, whether he/she had complaints on $t-1$, on $t-2$ (check for chronicity) and whether he/she received a physiotherapy intervention between $t$ and $t-1$, and between $t-1$ and $t-2$ (check for past experience of intervention).

We investigate the consequences of the constraints implied upon the model by performing Likelihood Ratio (LR) tests. The unconstrained model is estimated by excluding the chronicity variable and the intervention experience variable consecutively. The log likelihood of the unconstrained model is then compared to that of the constrained model $(-2(\log L$ constrained - $\log L f(u l))$; the outcome of this test is $\Pi^{2}$ distributed with 1 degree of freedom. The null hypothesis is that the effect of the constrained variable equals zero. If the constraint significantly reduces the likelihood of the model (which means that the -2 logLikelihood increases significantly) the null hypothesis is rejected. 


\section{Results}

\section{Descriptives}

To start with, the context in which the research questions are investigated is analyzed to provide a framework for the interpretation of the estimation results. Table 2 shows some trends in the percentage of people with musculoskeletal complaints receiving physiotherapy over the years, the percentage of people that recover from their complaints and the in- and outflow of the physiotherapy circuit. It can be seen that the percentage of people with musculoskeletal complaints has risen over the years, while the percentage of people recovering from these complaints shows a negative trend.

Table 2. Trends in received interventions, in- and outflow of the physiotherapy circuit, and recovery of people with musculoskeletal complaints in the sample (Source: BHPS ${ }^{31}$ ).

\begin{tabular}{lrrrrr}
\hline Year & $\begin{array}{r}\text { Received } \\
\text { intervention }\end{array}$ & $\begin{array}{r}\text { Primary } \\
\text { inflow }^{\mathrm{c}}\end{array}$ & $\begin{array}{r}\text { Secondary } \\
\text { inflow }^{\mathrm{d}}\end{array}$ & Outflow & Recovery \\
\hline $1993 / 1994$ & $(\%)$ & $(\%)$ & $(\%)$ & $(\%)$ & $(\%)$ \\
$1994 / 1995$ & 9.4 & - & - & - & 28.8 \\
$1995 / 1996$ & 11.1 & 9.6 & 61.6 & 6.6 & 26.8 \\
$1996 / 1997$ & 11.5 & 12.4 & 63.4 & 8.7 & 26.9 \\
$1997 / 1998$ & 11.2 & 11.4 & 57.9 & 8.5 & 23.2 \\
$1998 / 1999$ & 11.9 & 9.1 & 64.0 & 8.0 & 24.6 \\
\hline
\end{tabular}

Estimation results for the probability of receiving an intervention

Estimation results for the probability of receiving an intervention for the logit model are presented in table 3 . An effect is to be interpreted as a change in outcome (intervention/no intervention) by a change in the independent explanatory variable $(\mathrm{dP} / \mathrm{dX})$, holding all other variables constant. This marginal effect can be either positive (meaning the probability of receiving an intervention increases) or negative (the probability decreases).

c The primary inflow consists of those people who receive physiotherapy directly once they have reported complaints.

d The secondary inflow consists of people that do not receive physiotherapy directly, but flow into the physiotherapy circuit one year after they started to have complaints. 
$50 \mid$ Chapter 2

Table 3. Summary of parameter estimates of the logit model for the intervention equation

\begin{tabular}{|c|c|c|c|c|c|c|}
\hline \multicolumn{3}{|c|}{ Initial model } & \multicolumn{2}{|c|}{ Excluding chronicity } & \multicolumn{2}{|c|}{$\begin{array}{l}\text { Excluding intervention } \\
\text { experience }\end{array}$} \\
\hline & $\begin{array}{l}\text { Estimate } \\
\text { (st. error) }\end{array}$ & $\begin{array}{l}\mathrm{dP} / \mathrm{dX} \\
\text { Intervention }\end{array}$ & $\begin{array}{l}\text { Estimate } \\
\text { (st. error) }\end{array}$ & $\begin{array}{l}\mathrm{dP} / \mathrm{dX} \\
\text { Intervention }\end{array}$ & $\begin{array}{l}\text { Estimate } \\
\text { (st. error) }\end{array}$ & $\begin{array}{l}\mathrm{dP} / \mathrm{dX} \\
\text { Intervention }\end{array}$ \\
\hline 1 & $\begin{array}{l}0.586^{* *} \\
(0.227)\end{array}$ & 0.062 & $\begin{array}{l}0.584 * * \\
(0.227)\end{array}$ & 0.061 & $\begin{array}{l}0.626^{* *} \\
(0.218)\end{array}$ & 0.071 \\
\hline 2 & $\begin{array}{c}-0.845^{* *} \\
(0.274)\end{array}$ & -0.089 & $\begin{array}{l}-0.843^{* *} \\
(0.274)\end{array}$ & -0.089 & $\begin{array}{l}-0.881^{* *} \\
(0.264)\end{array}$ & -0.099 \\
\hline 3 & $\begin{array}{l}-0.806^{*} \\
(0.322)\end{array}$ & -0.085 & $\begin{array}{l}-0.808^{*} \\
(0.321)\end{array}$ & -0.085 & $\begin{array}{l}-0.939 * * \\
(0.313)\end{array}$ & -0.106 \\
\hline 4 & $\begin{array}{l}-0.448^{*} \\
(0.211)\end{array}$ & -0.047 & $\begin{array}{l}-0.448^{*} \\
(0.211)\end{array}$ & -0.047 & $\begin{array}{l}-0.514^{*} \\
(0.206)\end{array}$ & -0.058 \\
\hline 5 & $\begin{array}{l}-0.252 \mathrm{E}-04^{*} \\
(0.127 \mathrm{E}-04)\end{array}$ & $-2.655 \mathrm{D}-06$ & $\begin{array}{l}-0.251 \mathrm{E}-04^{*} \\
(0.127 \mathrm{E}-04)\end{array}$ & $-2.643 \mathrm{D}-06$ & $\begin{array}{l}-0.309 \mathrm{E}-04^{*} \\
(0.124 \mathrm{E}-04)\end{array}$ & $-3.479 D-06$ \\
\hline 6 & $\begin{array}{l}1.515^{* *} \\
(0.127)\end{array}$ & 0.159 & $\begin{array}{l}1.516 * * \\
(0.127)\end{array}$ & 0.159 & - & - \\
\hline 7 & - & - & - & - & $\begin{array}{l}-0.013^{*} \\
(0.553 \mathrm{E}-02)\end{array}$ & -0.002 \\
\hline 8 & - & - & - & - & $\begin{array}{l}-0.390 * * \\
(0.147)\end{array}$ & -0.044 \\
\hline 9 & - & - & - & - & $\begin{array}{l}-0.503^{*} \\
(0.234)\end{array}$ & -0.057 \\
\hline 10 & $0-$ & - & - & - & $\begin{array}{l}-0.623^{*} \\
(0.287)\end{array}$ & -0.070 \\
\hline 11 & $1-$ & - & - & - & $\begin{array}{l}-514 * \\
(0.253)\end{array}$ & -0.058 \\
\hline 12 & $2-$ & - & - & - & $\begin{array}{l}-0.519^{*} \\
(0.259)\end{array}$ & -0.058 \\
\hline 13 & $3-$ & - & - & - & $\begin{array}{l}-0.514 * \\
(0.253)\end{array}$ & -0.058 \\
\hline 14 & $4 \quad-992.291$ & - & -992.327 & & -1059.950 & \\
\hline
\end{tabular}

\section{Specifications:}

1 Educational qualifications: higher degree, first degree (reference category: GCE A levels, GCE O levels or equivalent)

2 Occupation: professional occupations (reference category: clerical \& secretarial occupations)

3 Sector: other manufacturing industries (reference category: other services)

4 Sector: distribution, hotels \& catering (repairs) (reference category: other services)

5 Physiotherapy density

6 Intervention experience $(0=$ no; $1=$ yes $)$

$7 \quad$ Age

8 Firm size: 24 employees or less (reference category: 100 employees or more) 
9 Occupation: associate professional \& technical occupations (reference category: clerical \& secretarial occupations)

10 Occupation: craft \& related occupations (reference category: clerical \& secretarial occupations)

11 Occupation: plant \& machine operatives (reference category: clerical \& secretarial occupations)

12 Occupation: other occupations (reference category: clerical \& secretarial occupations)

13 Occupation: plant \& machine operatives (reference category: clerical \& secretarial occupations)

14 LogLikelihood

Only significant values are shown: * significant at $5 \%$ level; ** significant at $1 \%$ level.

Control variables include: immigrant status, four dummies for education, three dummies for firm size, eight dummies for occupation, nine dummies for industry, pay, chronicity of complaints and twelve dummies for comorbidity.

Positive effects are found for "intervention experience" and high educational qualifications. Having received a physiotherapy treatment the year before the interview increases the probability of receiving such an intervention again by $15,9 \%$. People with high educational qualifications (higher degree or first degree) have a $6,2 \%$ greater probability of receiving an intervention than people with lower educational qualifications (i.e. the reference category: GCE A levels, GCE O levels or equivalent). Variables that are negatively related to the probability of receiving an intervention are occupation, industrial sector and physiotherapy density (i.e. availability of physiotherapists in the region). A higher density of physiotherapists per square kilometer leads to a lower probability of receiving an intervention.

The "chronicity" and "intervention experience" constraints that were imposed upon the model are tested with Likelihood Ratio Chi Square $\left(\operatorname{LR} \Pi^{2}\right)$ tests. The effect of having "intervention experience" on the probability of receiving an intervention is significant at the .05 level (LR $\left.\Pi^{2}=135,218 ; d f=1 ; p=.05\right)$, whereas the effect of "chronicity" on the probability of receiving an intervention is not statistically significant (LR $\left.\Pi^{2}=0,072 ; d f=1 ; p=.05\right)$. 
$52 \mid$ Chapter 2

Table 4. Summary of parameter estimates of the logit model for the recovery equation

\begin{tabular}{|c|c|c|c|c|c|c|}
\hline & \multicolumn{2}{|l|}{ Initial model } & \multicolumn{2}{|c|}{ Excluding chronicity } & \multicolumn{2}{|c|}{$\begin{array}{l}\text { Excluding intervention } \\
\text { experience }\end{array}$} \\
\hline & $\begin{array}{l}\text { Estimate } \\
\text { (st. error) }\end{array}$ & $\begin{array}{l}\mathrm{dP} / \mathrm{dX} \\
\text { Recovery }\end{array}$ & $\begin{array}{l}\text { Estimate } \\
\text { (st. error) }\end{array}$ & $\begin{array}{l}\mathrm{dP} / \mathrm{dX} \\
\text { Recovery }\end{array}$ & $\begin{array}{l}\text { Estimate } \\
\text { (st. error) }\end{array}$ & $\begin{array}{l}\mathrm{dP} / \mathrm{dX} \\
\text { Recovery }\end{array}$ \\
\hline 1 & $\begin{array}{l}-0,013^{* *} \\
(0,425 \mathrm{E}-02)\end{array}$ & $-0,003$ & $\begin{array}{l}-0,019 * * \\
(0,462 \mathrm{E}-02)\end{array}$ & $-0,004$ & $\begin{array}{l}-0,013 * \\
(0,514 \mathrm{E}-02)\end{array}$ & $-0,003$ \\
\hline 2 & $\begin{array}{l}-1,378^{* *} \\
(0,489)\end{array}$ & $-0,273$ & $\begin{array}{l}-1,423 * * \\
(0,462)\end{array}$ & $-0,315$ & - & - \\
\hline 3 & $\begin{array}{l}-0,457^{*} \\
(0,209)\end{array}$ & $-0,091$ & $\begin{array}{l}-0,516^{* *} \\
(0,197)\end{array}$ & $-0,114$ & - & - \\
\hline 4 & $\begin{array}{l}-1,434^{* *} \\
(0,086)\end{array}$ & $-0,284$ & - & - & $\begin{array}{l}-1,431 * * \\
(0,088)\end{array}$ & $-0,284$ \\
\hline 5 & - & - & $\begin{array}{l}-0,325^{*} \\
(0,126)\end{array}$ & $-0,072$ & - & - \\
\hline 6 & - & - & $\begin{array}{l}0,259 E-03 * \\
(0,102 E-03)\end{array}$ & $0,57 \mathrm{E}-04$ & - & - \\
\hline 7 & $-1624,05$ & & $-1771,11$ & & $-1627,95$ & \\
\hline 8 & $\begin{array}{l}-1,531^{* *} \\
(0,502) \\
-1,171^{* *} \\
(0,154)\end{array}$ & & & & & \\
\hline
\end{tabular}

Specifications:

1 Age

2 Probability of receiving intervention

3 Occupation: professional occupations (reference category: clerical \& secretarial occupations)

$4 \quad$ Chronicity

5 Comorbidity: problems with chest/breathing $(0=$ no; $1=$ yes $)$

6 Pay

7 logLikelihood

8 Hausman test: Probability of receiving intervention

9 Hausman test: Residual

Only significant values are shown: * significant at $5 \%$ level; ** significant at $1 \%$ level. Control variables include: immigrant status, four dummies for education, three dummies for firm size, eight dummies for occupation, nine dummies for industry, pay, chronicity of complaints and twelve dummies for comorbidity. 
Estimation results for the probability of recovery

The probability of recovery is estimated using instrumental variables for the probability of receiving an intervention. The instruments for the intervention variable are tested on their validity with a Hausman test (see table 4). This test shows a significant correlation between the instruments and the error term of the recovery equation, i.e. intervention is an endogenous variable in the recovery equation. The contribution of the probability of receiving an intervention to the probability of recovery can therefore not precisely be estimated. Table 4 indicates, however, that the effect of the intervention on recovery is negative.

\section{Discussion}

This study takes a different approach in investigating the effectiveness of an intervention. This approach solves some of the most important methodological problems of previous research. The large number of observations (2793) is beneficial for the generalizability of the results. The aim of this study was twofold. First, we tried to solve some methodological problems, of which the selectivity problem was the most important. Secondly, the effect of a physiotherapy treatment on recovery of people with musculoskeletal complaints was investigated.

Determinants of the probability of receiving a physiotherapy intervention

With respect to the selectivity problem - the first research question - several factors were hypothesized to be of influence on the probability of receiving an intervention (see table 1). Positive effects were expected for females, people with higher educational qualifications, people working in larger firms and people with experience with physiotherapists in the past. A high physiotherapy density (more physiotherapists per square kilometer) was also expected to be positive.

Our results show a major positive effect for 'intervention experience'. Having had a physiotherapy treatment the year before the interview increases the probability of receiving another treatment by $15,9 \%$. Comparable findings are reported by Mielenz et al ${ }^{30}$. Subjects with low back pain in that study were found to be twice as likely to be treated by physiotherapists for their current episode of low back pain if they had been treated by physiotherapists in the past. The question is whether the effect we found can be ascribed to true or spurious state dependence. 
54 Chapter 2

In other words; is this a behavioral effect or is it caused by unobserved individual effects? Spurious state dependence could for example be caused by a selection bias in the intervention group. In the present study, we tried to rule out this selection bias by controlling for several variables, like for example age and educational qualifications. Still, one important factor has not been taken completely into account, namely the severity of the complaints. Patients that receive physiotherapy can be grouped according to their level of chronicity (acute, chronic) ${ }^{\mathrm{1}}{ }^{16}$. The level of chronicity influences the probability of receiving an intervention. When chronicity is not controlled for properly it may cause a selection effect, which can cause an underestimation of the effect of the intervention. We corrected for chronicity, but this correction did not improve the fit of the research model significantly. This means that irrespective of chronicity of complaints, receiving physiotherapy in the past increases the probability of physiotherapy in the future. This decreases the probability that a selection effect is caused by a proportion of 'severe' (chronic) cases in the intervention group. But since we did not have a 'severity' variable at our disposal, like for instance initial functional status, we cannot exclude the selection effect completely. We therefore need to allow for an unknown proportion of 'severe' cases that contribute to the effect of 'intervention experience'. However, the remaining part of the effect of 'intervention experience' still has to be explained. Why do people with intervention experience have a greater probability of receiving physiotherapy again? We can only speculate about possible explanations for this phenomenon. The earlier study by Mielenz et al ${ }^{30}$, that also demonstrates such an effect for intervention experience, proposes that this effect might be related to satisfaction with improved functioning or decreased symptoms due to previous physiotherapy, either of the subjects themselves or of the health care professional that referred them to a physiotherapist ${ }^{30}$. Patients may be inclined to return to the physiotherapist sooner if they were satisfied with a previous visit, while health care professionals may be inclined to refer the same patient to a physiotherapist again if they believe that a previous treatment was beneficial. In the literature, this phenomenon is referred to as 'medicalization' ${ }^{39-41}$. The concept of medicalization describes the redefinition of social processes into medical terms ${ }^{40}$. It is known that

\footnotetext{
e Some people in this sample had lifelong chronic conditions, that is, rheumatoid conditions.
} 
persons tend to adjust their life and lifestyle as a result of medical treatments ${ }^{40}$ and that a certain dependence upon these treatments can be created ${ }^{41}$. This brings along great costs ${ }^{39}$. The consumer dependence upon medicine, or in this case paramedicine, is sometimes seen as an example of a more general dependence upon consumer goods in post-industrial societies ${ }^{39,}{ }^{41}$. It is argued that conceptualization of pain is linked to values of society, and the assessment of outcomes is part of this conceptual framework ${ }^{39}$. In this framework it is very well possible that what gets the patient better may be non-specific (placebo) effects and natural history, while the role of the treatment itself may be small ${ }^{39}$. Our results seem to indicate that once someone has entered the physiotherapy circuit, a form of dependence is created, which increases the probability he/she will visit a physiotherapist again. Trends in our data show that the percentage of people with musculoskeletal complaints receiving physiotherapy has risen over the years (see table 2). Unless musculoskeletal complaints as a whole have become more severe over the years, this also indicates a possible medicalization effect. Other indications are found when looking at the recovery equation. Summarizing, the effect of 'intervention experience' is likely to be caused by two phenomena. The first is the probability that a certain amount of 'severe' cases is present in the intervention group. The second is the effect of medicalization.

Besides the large effect we found for 'intervention experience', several minor effects can be seen in the results. We cannot prove a significant difference in the probability of receiving an intervention between men en women. Other studies have shown a relationship between sex and the prevalence of interventions within firms. When it is initiated by the firm, women seem to have a higher probability of receiving an intervention than men ${ }^{13,42}$. Our results and those of Vinke et al ${ }^{43}$ indicate that when it is not specified by whom the intervention is initiated (the firm or the person himself/herself), this difference cannot be demonstrated. This suggests that firms discriminate in favor of women in the application of interventions. This could be related to the fact that women seem to talk more about their problems ${ }^{43}$.

Another minor effect is found for educational qualifications. People with higher educational qualifications have a greater probability of receiving an intervention than people with lower qualifications. This is in accordance with the results of Gründemann ${ }^{13}$ and Mielenz ${ }^{30}$. This could be explained by the fact that higher educated people are more assertive and more informed about the possibilities of 
$56 \mid$ Chapter 2

receiving treatment. For people in certain occupations and industries, negative effects are found, as expected. People in professional occupations and workers in manufacturing industries and in distribution, hotels and catering services have a lower probability of receiving a physiotherapy treatment. The effect of physiotherapy density on the probability of receiving an intervention contradicts our expectations. The effect found is negative, indicating that a relatively higher number of physiotherapists per square kilometer leads to a lower probability of receiving a physiotherapy treatment. It could be that we found this negative effect because we did not control for the number of patients. When two urban areas with a high population density (London and Manchester) are controlled for, the effect of physiotherapy density is no longer significant. Apparently, the availability or accessibility of physiotherapists is not an important predictor for the probability of receiving an intervention. This contradicts our expectation of a supply-induced demand for physiotherapy.

\section{Determinants of the probability of recovery}

The fact that the exogenous variables were not sufficiently correlated with the intervention variable causes a major problem for the interpretation of the estimates of the recovery equation. According to the Hausman test, the instruments are correlated with the error term of the recovery equation, meaning that our instruments are not validf. This makes the estimates of the contribution of the intervention to recovery not valid either. Although it is clearly a shortcoming of this study that we are not able to make statements regarding the effectiveness of the intervention on recovery, some other conclusions still remain. Recovery from musculoskeletal complaints shows a negative trend over the years. Table 2 shows, for example, that relatively less people perceive themselves as being recovered from their complaints in $1998 / 1999(35,0 \%)$ than in $1994 / 1995(38,6 \%)$. This finding in combination with the fact that relatively more people receive an

'Note that 'instruments' refer to instrumental variables. This does not concern the questionnaire with which the data were gathered. Good instrumental variables are not always available (McClellan, Newhouse, 2000). Even if they are available, the variation they induce in $X$ may not be sufficient to establish the effect of $X$ on $Y$ with any useful degree of precision (McClellan, Newhouse, 2000). Finding good instruments is a question of looking for possibly appropriate variables and then assessing whether they meet the requirements for IV. 
intervention, make it plausible that the effect of these interventions is negative. People who undergo a physiotherapy treatment appear to have a lower probability of recovery. Again, the concept of medicalization seems to offer an explanation, besides the assumption that it is partly caused by 'severe' cases. It is known that the redefinition of social processes into medical terms has led to the phenomenon that people tend to consider even normal situations or activities from a medical perspective ${ }^{40}$. From a medical perspective, fewer people will see themselves as being recovered from their complaints. Medicalization can thus explain our finding that the effect of the intervention on recovery is negative. The present study shows that medicalization can create dependence upon physiotherapy treatments. But the question arises whether these physiotherapy treatments are effective for people with musculoskeletal complaints. As we mentioned before, scientific evidence for the effectiveness of physiotherapy on different kinds of patients is lacking. Some studies find positive effects on for example pain and functional status ${ }^{7}{ }^{15}$, but there is no hard scientific evidence on the positive effects of physiotherapy on recovery as a whole. A study that did find a positive effect concluded that a substantial part of the effect of physiotherapy appeared to be due to non-specific (placebo) effects ${ }^{14}$. It has not been proven that people with musculoskeletal complaints who receive physiotherapy, actually recover more quickly (due to this treatment) than people who do not receive this kind of treatment. This is partly caused by the methodological problems we mentioned before, but it could also remain unproven because physiotherapy is simply not effective enough. Medicalization of physiotherapy treatments does not seem to be desirable. Since many people with musculoskeletal complaints actually receive physiotherapy, the effect of medicalization on treatment outcomes is an important problem.

\section{Conclusions}

From this study it can be concluded that previous experience with physiotherapy is an important predictor for the probability of receiving physiotherapy in the future. Given the observational design of our study, we cannot make any causal statements regarding the influence of the predictors. With respect to the association between previous intervention experience and the probability of 
$58 \mid$ Chapter 2

receiving an intervention in the future, there are several indications that this effect can be ascribed to true state dependence, although we cannot exclude the possibility of spurious state dependence completely. It is plausible that the effect of 'intervention experience' is partly explained by medicalization and partly by the presence of 'severe' cases in the intervention group. With respect to the effect of the intervention on recovery, solid conclusions cannot be drawn due to the fact that the instruments for the intervention variable were not valid. We did however find indications towards a negative effect. The medicalization framework could provide an explanation for this. Overall, we can say that solving some of the methodological problems seemed a promising step towards more clarity on the effectiveness of physiotherapy. It is however necessary to use valid instruments for the estimation of the effect of the intervention on recovery, for example variables related to the concept of medicalization. These were not in all respects available in the present study. But even though this study has some shortcomings related to the data, we demonstrated that the method used could be a valuable supplement to the traditional methods of studying effectiveness. Traditional methods to evaluate effectiveness have not yet led to the desired results (i.e. solid evidence on the effectiveness of interventions), due to flaws in the design. Moreover, these methods are very costly. When all conditions are met, the method used in the present study can surely have incremental value to the traditional ones. It gives insight into the use of physiotherapy interventions in a population of workers. It controls for selection effects, one of the most important problems in intervention studies and it is less costly. It is therefore worthwhile to further improve this method, which will make it possible to acquire more knowledge on the effectiveness of physiotherapy in the future. 


\section{References}

1. Beek AJvd, Frings-Dresen MHW, Elders LAM. Effectiviteit van werkaanpassingen bij werkhervatting na klachten aan het bewegingsapparaat. TBV 2000;8(5):137-143.

2. LISV. Kerncijfers Werknemersverzekeringen tot en met maart 2000. Amsterdam: Landelijk Instituut Sociale Verzekeringen; 2000.

3. Jørgensen CK, Fink P, Olesen F. Psychological distress and somatisation as prognostic factors in patients with musculoskeletal illness in general practice. British journal of General Practice 2000(July):537-541.

4. Hoogendoorn WE, Poppel MNMv, Bongers PM, Koes BW, Bouter LM. Systematic Review of Psychosocial Risk Factors at Work and Private Life as Risk Factors for Back Pain. Spine 2000;25(16):2114-2125.

5. Burdorf A, Naaktgeboren B, Post W. Prognostic factors for musculoskeletal sickness absence and return to work among welders and metal workers. Occupational and Environmental Medicine 1998;55:490-495.

6. Miedema HS, Chorus AM, Wevers CWJ, Linden Svd. Chronicity of Back Problems During Working Life. Spine 1998;23(18):2021-2029.

7. Green S, Buchbinder R, Glazier R, Forbes A. Interventions for shoulder pain (Cochrane Review). The Cochrane Library 2000(4).

8. Maniadakis N, Gray A. The economic burden of back pain in the UK. Pain 2000;84:95-103.

9. Foster NE, Thompson KA, Baxter GD, Allen JM. Management of Nonspecific Low Back Pain by Physiotherapists in Britain and Ireland. Spine 1999;24(13):1332-1342.

10. Grossi G, Soares JJF, Angesleva J, Perski A. Psychosocial correlates of long-term sick-leave among patients with musculoskeletal pain. Pain 1999;80(3):607-619.

11. Bigos SJ, Battié MC, Sprengler DM, Fischer LD, Fordyce WE, Hansson TH, et al. A Prospective Study of Work Perceptions and Psychosocial Factors Affecting the Report of Back Injury. Spine 1991;16(1):1-6.

12. Cuelenaere B, Giezen AMvd, Veerman T], Prins R. Werkhervatting na rugklachten. Langdurig zieke werknemers twee jaar gevolgd. Zoetermeer: College van Toezicht Sociale Verzekeringen; 1999.

13. Gründemann RWM, Nijboer ID. WAO-intrede en werkhervatting. Amsterdam: Universiteit van Amsterdam; 1998.

14. Koes BW, Bouter LM, Mameren Hv, Essers AHM, Verstegen GMJR, Hofhuizen $D M$, et al. The Effectiveness of Manual Therapy, Physiotherapy, and Treatment by the General Practitioner for Nonspecific Back and Neck Complaints. A randomized Clinical Trial. Spine 1992;17(1):28-35. 
$60 \mid$ Chapter 2

15. Skargren El, Öberg BE, Carlsson PG, Gade M. Cost and Effectiveness Analysis of Chiropractic and Physiotherapy Treatment for Low Back and Neck Pain. Spine 1997;22(18):2167-2177.

16. Di Fabio RP, Mackey G, Holte JB. Disability and Functional Status in Patients With Low Back Pain Receiving Workers' Compensation: A Descriptive Study With Implications for the Efficacy of Physical Therapy. Physical Therapy 1995;75(3):180-193.

17. Cherkin DC, Deyo RA, Battié M, Street J, Barlow W. A Comparison of Physical Therapy, Chiropractic Manipulation, and Provision of an Educational Booklet for the Treatment of Patients with Low Back Pain. New England Journal of Medicine 1998;339(15):1021-1029.

18. Karjalainen K, Malmivaara A, Tulder MWv, Roine $R$, Jauhiainen M, Hurri $H$, et al. Multidisciplinary biopsychosocial rehabilitation for neck and shoulder pain among working age adults. The Cochrane Library 2000(4).

19. Heckman JJ. Statistical Models for Discrete Panel Data. In: Manski CF, McFadden DL, editors. Structural Analysis of Discrete Data and Econometric Applications. Cambridge: MIT Press; 1981.

20. Hsiao C. Analysis of panel data. Cambridge: Cambridge University Press; 1986.

21. Magnac T. Subsidised Training and Youth Employment: Distinguishing Unobserved Heterogeneity from State Dependence in Labour Market Histories. The Economic Journal 2000(October):805-837.

22. Heckman JJ. Sample Selection Bias as a Specification Error. Econometrica 1979;47(1):153-161.

23. Riihimäki H. Musculoskeletal diseases - a continuing challenge for epidemiologic research. Scandinavian Journal of Work, Environment and Health 1999;25(suppl 4):31-35.

24. Zigenfus GC, Yin J, Giang GM, Fogarty WT. Effectiveness of Early Physical Therapy in the Treatment of Acute Low Back Musculoskeletal Disorders. Journal of Occupational and Environmental Medicine 2000;42(1):35-39.

25. Hoogen HJMvd, Koes BW, Eijk JTM, Bouter LM, Devillé W. On the course of low back pain in general practice: a one year follow up study. Annals of the Rheumatic Diseases 1998;57:13-19.

26. Von Korff $M$, Saunders $K$. The course of Back Pain in Primary Care. Spine 1996;21(24):2833-2839.

27. Amemiya T. Advanced Econometrics. Oxford: Basil Blackwell Ltd.; 1985.

28. Department of Health. Physiotherapy Services. Summary Information for 1998-99. London: Department of Health; 1999.

29. Brug J, Schaalma H, Kok G, Meertens RM, Molen HTvd. Gezondheidsvoorlichting en gedragsverandering. Een planmatige aanpak. Assen: Van Gorcum; 2000. 
30. Mielenz TJ, Carey TS, Dyrek DA, Harris BA, Garret JM, Darter JD. Physical Therapy Utilization by Patients with Acute Low Back Pain. Physical Therapy 1997;77(10):1040-1051.

31. ISER. British Houshold Panel Survey. In.: Institute for Social and Economic Research; 1999-2001.

32. Taylor MF, Brice J, Buck N, Prentice-Lane E, editors. British Household Panel Survey User Manual Volume A: Introduction, Technical Report and Appendices. Colchester: University of Essex; 1999.

33. Clymer JR. Systems Analysis using Simulation and Markov Models. Englewood Cliffs, New Jersey: Prentice-Hall; 1990.

34. Scott Long J. Regression Models for Categorical and Limited Dependent Variables. Thousand Oaks, California: Sage Publications, Inc.; 1997.

35. Levin J, Plug EJS. Instrumenting education and the returns to schooling in the Netherlands. Labour Economics 1999(6):521-534.

36. Heckelman JC, Berument H. Political Business Cycles and Endogenous Elections. Southern Economic Journal 1998;64(4):987-1000.

37. Ettner SL. New evidence on the relationship between income and health. Journal of Health Economics 1996(15):67-85.

38. Hausman JA. Specification Tests in Econometrics. Econometrica 1978;46(6):12511271.

39. Loeser JD. Economic Implications of Pain Management. Acta Anaesthesiologica Scandinavica 1999;43:957-959.

40. Verweij M. Medicalization as a moral problem for preventive medicine. Bioethics 1999;13(2):89-113.

41. Williams SJ, Calnan $M$. The 'limits' of medicalization?: modern medicine and the lay populace in 'late' modernity. Social Science and Medicine 1996;42(12):1609-1620.

42. Giezen AMvd, Molenaar-Cox PGM, Jehoel-Gijsbers G. Langdurige arbeidsongeschiktheid in 1998. Een analyse van arbeidsongeschiktheidsrisico's en ontwikkelingen in de tijd. Amsterdam: Landelijk Instituut Sociale Verzekeringen; 1999.

43. Vinke H, Andriessen S, Heuvel SGvd, Houtman ILD, Rijnders S, Vuuren CVV, et al. Vrouwen en reïntegratie. Hoofddorp: TNO Arbeid; 1999. 
$62 \mid$ Chapter 2

\section{Appendix}

Operationalization of the variables:

Intervention: physiotherapy treatment. $0=$ no physiotherapy; $1=$ received physiotherapy.

Recovery: musculoskeletal complaints at time $t$, free of complaints at time $t+1$.

Age: age of respondent at date of interview.

Sex: sex of respondent. $1=$ male; $2=$ female.

Immigrant status: country of birth. $0=$ Great Britain; $1=$ other.

Educational qualifications: highest educational qualifications. $1=$ higher degree, first degree; 2 = teaching QF, other higher QF, nursing QF; $3=$ GCE A levels, GCE $O$ levels or equivalent (reference category); $4=$ commercial QF (no O), CSE grade 2-5, Scottish Grade 4-5, Apprenticeship, other QF; $5=$ No QF or still at school.

Firm size: number employed at workplace. $1=1-24 ; 2=25=49 ; 3=50-99 ; 4=$ 100 and more (reference category).

Occupation: belonging to one of the major groups of the standard occupational classification $(\mathrm{SOC}) .1=$ managers $\&$ administrators; $2=$ professional occupations; $3=$ associate professional \& technical occupations; $4=$ clerical \& secretarial occupations (reference category); $5=$ craft $\&$ related occupations; $6=$ personal \& protected service occupations; $7=$ sales occupations; $8=$ plant $\&$ machine operatives; $9=$ other occupations.

Sector: belonging to one of the major groups of the standard industrial classification (SIC). 1 = agriculture, forestry \& fishing; 2 = energy \& water supplies; $3=$ extraction of minerals \& ores other than fuels; manufacture of metals, mineral products \& chemicals; $4=$ other manufacturing industries; $5=$ construction; $6=$ distribution, hotels \& catering (repairs); $7=$ transport \& communication; $8=$ 
banking finance, insurance, business services \& leasing; $9=$ other services (reference category).

Physiotherapy density: number of whole time equivalents (WTE) of physiotherapists per square $\mathrm{km}$ per region. Regions are: Northern \& Yorkshire, Trent, West Midlands, North West, Eastern, London, South East, South West, Wales, Scotland.

Pay: usual net pay per month.

Intervention experience: had physiotherapy at time $\mathrm{t}-1$.

Chronicity of complaints: had complaints at time $\mathrm{t}-1$.

Other health problems: comorbidity. Respondent reports to have complaints with sight, hearing, skin conditions/allergy, chest/breathing, hart/blood pressure, stomach or digestion, diabetes, anxiety/depression, alcohol/drugs, epilepsy, migraine, or other. 
64 Chapter 2 
Chapter 3

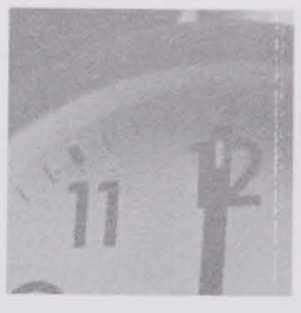

\section{The timing of an intervention by the occupational physician}

Published as:

Joling C, Groot W, Janssen PPM. Waiting for the Doctor. Gender differences in the timing of an intervention by the occupational physician. Journal of Occupational Rehabilitation 2003;13(1):45-61. 
66 Chapter 3 


\begin{abstract}
$^{\mathrm{a}}$
This study aims to answer the question whether the relatively high inflow risk into disability for women, compared to that for men, is reflected in a disadvantage in the probability of being called by the occupational physician during sickness absence. This probability is influenced by sociodemographic, health related and work related factors, as well as by duration of sickness absence. Using a proportional hazards model, the 'risk' of being called by the physician within a certain time period (the so-called hazard rate) is estimated for workers that were called in sick in the Netherlands. Kaplan-Meier curves show a gender difference in the hazard rate. Women appear to have a higher probability of being called by the occupational physician (i.e. a shorter waiting time). The influence of the covariates on the hazard rate is estimated using a Weibull model. The Weibull estimations show that women experience a negative duration dependence, while men's duration dependence is constant. It is concluded that the higher probability women have to be called by the occupational physician is not caused by a gender difference in treatment. Rather, it is the result of a gender difference in underlying characteristics. Underlying characteristics that significantly predict the waiting time for the occupational physician are mostly related to the labor market position of the worker.
\end{abstract}

a Note that Chapter 3 concerns a different sample of workers than Chapter 2. Where Chapter 2 concerned British workers, Chapter 3 uses a sample of Dutch workers. The gender perspective is chosen because of the particular situation in the Netherlands that there is a gender difference in disability risk. 
68 Chapter 3 


\section{Introduction}

Among western countries, the Netherlands stands out for its high number of workers claiming sickness and disability benefits. Studies have shown that work incapacity in the Netherlands in the '90's was about twice as high as in Belgium, Denmark, Germany, Great Britain and Sweden '. In 1990, 8,9\% of the working population in the Netherlands was absent from work because of sickness. In 1995, this was $8 \%{ }^{1}$. In the year 2000, more than one hundred thousand new benefit claims were staked ${ }^{2}$. Social security makes a heavy demand on public money. It is one of the most expensive (semi) public policy domains in most European countries ${ }^{3}$. Every year, in the Netherlands about $1,7 \%$ of the total working population enters the disability benefit system. With this, one of the most remarkable facts is that women have a much greater inflow risk than men. While men run a $1.2 \%$ risk of flowing in, women run a risk that is about 1.6 times as high $(2.0 \%)^{4}$. The question is where and when this disadvantage arises. Some researchers put it down to women's health problems, the labor market position of women, to the sectors that they generally work in, or to the social roles women fulfill ${ }^{5,6}$. It is also possible that the probability of intervention during sickness absence differs between women and men and that this influences the inflow risk. Interventions during sickness absence have a positive effect on the duration of the sick leave ${ }^{7-9}$. The timing of these interventions is a crucial factor in their success: early interventions during sickness absence are proven to be cost-effective for workers, employers and insurers ${ }^{10}$. Early intervention is one of the key issues in Disability Management (DM) strategies worldwide ${ }^{11}$. Although the importance of time (or duration), as well as of interventions during sickness absence is recognized, the interaction between the two has not been thoroughly studied. Namely, besides the influence of interventions on the duration of the sick leave, it is also possible that the duration of the sick leave affects the probability of receiving an intervention. We know that the duration of sickness absence affects the inflow risk into disability. The inflow risk increases with the duration of sickness absence: the longer someone stays away from work, the more difficult it s to return to the workplace and the higher the risk of flowing into the disability benefit system after a period of absence ${ }^{7,9,12}$. This study analyses the relationship between the elapsed duration in the sickness absence process and the occurrence of an intervention by the occupational physician. Since it is known that both 
$70 \mid$ Chapter 3

interventions and duration affect the inflow risk, and the inflow risk differs between men and women, it is possible that there are gender differences in the duration dependence effect on the probability of being selected for an intervention. We focus upon possible gender differences in interventions undertaken by the occupational physician because in the Netherlands this physician is an important actor in the sickness absence process ${ }^{b}$. The occupational physician mostly supervises the sickness absence process of the worker ${ }^{13}$ and legally has the task, among other things, to reduce the sickness absence duration and to promote return to work. In the light of the duration effect these are important tasks. Together with primary prevention these activities are labeled as 'prevention of avoidable absence' ${ }^{14}$. Besides this, the occupational physician also has to prevent illegal absence by means of a health evaluation.

The aim of this study is to investigate gender differences in the probability of being called by the occupational physician. The first question we ask ourselves is whether there are gender differences in the probability of being called by the occupational physician within a certain time period. We call this the hazard rate. If gender differences are found, the second question involves the causes of these gender differences. For this purpose, the effect of predictors upon the hazard rate of men and women is investigated. The relative contribution of each predictor to the probability of receiving an intervention can be calculated. We estimate expected durations for specific values of the predictors.

\section{Predictors of the hazard rate}

To find out what possibly determines the probability that someone is selected for an intervention, a literature review was performed. The probability of receiving an intervention is influenced by factors related to work and working conditions, health, and opinions, attitudes and social roles ${ }^{5}$. First thing to note is that the

b The occupational physician we refer to in our study works in the public sector and has assessment, prevention and disability management tasks. A reallocation of tasks has recently taken place, splitting these tasks up between physicians in the public and the private sector. The 'occupational' physician presently works in the private sector and only has prevention and disability management tasks. The assessment task has remained with 'insurance' physicians in the public sector. 
duration effect has, until now, not been taken into account within a similar framework. We therefore explain the basic principle. After that, other possible predictors are discussed.

\section{Duration}

If duration itself is a predictor of the probability of receiving an intervention, this is called "duration dependence" 15, 16 . Duration dependence can occur because a dynamic interdependence exists between duration and behavior of the individual $^{15}$. Duration dependence can either be positive or negative. Positive duration dependence implies that the 'risk' of being selected (the hazard) increases over time. The expected duration of a spell, the remaining waiting time before the worker is called by the health care professional, will therefore be shorter the longer the elapsed time. Negative duration dependence is marked by a decreasing hazard and larger expected remaining spell durations as time elapses. As certain workers have a higher probability of being selected than others and will be called sooner, this means other people have to wait to be selected. Depending on how this selection process is organized, a positive or negative duration effect can occur. For example, when the most promising cases are selected first, the 'difficult' cases remain waiting. Since the population is then increasingly made up of individuals with a low selection risk, a negative duration dependence is brought about. Duration could also bring about changes in other predictors. In that case, duration influences the probability of receiving an intervention indirectly.

\section{Other predictors}

The probability of being called by the occupational physician is predicted by sociodemographic, health related and work related factors. When someone is reported sick for work in the Netherlands, he or she enters the occupational medicine circuit. In most cases, this means that the occupational health service is informed and the occupational physician receives the personal file of the absent worker, containing information on reason of absence, history of complaints and previous absence record ${ }^{13}$. The physician can then call the worker for an interview. But because of an overcrowded occupational medicine circuit and the large amount of cases to deal with ${ }^{17}$, physicians have to make a selection as to which workers are called in first. The physician's expectations about the outcome of the sickness absence process, based upon the information in the worker's 
72 Chapter 3

personal file, form the basis of the decision to call an worker for a visit. One previous study argued that important selection criteria for the physician are related to the duration of absence and the type and history of complaints ${ }^{17}$. The probability that someone is selected is determined by the information the physician has about the worker. The personal file contains information on the reason of absence, history of complaints and previous absence record. Besides health related characteristics, the physician has information about demographic characteristics like age and gender. Moreover, the physician is likely to have information about the company. In most cases, he or she does not have any information about diagnosis or treatment from the general practitioner ${ }^{17}$. Some theories indicate that the physician's decision to call the worker is colored by expectations and prejudices he or she might have regarding this patient and the outcome of the sickness absence process ${ }^{5,18-21}$. From a sociological perspective, for example, opinions and attitudes of physicians, as well as of the workers themselves and the employers are determined by the social roles people fulfill ${ }^{5,18}$. Marital status, having children, being a breadwinner, social status and definition and assignment of tasks might therefore have an effect on the probability that someone is selected. From a labor market perspective, expectations and prejudices are related to the worker's background, which consists of individual or group characteristics, labor position and labor history. The selection takes place on the basis of this background ${ }^{19-21}$. Knowledge about the company and the labor market position of the worker could thus influence the physician's decision. Possible predictors of being selected by the occupational physician are summarized in table 1.

\section{Methods}

\section{$\underline{\text { Design }}$}

In order to investigate the effect of possible predictors on the hazard rate of men and women, analyses are performed at population level using data from a major longitudinal survey on work incapacity and return to work in the Netherlands (Project Evaluatie Stelselherziening, 1991-1994) ${ }^{22}$. The baseline measurement is used in the present study. The intervention studied is the first contact with the occupational physician. Subjects include all workers that reported themselves sick 
in November 1990 and whose cases were reported to the medical administration service (GMD) nine months thereafter.

Table 1. Summary of possible determinants of selection by the occupational physician and their frequencies in the sample

\begin{tabular}{|c|c|c|c|}
\hline Determinants & Total sample & Men & Women \\
\hline \multicolumn{4}{|l|}{ Sociodemographic } \\
\hline Gender & $N=2622$ & $N=1614$ & $N=1008$ \\
\hline Age (years) & Mean $=40.5$ & Mean $=42.8$ & Mean $=36.8$ \\
\hline \multicolumn{4}{|l|}{ Nationality } \\
\hline \multicolumn{4}{|l|}{ Educational level } \\
\hline - Primary $(\%)$ & 29.9 & 31.5 & 27.3 \\
\hline - Lower vocational $(\%)$ & 29.4 & 31.8 & 25.6 \\
\hline - Junior general secondary $(\%)$ & 9.9 & 8.1 & 12.8 \\
\hline - Senior secondary vocational (\%) & 17.8 & 16.9 & 19.2 \\
\hline - Senior general secondary or pre-university (\%) & 4.3 & 3.4 & 5.8 \\
\hline - Higher vocational (\%) & 7.2 & 6.4 & 8.5 \\
\hline - University (\%) & 1.4 & 1.9 & 0.8 \\
\hline Breadwinner $(\%)$ & 59.6 & 87.2 & 15.4 \\
\hline Marital status & - & - & - \\
\hline Social status & - & - & - \\
\hline \multicolumn{4}{|l|}{ Health related } \\
\hline \multicolumn{4}{|l|}{ Diagnosis } \\
\hline - Psychological $(\%)$ & 21.0 & 18.5 & 25.1 \\
\hline - Musculoskeletal (\%) & 43.3 & 35.1 & 32.9 \\
\hline \multicolumn{4}{|l|}{ Subjective health } \\
\hline - Good & 23.3 & 24.2 & 21.9 \\
\hline - Fair & 35.4 & 36.2 & 34.1 \\
\hline - Poor & 21.2 & 20.5 & 22.4 \\
\hline - Bad & 20.1 & 19.1 & 21.5 \\
\hline \multicolumn{4}{|l|}{ History of complaints / previous health record } \\
\hline - Had same complaints before & 68.4 & 69.1 & 67.4 \\
\hline - Has not had same complaints before & 31.6 & 30.9 & 32.6 \\
\hline \multicolumn{4}{|l|}{ Work related } \\
\hline \multicolumn{4}{|l|}{ Occupational level } \\
\hline - management position & 27.5 & 33.7 & 17.5 \\
\hline - no management position & 72.5 & 66.3 & 82.5 \\
\hline \multicolumn{4}{|l|}{ Workload } \\
\hline $\begin{array}{l}\text { - Low physical workload, high mental workload } \\
\text { and favorable working conditions }\end{array}$ & 24.0 & 21.4 & 28.3 \\
\hline $\begin{array}{l}\text { - Moderate physical workload, high mental } \\
\text { workload and favorable working conditions }\end{array}$ & 6.7 & 5.4 & 8.8 \\
\hline $\begin{array}{l}\text { - Moderate/high physical workload, moderate } \\
\text { mental workload and favorable working conditi }\end{array}$ & ions & 12.6 & 37.8 \\
\hline
\end{tabular}


$74 \mid$ Chapter 3

Table 1. Continued

\begin{tabular}{lrrr}
\hline Determinants & Total sample & Men & Women \\
\hline - High physical workload, low mental workload & 31.5 & 35.9 & 24.4 \\
and unfavorable working conditions & & & \\
- Very high physical workload, low mental & 15.5 & 24.8 & 0.7 \\
workload and unfavorable working conditions & & & \\
Employment contract & & & \\
- Permanent (\%) & 93.5 & 95.3 & 90.6 \\
- Temporary (\%) & 6.5 & 4.7 & 9.4 \\
Contractual working hours & 34.7 & 38.7 & 28.2 \\
Monthly pay (mean in euros) & 1023.04 & 1159.20 & 805.03 \\
Firm size & & & \\
- less than 10 workers (\%) & 18.0 & 15.3 & 22.4 \\
- 10 - < 49 workers (\%) & 28.1 & 28.9 & 26.9 \\
- 50 -< 99 workers (\%) & 13.5 & 14.7 & 11.6 \\
- 100 workers or more (\%) & 40.4 & 41.1 & 39.1 \\
Industry & & & \\
- Agriculture/fishery (\%) & 1.3 & 1.3 & 1.4 \\
- Manufacturing industries (\%) & 25.8 & 33.3 & 13.9 \\
- Construction (\%) & 15.3 & 24.0 & 1.3 \\
- Trade (\%) & 18.3 & 14.9 & 23.8 \\
- Transport (\%) & 8.4 & 10.9 & 4.4 \\
- Banking/insurance (\%) & 9.2 & 8.2 & 10.6 \\
- Other sectors (\%) & 21.7 & 7.4 & 44.6 \\
Labor history: job tenure (months) & 117.43 & 141.30 & 79.21 \\
\hline
\end{tabular}

\section{$\underline{\text { Sample }}$}

The sample includes 2622 people that were interviewed at baseline: 1614 males and 1008 females, in the age of 17 to 64 years. Mean age of the people in the sample was 40.5 years. Of the workers in the sample, 2034 people received treatment from the occupational physician during the first year of absence. The most common reasons for sickness absence of these workers were musculoskeletal complaints $(N=899)$ and psychological complaints $(N=551)$. For more details see table 1.

\section{Instruments}

The data are obtained by means of a questionnaire. This questionnaire includes questions about demographic characteristics, health, health history, employment situation before and after sickness absence, return to work, perception and financial situation. The probability of being selected by the occupational physician 
is estimated for men and women separately. Explanatory variables are selected on the basis of the literature (see table 1).

\section{Analyses}

The analyses are performed using a discrete-state, continuous-time proportional hazard model. Two states are identified in which subjects can be found: 'called for interview' and 'not called'. Subjects can be in one of these states. For each individual, the 'risk' of being selected during the interval $[t, t+d t]$ is estimated, given that the individual has not yet been selected in the preceding period. This risk is expressed in terms of a hazard function, which takes into account certain attributes or patterns of covariates ${ }^{23}$. The basic time unit used to measure the influence of the explanatory variables on the hazard rate is one month. The estimation procedure in a proportional hazard model is divided into two components: one which estimates the form of the duration dependency (i.e. how does the hazard profile change over time) and one which estimates the impact of the covariates.

To gain an impression of possible gender differences in the probability of being called by the occupational physician, Kaplan-Meier estimates are calculated of the hazard rate for men and women. The Kaplan-Meier estimates also provide a picture of the form of the duration dependence. If the hazard is monotonically increasing or decreasing, a Weibull model is appropriate ${ }^{24}$. We allow for a monotonic change in the hazard profile over time (non-stationary) by assuming a Weibull distribution. The legitimacy of this assumption is checked by means of the preliminary Kaplan-Meier analyses.

The hazard function $(h(t))$ of a Weibull model is denoted by ${ }^{24}$ :

$$
h(t)=\exp \left(\mathrm{X}^{\prime} \beta\right) \alpha t^{\alpha-1}
$$

Where $\exp \left(X^{\prime} \beta\right)$ is a regression function of observed worker characteristics. $\alpha$ and $\beta$ are the model parameters to be estimated. The parameter $\alpha$ represents the duration dependence. This hazard function increases monotonically if $\alpha>1$, decreases if $\alpha<1$ and is constant if $\alpha=1^{24}$. An increasing hazard rate denotes positive duration dependence and a decrease in state duration (i.e. a quicker change). 
76 Chapter 3

The effect of a covariate on the hazard rate, specified as percent change in the hazard rate per one unit change in the covariate, is obtained by ${ }^{15}$ :

$$
(\exp (\beta)-1 * 100)=\% \text { change }
$$

The probability that someone receives an intervention described by a density function of the duration $T$, which is denoted by $f(t)$ :

$$
f(t)=\exp \left(\mathrm{X}^{\prime} \beta\right) \alpha t^{\alpha-1} \exp \left(-\exp \left(\mathrm{X}^{\prime} \beta\right) t^{\alpha}\right)
$$

The probability that someone will not receive an intervention is expressed by a distribution function of the duration $\mathrm{T}$, denoted by $F(t)$ :

$$
F(t)=\exp \left(-\exp \left(\exp \mathrm{X}^{\prime} \beta\right) t^{\alpha}\right)
$$

The expected duration is expressed by:

$$
E(t)=G((1 / \alpha)+1) \exp \left(\mathrm{X}^{\prime} \beta / \alpha\right)
$$

To analyze whether possible gender differences may be ascribed to differences in characteristics or differences in treatment by the occupational physician, characteristics and coefficients are interchanged between males and females. For example, if there is no gender difference in treatment, male characteristics should lead to approximately the same expected duration when using male coefficients as when female coefficients are used. Likewise, if there is no gender difference in characteristics, male coefficients should lead to the same expected duration for both male and female characteristics.

\section{Results}

\section{Preliminary results}

A picture of the overall hazard, estimated by the Kaplan-Meier procedure, is shown in figure 1. This figure shows that the overall hazard is monotonically increasing, i.e. the risk of being selected for an intervention increases over time. This implies that our assumption of a Weibull distribution of the hazard seems appropriate. 
Figure 1. Overall hazard function

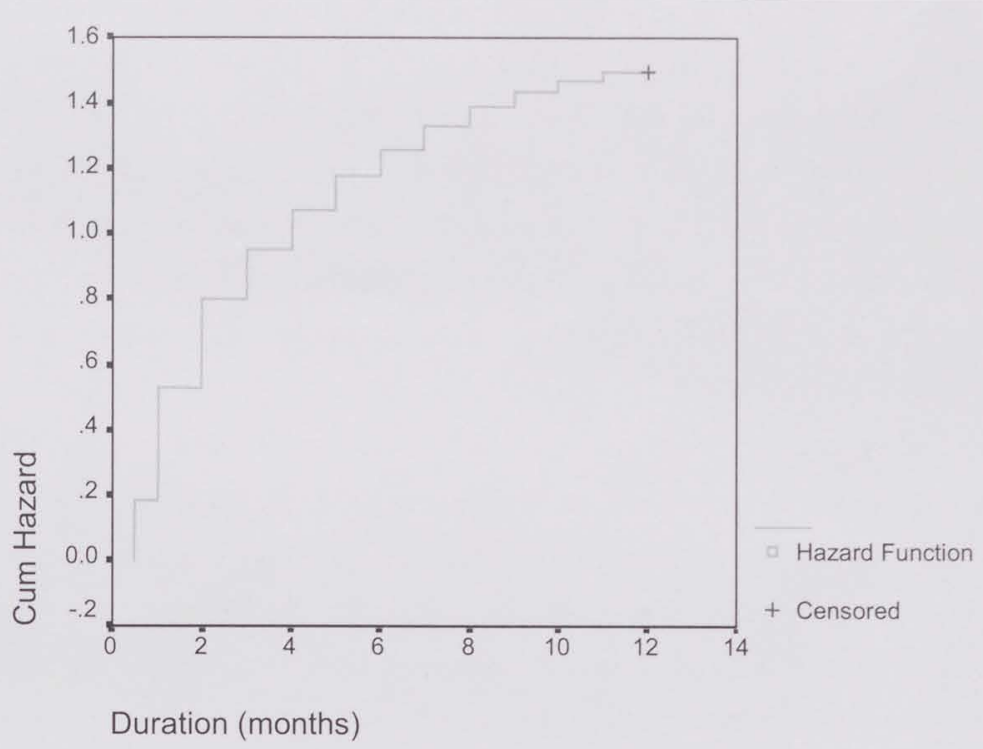

Figure 2. Hazard function by gender

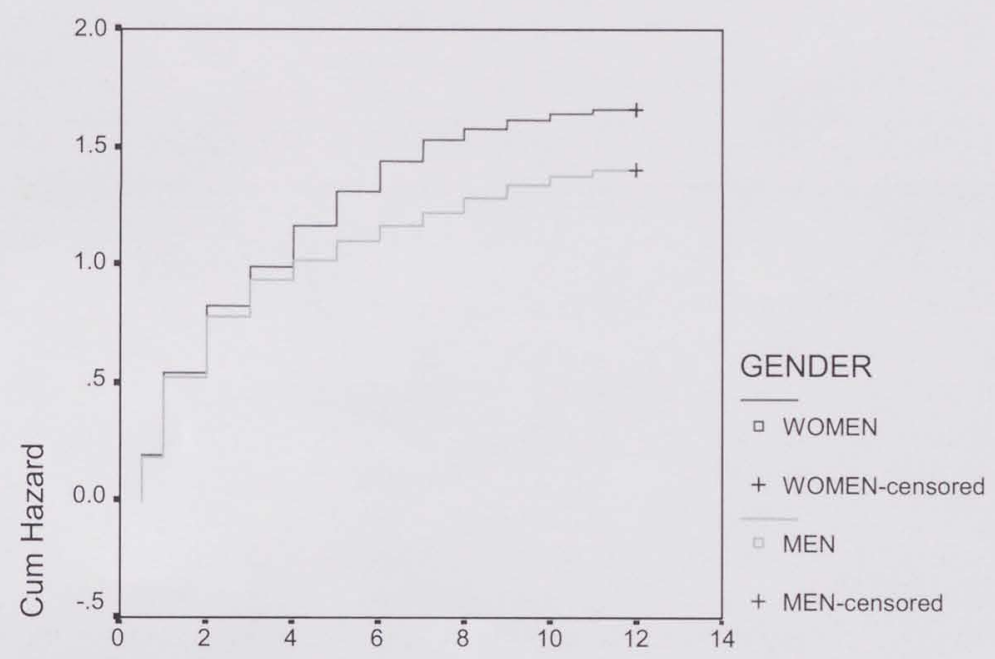

Duration (months) 
$78 \mid$ Chapter 3

Figure 2 shows the hazard function for men and women. To test the equality of survival distributions for these subgroups, a Log Rank test is performed. The test statistic is significant at the 0.01 level $(L R=9.09 ; \mathrm{df}=1 ; p=0.0026)$, which means that the hazard functions for men and women are not equal. The 'risk' or the conditional probability of women to be called by the occupational physician increases relatively faster than that of men. This means that on average women are called sooner than men. Therefore, a distinction between men and women in estimating the effect of the explanatory variables on the hazard rate is justified.

\section{Parameter estimates}

The influence of the covariates on the hazard rate is estimated by means of a Weibull model. If the hazard rate depends on the covariates, a positively (negatively) significant regression coefficient indicates an acceleration (deceleration) of the timing of the intervention. Different models are specified: an initial model, and nine models including interaction terms. The significant estimates are presented in table 2.

Table 2. Summary of parameter estimates of the different specifications

\begin{tabular}{|c|c|c|c|c|c|c|}
\hline & $\begin{array}{l}\text { Initial } \\
\text { model }\end{array}$ & Male & Female & $\begin{array}{l}\text { Interaction } \\
\text { gender* } \\
\text { duration }\end{array}$ & $\begin{array}{l}\text { Interaction } \\
\text { gender* } \\
\text { occ. } \\
\text { workload }\end{array}$ & $\begin{array}{l}\text { Interaction } \\
\text { gender* } \\
\text { psych. } \\
\text { complaints }\end{array}$ \\
\hline & $\begin{array}{l}\text { Estimate } \\
\text { (st. error) }\end{array}$ & $\begin{array}{l}\text { Estimate } \\
\text { (st. error) }\end{array}$ & $\begin{array}{l}\text { Estimate } \\
\text { (st. error) }\end{array}$ & $\begin{array}{l}\text { Estimate } \\
\text { (st. error) }\end{array}$ & $\begin{array}{l}\text { Estimate } \\
\text { (st. error) }\end{array}$ & $\begin{array}{l}\text { Estimate } \\
\text { (st. error) }\end{array}$ \\
\hline 1 & $\begin{array}{l}0.287^{* *} \\
(0.053)\end{array}$ & $\begin{array}{l}0.324 * * \\
(0.068)\end{array}$ & $\begin{array}{l}0.203^{*} \\
(0.090)\end{array}$ & $\begin{array}{l}0.261^{* *} \\
(0.056)\end{array}$ & $\begin{array}{l}0.294 * * \\
(0.053)\end{array}$ & $\begin{array}{l}0.281^{* *} \\
(0.053)\end{array}$ \\
\hline 2 & $\begin{array}{l}0.205^{* *} \\
(0.064)\end{array}$ & $\begin{array}{l}0.171 * \\
(0.082)\end{array}$ & $\begin{array}{l}0.243^{*} \\
(0.108)\end{array}$ & $\begin{array}{l}0.129 \\
(0.068)\end{array}$ & $\begin{array}{l}0.213 * * \\
(0.064)\end{array}$ & $\begin{array}{l}0.200 * * \\
(0.064)\end{array}$ \\
\hline 3 & $\begin{array}{l}0.258^{*} \\
(0.102)\end{array}$ & $\begin{array}{l}0.281 \\
(0.147)\end{array}$ & $\begin{array}{l}0.252 \\
(0.151)\end{array}$ & $\begin{array}{l}0.118 \\
(0.128)\end{array}$ & $\begin{array}{l}0.260^{*} \\
(0.102)\end{array}$ & $\begin{array}{c}0.256^{*} \\
(0.101)\end{array}$ \\
\hline 4 & $\begin{array}{l}0.218 * * \\
(0.058)\end{array}$ & $\begin{array}{l}0.305^{* *} \\
(0.078)\end{array}$ & $\begin{array}{l}0.109 \\
(0.088)\end{array}$ & $\begin{array}{l}0.187^{* *} \\
(0.065)\end{array}$ & $\begin{array}{l}0.213 * * \\
(0.058)\end{array}$ & $\begin{array}{l}0.310^{* *} \\
(0.07)\end{array}$ \\
\hline 5 & $\begin{array}{l}-0.019 \\
(0.096)\end{array}$ & $\begin{array}{l}-0.167 \\
(0.117)\end{array}$ & $\begin{array}{l}0.365^{*} \\
(0.182)\end{array}$ & $\begin{array}{l}-0.155 \\
(0.097)\end{array}$ & $\begin{array}{l}-0.025 \\
(0.096)\end{array}$ & $\begin{array}{l}-0.011 \\
(0.096)\end{array}$ \\
\hline 6 & $\begin{array}{l}0.125^{*} \\
(0.051)\end{array}$ & $\begin{array}{l}0.228 * * \\
(0.065)\end{array}$ & $\begin{array}{l}-0.032 \\
(0.084)\end{array}$ & $\begin{array}{l}0.151^{* *} \\
(0.054)\end{array}$ & $\begin{array}{l}0.123^{*} \\
(0.051)\end{array}$ & $\begin{array}{l}0.126^{*} \\
(0.051)\end{array}$ \\
\hline $7 a$ & $\begin{array}{l}-0.580^{* *} \\
(0.206)\end{array}$ & $\begin{array}{l}-0.542 \\
(0.278)\end{array}$ & $\begin{array}{l}-0.604^{*} \\
(0.303)\end{array}$ & $\begin{array}{l}-0.489^{*} \\
(-0.226)\end{array}$ & $\begin{array}{l}-0.589^{* *} \\
(0.205)\end{array}$ & $\begin{array}{l}-0.573^{* *} \\
(0.206)\end{array}$ \\
\hline $7 b$ & $\begin{array}{l}0.117 \\
(0.077)\end{array}$ & $\begin{array}{l}0.078 \\
(0.083)\end{array}$ & $\begin{array}{l}0.673^{*} \\
(0.295)\end{array}$ & $\begin{array}{l}0.076 \\
(-0.07)\end{array}$ & $\begin{array}{l}0.106 \\
(0.078)\end{array}$ & $\begin{array}{l}0.119 \\
(0.077)\end{array}$ \\
\hline
\end{tabular}




\begin{tabular}{|c|c|c|c|c|c|c|}
\hline \multirow[t]{2}{*}{$7 \mathrm{C}$} & 0.128 & 0.121 & 0.104 & $0.160^{*}$ & 0.117 & 0.122 \\
\hline & $(0.067)$ & $(0.086)$ & $(0.120)$ & $(-0.071)$ & $(0.067)$ & $(0.067)$ \\
\hline \multirow[t]{2}{*}{$7 d$} & $0.375 * *$ & $-0.297 * *$ & $-0.672 * *$ & $-0.331 * *$ & $-0.370 * *$ & $-0.373 * *$ \\
\hline & $(0.087)$ & $(0.100)$ & $(0.197)$ & $(-0.086)$ & $(0.087)$ & $(0.087)$ \\
\hline \multirow[t]{2}{*}{$7 e$} & $0.335 * *$ & $0.375 * *$ & $0.285^{* *}$ & $0.223^{*}$ & $0.326^{* *}$ & $0.332 * *$ \\
\hline & $(0.068)$ & $(0.109)$ & $(0.106)$ & $(-0.092)$ & $(0.069)$ & $(0.068)$ \\
\hline \multirow[t]{2}{*}{$8 a$} & 0.169 & $0.311^{*}$ & 0.014 & 0.148 & $0.282^{*}$ & 0.174 \\
\hline & $(0.098)$ & $(0.143)$ & $(0.151)$ & $(0.117)$ & $(0.133)$ & $(0.099)$ \\
\hline \multirow[t]{2}{*}{$8 b$} & 0.041 & 0.115 & $-1.273^{*}$ & 0.085 & 0.081 & 0.05 \\
\hline & $(0.075)$ & $(0.081)$ & $(0.545)$ & $(0.067)$ & $(0.078)$ & $(0.075)$ \\
\hline \multirow[t]{2}{*}{9} & $-0.094 * *$ & $-0.130 * *$ & -0.052 & $-0.098 * *$ & $-0.094 * *$ & $-0.093 * *$ \\
\hline & $(0.024)$ & $(0.285)$ & $(0.055)$ & $(0.024)$ & $(0.024)$ & $(0.024)$ \\
\hline \multirow[t]{2}{*}{10} & -0.018 & - & - & $2.210 * *$ & 0.047 & 0.04 \\
\hline & $(0.058)$ & - & - & $(0.163)$ & $(0.084)$ & $(0.065)$ \\
\hline \multirow[t]{2}{*}{11} & - & - & - & $-0.468 * *$ & - & - \\
\hline & - & - & - & $(0.032)$ & - & - \\
\hline \multirow[t]{2}{*}{12} & - & - & - & - & $-1.083 *$ & - \\
\hline & - & - & - & - & $(0.541)$ & - \\
\hline \multirow[t]{2}{*}{13} & - & - & - & - & - & $-0.195^{*}$ \\
\hline & - & - & - & - & - & $(0.096)$ \\
\hline \multirow[t]{2}{*}{14} & $0.765 * *$ & $0.749 * *$ & $0.805 * *$ & 1.032 & $0.765^{* *}$ & $0.765^{* *}$ \\
\hline & $(0.024)$ & $(0.032)$ & $(0.037)$ & $(0.023)$ & $(0.024)$ & $(0.024)$ \\
\hline 15 & -5356.49 & -3265.48 & -2067.39 & -4624.43 & -5352.45 & -5354.91 \\
\hline
\end{tabular}

Specifications:

1 Educational qualifications (reference category: primary education): lower vocational

2 Senior secondary vocational

3 Senior general secondary/pre-university

4 Diagnosis (reference category: musculoskeletal): Psychological

5 Accidents

6 Firm size ( reference category: musculosketal): 10-49 workers

7 Industry (reference category: manyfacturing industries)

7a Agriculture/fishery

$7 \mathrm{~b} \quad$ Construction

7c Trade

$7 d \quad$ Transport

7 Other sectors

8 Occupational workload (reference category: high physical workload, low mental workload and unfavorable working conditions)

8a Moderate physical workload, high mental workload and favorable working conditions

8b Very high physical workload, low mental workload and unfavorable working conditions

9 job tenure / 100

10 Female 
$80 \mid$ Chapter 3

11 Female * duration

12 Female* occupational workload: very high physical workload, low mental workload and unfavorable working conditions

13 Female* psychological complaints

14 Duration

15 Log likelihood

*significant at $5 \%$ level; ** significant at $1 \%$ level.

Control variables include age, nationality, six dummies for educational qualifications, four dummies for diagnosis, subjective health, complaints history, employment contract, contractual working hours, three dummies for firm size, six dummies for industry, four dummies for occupational workload, job tenure, monthly pay, absence history, management position and gender. Tested against null hypothesis : HO: $\mu=1$

Significant effects are found for educational qualifications, diagnosis, firm size, industry, occupational workload, job tenure and duration. It seems that having lower vocational educational qualifications brings about a 33 percent $[\exp (0.287)]$ higher probability of receiving an intervention by the occupational physician than having only primary educational qualifications. Workers with senior secondary vocational qualifications have a $23 \%$ higher probability to receive an intervention than workers with primary education only. With respect to the diagnosis, workers with psychological complaints have a $24 \%$ higher probability to be called by the occupational physician than workers with musculoskeletal complaints. Workers in relatively small firms (10-49 workers) have a 13\% higher probability of being selected for an intervention by the occupational physician than workers in large firms (more than 100 workers).

Certain industries show negative parameter estimates, indicating a longer waiting time than the reference category manufacturing industries. Workers in agriculture or fishery have a $44 \%$ lower probability of being selected than workers in manufacturing industries, while workers in transport also have a lower probability (31\% less). Workers in the rest category of other sectors have a $40 \%$ higher probability of receiving an intervention than workers in manufacturing industries.

For job tenure, the coefficient is negative, indicating that job tenure decreases the hazard rate, thereby lengthening the duration before selection for an intervention. Each additional month of job tenure decreases the hazard with $0.09 \%$ [exp($0.936 \mathrm{E}-03)-1 * 100]$. 
The probability of receiving an intervention is also significantly determined by the elapsed duration. The estimates of the initial model show a negative duration dependence of 0.77 . This means that the probability of being called by the occupational physician decreases as time passes. If the model is estimated for men and women separately, it seems that men experience a stronger negative duration dependence than women; 0.75 versus 0.81 .

The possibility of effect modification by gender is investigated by means of different specifications of the initial model. These specifications include interaction terms. To begin with, the interaction between gender and duration is investigated. The effect of duration upon the probability of receiving an intervention appears to differ significantly between men and women at the $1 \%$ level. Table 3 shows the results of the Likelihood Ratio Tests. The addition of the interaction term significantly improves the likelihood of the model $\left(L R \Pi^{2}=1464.12, D f=1\right.$, $p=0.01$ ). The duration dependence for men then becomes constant (1.03) instead of negative, while women experience a stronger negative duration dependence (0.56). This implies that, as time elapses, women's chances of receiving an intervention decrease relative to those of men.

Table 3. Likelihood Ratio tests of the different specifications ${ }^{c}$

\begin{tabular}{lrrr}
\hline Model including interaction term & LogLikelihood & Df & Test statistic $\left(\Pi^{2}\right)$ \\
\hline Gender * duration & -4624.43 & 1 & $1464.12^{* *}$ \\
Gender * occupational workload & -5352.45 & 4 & 8.08 \\
Gender * educational qualifications & -5355.08 & 6 & 2.82 \\
Gender * age & -5356.47 & 1 & 0.04 \\
Gender * industry & -5354.75 & 6 & 3.48 \\
Gender * complaints history & -5355.63 & 1 & 1.72 \\
Gender * psychological complaints & -5354.91 & 1 & 3.16 \\
Gender * monthly pay & -5356.29 & 1 & 0.40 \\
Gender * absence history & -5356.32 & 1 & 0.34 \\
\hline
\end{tabular}

A second significant interaction effect is found for occupational workload. The occupational workload has three components: physical workload, mental workload and working conditions. The effect of a very high physical workload, low mental workload and unfavorable working conditions on the hazard rate appears to be different for men and women. The negative coefficient indicates that 
82 Chapter 3

a deceleration of the timing of the intervention occurs for women with this workload relative to men with the same workload.

A third significant interaction effect is that of having psychological complaints. While having psychological complaints significantly affects the hazard of men, a significant effect for women cannot be found. Other interaction terms that were investigated were not found to be significant. A comparison of the initial model with the specifications, by means of Likelihood Ratio tests, shows that only the interaction of gender and duration significantly improves the model (see table 3). The other interaction terms do not significantly improve the likelihood of the model.

\section{Expected duration}

In order to assess the relative contribution of each predictor to the probability of receiving an intervention, we calculated expected waiting times until absent workers are called by the occupational physician for specific values of the covariates. From table 4 , the effect of the separate covariates on the expected duration can be calculated. While a 'typical' male ${ }^{d}$ (keeping all other variables at their median values) has an expected duration of 9.8 months, being a female increases this expected duration by 0.9 months. Remarkable is the influence of having lower vocational qualifications; it decreases the expected duration by 3.1 month (9.8 months of typical male with primary education only minus 6.7 months; see table 4). Also striking is the effect of psychological complaints. If the typical male has this type of complaints (instead of musculoskeletal complaints), the expected duration is decreased by 2.4 months.

Table 5 shows gender differences in expected duration. It can be determined whether the expected duration is mostly influenced by the individual characteristics or by the coefficients. The 'coefficients' can be interpreted as the effect of the characteristics on the expected duration. Table 5 shows that the characteristics have the largest effect on the expected duration. The gender difference in waiting time for an occupational physician is mainly caused by a difference in characteristics between men and women, i.e. by the composition of these two subgroups, instead of by a difference in treatment. Hereby, female characteristics lead to a lower expected duration. 
Table 4. Relative contribution of the predictors to the expected duration

\begin{tabular}{lr}
\hline Predictor & Expected duration (months) \\
\hline Typical male & 9.8 \\
Female & 10.1 \\
Age 20 & 10.7 \\
Age 50 & 9.5 \\
Educational qualifications & \\
- Lower vocational & 6.7 \\
- Junior general secondary & 8.5 \\
- Senior secondary vocational & 7.5 \\
- Senior general secondary or pre-university & 7.0 \\
- Higher vocational & 9.0 \\
- University & 8.8 \\
Psychological diagnosis & 7.4 \\
No history of complaints & 9.5 \\
Temporary employment contract & 10.3 \\
Occupational workload & \\
- Low physical workload, high mental workload & 9.0 \\
and favorable working conditions & \\
- Moderate physical workload, high mental workload & \\
and favorable working conditions & 7.9 \\
- Moderate/high physical workload, moderate mental workload & \\
and favorable working conditions & \\
- Very high physical workload, low mental workload & 9.6 \\
and unfavorable working conditions &
\end{tabular}

Table 5. Gender differences in expected duration

\begin{tabular}{llrrr}
\hline & & Coefficients & Male & Female \\
\hline Characteristics & Male & 7.9 & 9.9 \\
& Female & 5.8 & 5.9 \\
\hline
\end{tabular}

d The 'typical' male in this sample is 41 years of age, dutch, has primary educational qualifications, musculoskeletal complaints, a fair subjective health, has a complaints history, a permanent employment contract, worked 38 contractual hours a week, in a large firm (more than 100 workers), in manufacturing industry, experienced high physical workload, low mental workload and unfavorable working conditions, was absent from work for one week in the past year, does not have a management position and has a job tenure of 84 months. 
$84 \mid$ Chapter 3

\section{Discussion}

The aim of this paper was to study gender differences in the probability of being called by the occupational physician (the hazard rate). To check if this is the case, Kaplan-Meier estimates were calculated. These estimates indeed show that there is a gender difference in the hazard rate. From figure 2 it can be derived that for both men and women the probability of receiving an intervention increases as time passes, but seems to increase more rapidly for women than for men. This finding not only confirms our hypothesis but also triggers a search for possible causes. Because the Kaplan-Meier procedure does not provide insight into the influence of the covariates, we performed additional analyses using a Weibull model. Possible gender specific predictors of the hazard rate were explored. We were particularly interested in a possible gender specific effect of duration, because duration proves to be an important factor in the sickness absence process ${ }^{7,9,12}$. The estimation results of the initial model show that important predictors of the hazard rate are educational qualifications, diagnosis, firm size, industry, occupational workload, job tenure and duration. Gender specific predictors are identified by including an interaction term in the model.

\section{Effect of duration}

Duration appears to be the most important gender specific predictor in this study. Inclusion of an interaction term of gender and duration significantly improves the likelihood of the model. The hazard plot (see figure 2) shows that both men and women have an increasing hazard. The interaction of gender and duration implies that the effect of duration upon this hazard varies between men and women, however. From the model with the interaction term it can be derived that the duration dependence effect is strongly negative for women $(1.032-0.468=$ 0.564) while it is rather constant for men (1.032). In other words, as time progresses in the sickness absence process, womens' chances decrease relative to those of men. So both hazards are increasing, but duration stimulates the probability of being selected for men and inhibits this probability for women. What makes this effect occur? It could be because of heterogeneity between the two subgroups (men and women) 23, 25. Failure to correct for unobserved heterogeneity could lead to an estimated hazard that declines more steeply or rises more slowly than the true hazards of homogenous subgroups, as well as to biases 
in the parameter estimates for the included covariates ${ }^{25}$. We therefore tried to correct for unobserved heterogeneity by including the effect of the omitted regressors (i.e. effect of error) in the model. Following Lancaster ${ }^{26}$, we assumed the error to be gamma distributed ${ }^{e}$ However, we kept encountering estimation problems and were therefore not able to obtain reliable estimates. Another way in which the effect of unobserved heterogeneity could be minimized is by including factors which correct for the population heterogeneity related to, for example, becoming sick in the first place. In our case this means that factors related to the history of complaints or the previous absence record will be effective in eliminating a major confounding factor in assessing the effects of the covariates on the probability of receiving an intervention. Other confounding effects can be minimized by correcting for gender specific variables, like industry and occupation.

Women seem to have characteristics which favor the probability of being called by the occupational physician (see table 5). They have a shorter expected duration (i.e. are selected sooner) than men. Consequently, as time progresses, the proportion of women in the population yet to be selected will decrease compared to the proportion of men. As time passes, more women will have been called by the physician so that the population (the so called 'risk set') is increasingly made up of men. As a result of the larger proportion of men, men's chances increase relative to those of women. Because women are removed from the risk set, the distribution of characteristics changes over time and this affects the shape of the hazard. The effect of the characteristics on the expected duration can be derived from table 5. By interchanging the coefficients and the characteristics of men and women, we calculated expected durations for women as if they were treated as men, and for men as if they were treated as women. This way, if there are differences in treatment on the basis of the factor gender, they should be revealed. Table 5 clearly shows that it is mainly the difference in underlying characteristics, instead of differences in treatment, what causes the gap in expected durations between men and women. Because gender differences seem to have their origins

${ }^{e}$ The distribution function $f(t)$ is then given by (Lancaster, 1979):

$f(t)=\exp (x b) \alpha t^{\alpha-1} *\left[1+\sigma^{2} \exp (x b) t^{\alpha}\right]^{-1}$ 
$86 \mid$ Chapter 3

in underlying characteristics, a distinction between men and women is somewhat artificial. Women simply have a different pattern of covariate values than men and this seems to be the major reason for their deviating hazard. A distinction of subgroups on the basis of another predictor of the hazard rate, such as educational qualifications or industry, could therefore be equally (or maybe even more) plausible.

\section{Effect of other predictors}

Other predictors of the hazard rate are educational qualifications, diagnosis, firm size, industry, occupational workload and job tenure. These are mostly related to the labor market position of the worker. It seems that someone's chance of being selected is not so much related to his gender, but rather to his or her prospects of return to work. People with a better labor market position seem to be more likely to be called by the occupational physician. In this respect, having vocational educational qualifications and a favorable occupational workload (i.e. moderate physical workload, high mental workload and favorable working conditions) is helpful to get attention from the occupational physician sooner rather than later. Job tenure appears to be correlated with age $(\rho=0.55)$, which explains the negative effect we found on the hazard rate. A shorter job tenure indicates a younger age and probably a better labor market position.

Not all predictors we found to be significant for men, were also significant for women. Having psychological (instead of musculoskeletal) complaints, for example, does not provide a higher probability for women to be selected. Including an interaction term in the model between gender and psychological complaints leads to a significant effect (see table 2). It seems that the effect of having psychological complaints on the probability of being called by the occupational physician differs for men and women, although it does not improve the likelihood of the model significantly (see table 3). Women more frequently experience psychological complaints, but our results indicate that when men have psychological complaints, they are called in sooner. This is in accordance with a previous study, which suggested that occupational physicians are prone to view women's complaints more from a personal perspective, while men's complaints are viewed more from a medical perspective ${ }^{27}$. Since physicians are likely to have a higher self-efficacy in the medical area, it is plausible that they will then call the men sooner than the women. 
We also found a significant interaction between gender and occupational workload. The effect of a combination of a very high physical workload, low mental workload and unfavorable working conditions differs significantly between men and women. The significance of this effect is probably related to the number of women working in this kind of situation, however. Since this involves only seven women, the estimate is rather unreliable.

Another gender specific effect is job tenure. Job tenure does not provide a higher probability of being called by the physician for women, whereas it does so for men. This could be related to the fact that the women in the sample were on average younger than the men (mean age 36 years versus 44 years respectively) and we have seen that age and job tenure are correlated.

\section{Conclusions}

We stated in the introduction that women have a higher inflow risk into disability than men and that it remained unclear as to where this disadvantage arises from. This study shows that this disadvantage is not reflected in the probability of receiving an intervention from the occupational physician. In fact, on the basis of their characteristics, women are more likely to be called by the physician and have shorter expected durations. We cannot prove a gender difference in treatment. This study shows that duration dependence occurs with the selection of people for an intervention. Men experience a rather constant duration dependence, while women experience a strongly negative duration dependence. This can be caused by heterogeneity between these two subgroups. The distinction between men and women turns out to be somewhat artificial because it seems that not the factor 'gender' causes a difference in hazard between men and women, but rather the underlying characteristics. Educational qualifications, diagnosis, firm size, industry, occupational workload and job tenure are other significant predictors of the hazard rate. These are mostly related to the labor market position of the worker. Apparently, in the decision of the occupational physician to call someone, factors related to the prospects of return to work are more decisive than factors related to the health status of the worker.

The importance of time in the sickness absence process is emphasized in Disability Management (DM) strategies worldwide. Following countries like Canada and the USA, over the last decade European countries like France, Germany, Sweden and the Netherlands have also developed DM initiatives ${ }^{8}$. The interaction between the 
$88 \mid$ Chapter 3

duration of sickness absence and interventions is crucial for the success of DM strategies. An optimal timing of interventions during sickness absence will lead to lower emotional and financial costs for workers and employers and to a decrease of social security costs. We believe that this study adds valuable knowledge and increases the possibility of eventually answering the question what is the optimal timing of interventions for sick listed workers? 


\section{References}

1. Cuelenaere B, Veerman TJ, Prins R, Giezen AMvd. In distant mirrors. Work Incapacity and return to work. Zoetermeer: College van Toezicht Sociale Verzekeringen; 1999.

2. LISV. Trendrapportage Arbeids(on)geschiktheid 2001. Amsterdam: Landelijk Instituut Sociale Verzekeringen; 2001.

3. Einerhand MGK, Knol G, Prins R, Veerman TJ. Sickness and invalidity arrangements. Facts and figures from six European countries. Den Haag: Ministerie van Sociale Zaken en Werkgelegenheid; 1995.

4. Adviescommissie Arbeidsongeschiktheid. Werk maken van arbeidsgeschiktheid. Den Haag: Ministerie van Sociale Zaken en Werkgelegenheid; 2001.

5. Vinke H, Andriessen S, Heuvel SGvd, Houtman ILD, Rijnders S, Vuuren CVv, et al. Vrouwen en reïntegratie. Hoofddorp: TNO Arbeid; 1999.

6. Delft MLE. Sociale atlas van de vrouw. Den Haag: Sociaal en Cultureel Planbureau; 1991.

7. Shrey DE. Worksite disability management model for effective return-to-work planning. Occupational Medicine: state of the art reviews 2000;15(4):789-801.

8. Vos EL, de, Wevers CWJ. Aan de slag met een arbeidshandicap: internationale ervaringen: Landelijk Instituut Sociale Verzekeringen; 1998.

9. Akabas SH, Gates LB, Galvin DE. Disability Management. A Complete System To Reduce Costs, Increase Productivity, Meet Worker Needs, And Ensure Legal Compliance. New York: AMACOM; 1992.

10. Shrey DE. Disability management in industry: the new paradigm in injured worker rehabilitation. Disability and rehabilitation 1996;18(8):408-14.

11. Shrey DE, Lacerte M. Principles and Practices of Disability Management in Industry. Florida: CRC Press LLC; 1997.

12. Crook J, Moldofsky $H$. The probability of recovery and return to work from disability as a function of time. Quality of Life Research 1994;3(suppl. 1):s97-s109.

13. Meershoek A. Weer aan het werk. Verzekeringsgeneeskundige verzuimbegeleiding als onderhandeling over verantwoordelijkheden. Maastricht: Maastricht University; 1999.

14. Kaiser CP. Het verzekeringsgeneeskundig handelen en de verzuimduur. Maastricht: Universiteit Maastricht; 1992.

15. Griffin WA. Assessing State Changes in Microsocial Interaction: An Introduction to Event-History Analysis. In: Mordechai Gottman J, editor. The Analysis of Change. Mahwah, New Jersey: Lawrence Erlbaum Associates Publishers; 1995. p. 309-337. 
$90 \mid$ Chapter 3

16. Heckman JJ. Statistical Models for Discrete Panel Data. In: Manski CF, McFadden DL, editors. Structural Analysis of Discrete Data and Econometric Applications. Cambridge: MIT Press; 1981.

17. Schröer CAP. Ziekteverzuim wegens overspanning: een onderzoek naar de aard van overspanning, de hulpverlening en het verzuimbeloop. Maastricht: Universiteit Maastricht; 1993.

18. Delft MLEv. Sociale atlas van de vrouw. Rijswijk: Sociaal en Cultureel Planbureau; 1991.

19. Glebbeek AC. Perspectieven op loopbanen. Groningen: Rijksuniversiteit Groningen; 1993.

20. Beek KWHv. To be hired or not to be hired, the employer decides. Relative chances of unemployed job-seekers on the dutch labor market. Den Haag: Universiteit van Amsterdam; 1993.

21. Gründemann RWM, Nijboer ID. WAO-intrede en werkhervatting. Amsterdam: Universiteit van Amsterdam; 1998.

22. Molenaar-Cox PGM, Fiseler JG, Stelt HGvd, Smaal M, Kers WC. Databoek PES3. Amsterdam: GAK/GMD; 1995.

23. Yamaguchi K. Event History Analysis. Newbury Park, California: Sage Publications, Inc.; 1991.

24. Blossfeld HP, Hamerle A, Mayer KU. Event History Analysis. Hillsdale, New Jersey: Lawrence Erlbaum Associates Inc.; 1989.

25. Trussell J, Richards T. Correcting for unmeasured heterogeneity in hazard models using the Heckman-Singer procedure. In: Tuma N, editor. Sociological Methodology 1985. San Francisco CA: Jossey-Bass; 1985. p. 242-276.

26. Lancaster T. Econometric methods for the duration of unemployment. Econometrica 1979;47(4):939-956.

27. Cuelenaere $B$, Molenaar-Cox $P$, Brummelen $Y v$. Begeleiding van mannen en vrouwen in het eerste ziektejaar. Amsterdam: LISV; 2001. 


\section{Chapter 4}

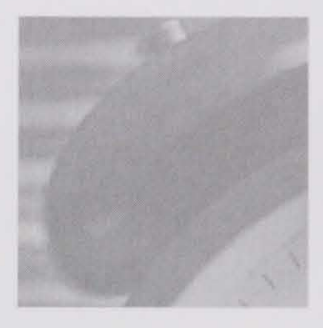

\section{Modelling return-to-work intervention strategies}

Published as:

Joling C, Janssen PPM, Groot W. Modelling return-to-work intervention strategies. A method to help target interventions. Journal of Occupational Rehabilitation $2004 ; 14(1): 43-62$. 
92 Chapter 4 


\section{Abstract}

The aim of this study is twofold: (1) to investigate the relationship between the probability of receiving an intervention by the occupational physician and the probability of return to work (RTW) of sick workers; (2) to explore the use of simultaneous modelling of the intervention and RTW process. Analyses are performed at population level using data from a major longitudinal survey on work incapacity and return to work in the Netherlands. A bivariate probit model is used to estimate the correlation between the probability of intervention and the probability of RTW. A bivariate hazard model is applied to explore the joint distribution of the waiting times for the intervention and RTW. The results of this study show that the probability that a worker is called by the occupational physician is not correlated with the probability of RTW. Neither is the timing of both events correlated. The analyses do not indicate that a limited intervention by the occupational physician provides incentives for sick workers to return to work quicker. 
94 Chapter 4 


\section{Introduction}

In the Netherlands, incapacity for work is one of the most important socioeconomic problems. In 2000, the ratio of the disabled and the working population was $1: 7$. This corresponds to almost one million disabled people ${ }^{1}$. The number of people receiving disability benefits is increasing, since the inflow exceeds the outflow by far: in 2000 , the inflow risk ${ }^{a}$ was $1.7 \%$, while the outflow risk for all those in the disability benefit system was $8.4 \%$ '. Social security costs are escalating ${ }^{2}$. This is, however, not only a national issue: other European and North American countries face similar problems ${ }^{2-4}$. Besides the apparent financial costs of work injury and disability, social costs of work incapacity are also eminent. Stigmatization and social exclusion are common problems for disabled people ${ }^{5}$. The social consequences of occupational injuries and illnesses are much broader than this: they reach beyond the boundaries of a person's workplace and home, extending into hospitals, courts, and the local community ${ }^{6}$. The international interest in work retention and return to work (RTW) is further stimulated by the globalization of economic markets that has taken place (and the resulting increased competitiveness), and attention to human and civil rights ${ }^{4}$.

Though the need to return sick workers back to work is great, it has proved to be difficult. Past efforts to understand the RTW process have led to the identification of predictors of work disability and RTW of a wide range of diseases and conditions ${ }^{7}$. These diseases and conditions require different intervention strategies $^{7}$. An intervention is seen as an action in response to the particular situation facing an individual ${ }^{8}$. During sickness absence interventions take place to facilitate and accelerate the RTW process. What kind of intervention is undertaken for whom and when (i.e. the timing) - we call this the intervention strategy - depends on the nature of the complaints (e.g., musculoskeletal, psychological), and on the phase of complaints or stage of absence the worker appears to be in (e.g., acute low back pain, chronic low back pain) ${ }^{9}$. Research has yielded knowledge on the effectiveness of specific interventions for specific groups of workers (e.g., working age adults with subacute low back pain ${ }^{10}$ ). However, mostly more than one intervention takes place (i.e. multidisciplinary

\footnotetext{
${ }^{a}$ Inflow risk: new claims as a percentage of the working population.
} 
96 Chapter 4

intervention) ${ }^{11}$. Hence, there is a wide range in intervention "packages" for individual workers ${ }^{9}$ and it is difficult to separate the effects of each single intervention. There is no consensus about the 'optimal' intervention strategy, that is, about the most favorable combination between the content and the timing of interventions ${ }^{9,12}$.

A RCT (or experiment) is commonly seen as the most appropriate design to study the effectiveness of interventions ${ }^{13-15}$. An experimental design is not always possible, though. Especially in the field of sickness absence there are legal requirements that make certain interventions compulsory for everyone. Moreover, it is often considered not ethical to exclude people in a control group from an intervention that is likely to benefit their health or their work status.

Because of the limited scope of many studies on the effectiveness of interventions and the methodological problems that are encountered, synthesizing results across different studies is problematic ${ }^{7}$. The knowledge on effectiveness of RTW interventions remains scarce. The effectiveness of an intervention is not only determined by its content, but also by other aspects of the intervention strategy: who is selected for the intervention and when does it take place? In this study, we are concerned with the intervention strategy and its relationship with RTW. In order to describe patterns in the intervention strategy, we explicitly focus our analyses on a higher abstraction level than usual (population level). This study is complementary to the studies on the effectiveness of interventions in the sense that it directs attention to aspects of interventions that are frequently disregarded (i.e. selection and timing), and it provides an alternative framework to model intervention strategies.

The timing of the intervention during the sickness absence process is important because the RTW process is shaped by individual, organizational, social and economic factors, which may be variable and which are likely to interact $7,16-19$. These factors can change the direction, as well as the size, of the effect of an intervention. The timing of interventions is furthermore of interest because RTW seems to be an urgent matter: it is found that the longer someone is off work, the more difficult it becomes to return to the workplace ${ }^{20-22}$.

In this paper, we investigate patterns in the probability that someone is called for an intervention within a certain time, as well as patterns in the relationship between this intervention and RTW of the individual. The intervention under study here is a call of a sick worker by the occupational physician. The occupational 
physician legally has tasks in the assessment, prevention and disability management ${ }^{b}{ }^{23}$. $\mathrm{He}^{\mathrm{c}}$ has the task to return the worker to the workplace and intervenes in the sickness absence process in order to achieve this goal ${ }^{23}$. The actions of the occupational physician and the probability of RTW are potentially interdependent. Prospects of RTW can influence the probability that someone is called for an interview by the physician. The way in which the actions of the occupational physician influence RTW is determined by the role this physician has during the period of absence from work. His tasks could entail potentially conflicting roles towards the worker, the employer and the state: the occupational physician is a counselor, medical advisor, social worker and a gatekeeper for social security benefits at the same time ${ }^{23}$. These roles influence the probability that a sick worker is called by the occupational physician, and thus his chance of RTW. Because of an overcrowded occupational medicine circuit ${ }^{24}$, the occupational physician has to make a selection which workers to call first. He could for example call those workers first who have bad prospects of RTW (the 'difficult' cases), or he could call in first those with good prospects of RTW (the 'easy' cases). As yet, we do not know how the intervention strategy and the probability of RTW are related. It is clear that given his different roles, seemingly paradoxal mechanisms may play a role in the intervention behavior of the occupational physician ${ }^{25}$. In this study we examine how the probability of intervention is related to the probability of RTW. It is not to be expected that this intervention alone will have a large influence on RTW. Rather, it can be seen as the beginning of the path towards RTW. So what we look at is the timing of the beginning of the intervention to RTW. Patterns we may find in the probability of intervention are connected to patterns in the probability of RTW. This way, we can indicate whether the right people are targeted by the physician at the right time.

Because in this study an experimental design is not possible, we will have to face potential threats of the internal validity that non-experimental designs encounter ${ }^{13}$. One of these threats is endogeneity bias. Endogeneity bias can occur if prospects

\footnotetext{
b The occupational physician we refer to in our study works in the public sector and has assessment, prevention and disability management tasks. A reallocation of tasks has recently taken place, splitting these tasks up between physicians in the public and the private sector. The 'occupational' physician presently works in the private sector and only has prevention and disability management tasks. The assessment task has remained with 'insurance' physicians in the public sector.

"Where it says he/his one can also read she/her.
} 
98 Chapter 4

of success on the outcome of a process (e.g., RTW), influence the probability of receiving an intervention, or the other way around. While endogeneity is commonly accounted for in economics and econometrics ${ }^{26}$, in RTW studies it has not been taken into account. Endogeneity needs to be considered when the effect of an RTW intervention is evaluated. Because the occupational physician has to make a selection of workers to call first, another problem we encounter is selection bias. Not everyone has the same chance of receiving an intervention ${ }^{27}$. A low probability of RTW could originate from a low probability of receiving an intervention. We therefore have to take the possibility of selection bias into account when chances of RTW are considered.

The validity of the estimates being questioned in two ways (an endogeneity problem and a possible selection bias), the question is how we can account for this in our research design, and how selectivity and endogeneity influence the probability of RTW. We cannot answer this question by means of a - generally accepted - structural model, because the (pseudo) isolation assumption, a condition for possible causal statements ${ }^{28}$, is violated. A different approach is needed. In this study, the selection bias is accounted for by estimating the probability of receiving an intervention by the occupational physician. To account for the interdependency between the intervention and RTW we treat the probability of intervention and the probability of RTW as simultaneous equations. This enables us to determine whether and how they are interrelated. A formal framework is used, in which one specific intervention is studied, namely an intervention by the occupational physician. This study examines patterns in (a) the intervention strategy of the occupational physician, and in (b) the relationship between the intervention strategy and RTW. Within the framework we specifically address the following question: what is the relationship between (the timing of the intervention and (the timing of) RTW?

\section{The modelling framework}

We use a formal intervention model (cf. Wittenboer, $1992^{29}$ ) as a framework for this study. A formal intervention model describes an intervention process in formal terms. In this study, the concepts of this model are applied to the field of sickness absence. Wittenboer defines an intervention as an integral part of a system. Within 
this framework, 'intervention' is defined as a goal directed activity to change a manifest, or an underlying latent process with the object to obtain a conceived goal ${ }^{29}$. The goal of the intervention under study is RTW. When evaluating the system, the initial state of the object at the outset of the intervention, the probability of success or failure given the state at the beginning and the preferred effects of the intervention need to be considered ${ }^{29}$. Figure 1 shows the object of intervention (the system) and the main concepts in the case of a worker on sickness absence.

Figure 1. System in which the intervention takes place for workers on sickness absence.

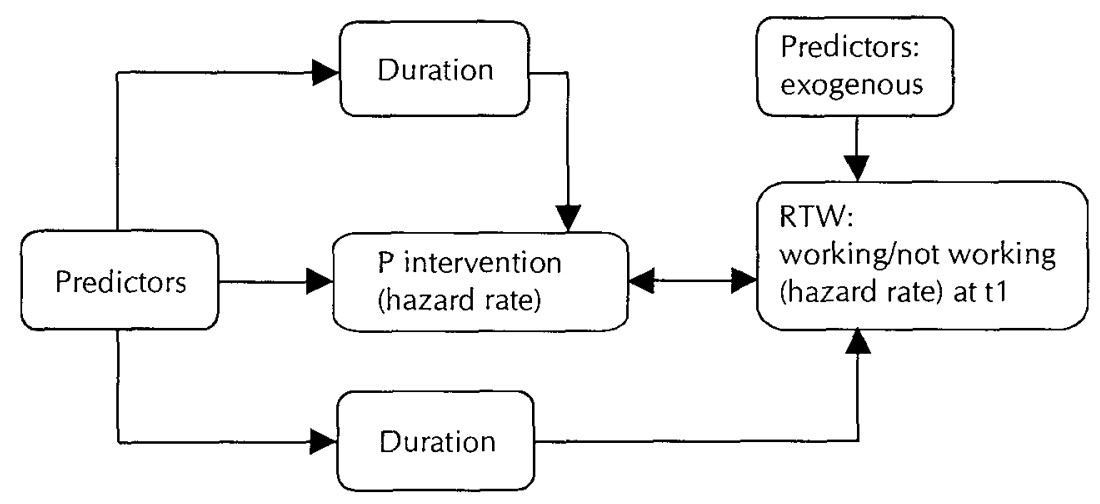

The concepts in this system are the intervention, the probability of intervention (Pintervention) (determined by several predictors), and the probability of return to work (RTW) (depending on several predictors, both exogenous and endogenous). These concepts are explained below. Possible relationships are represented by arrows. As argued in the introduction, the probability of intervention and the probability of RTW may be related (this is represented by a bilateral arrow). The predictor 'duration' is described separately to indicate that we investigate the timing of both events.

\section{Intervention}

Interventions can be seen as behaviors that inject into the ongoing social processes of a system ${ }^{30}$. They intervene in interactions between individuals, interactions between groups, the procedures used for transmitting information, making decisions, and planning actions or setting goals. Moreover, they intervene in the 
$100 \mid$ Chapter 4

strategies and policies guiding the system, norms or unwritten ground rules or values of the system, the attitude of people towards work, the organization, authority, and social values and the distribution of effort within the system ${ }^{30}$. The specific intervention under study here is a call by the occupational physician. In the Netherlands, this physician mostly supervises the sickness absence process of workers ${ }^{31}$. By law, the occupational physician has the task, among others, to reduce the sickness absence duration and promote RTW 32, 33. The disability management tasks of the physician are expressed by intervention in the natural course of disability, aimed at returning the worker back to the workplace ${ }^{23}$. His tasks do not include medical advice and treatment. His actions can comprise, for example, supporting the sick worker in enlarging his work capacity and adapting his workload ${ }^{25}$, but it can also include advice directed at the home situation ${ }^{23}$. An intervention by the occupational physician might for example change the attitude of the worker towards work and the planning of RTW activities or goals. Moreover, the physician may stimulate the worker to put forth more effort to return to work. Given his tasks we expect that the effect of an intervention by the occupational physician on RTW is positive.

\section{Predictors of the probability of intervention}

The probability of receiving an intervention is mainly predicted by work related and health related factors, as well as factors related to opinions, attitudes and social roles ${ }^{34-37}$ and the duration of the illness ${ }^{38,39}$. As mentioned above, we concentrate on interventions by the occupational physician. The probability that someone is called by the occupational physician within a certain time period was investigated in an earlier study ${ }^{27}$. This study showed that duration dependence affects the selection of people for an intervention. This means that the duration of sickness absence is an important factor in the process. Gender, educational qualifications, diagnosis, firm size, industry, occupational workload and job tenure were also found to be significant predictors of the probability that someone receives an intervention by the occupational physician ${ }^{27}$. Table 1 gives a summary of the predictors and their expected effect on the probability of receiving an intervention. 


\section{Predictors of RTW}

The goal of the process is the return to work of the worker. RTW is not only influenced by interventions, but also by personal and work related characteristics ${ }^{35}$ and by the duration of sickness absence ${ }^{20-22}$. With respect to RTW, a negative duration effect has been reported: the longer someone stays away from work, the more difficult it becomes to return to the workplace ${ }^{20-22}$. Reasons for this negative effect remain largely speculative. It has been proposed that a longer duration of absence increases the risk for sick-role behavior ${ }^{9}, 22$. Time spent out of work may have a negative effect on someone's attitude towards work. Staying at home might hamper return to work activities and impede the setting of goals.

In Disability Management programs, early intervention programs are a key issue ${ }^{20,}$ ${ }^{21}$. This is based on the assumption that early intervention leads to a quicker RTW. It is known, however, that early intervention can also aggravate the situation. For example, early aggressive treatment in the acute phase of low back pain is potentially iatrogenic ${ }^{9}$. Besides duration, many other factors predict the probability of RTW. Numerous studies have been performed ${ }^{35,40-43}$ (among many others). The predictors and their influence on RTW are summarized in table 1.

Table 1. Predictors of the probability of receiving an intervention and return to work: + positive influence; - negative influence; $+/$ - influence ambiguous, can go either way depending on the situation; ? influence unknown.

\begin{tabular}{|c|c|c|}
\hline Predictor & Intervention & Return to work \\
\hline Gender: Female & $\begin{array}{ll}+ & 27 \\
+\quad \text { in relationship with } \\
\\
\text { health care } \\
\text { consumption } 344445\end{array}$ & $\begin{array}{ll}- & 43 \\
- & \text { in relationship with } \\
& \text { labor market } \\
& \text { position }{ }^{34} 35\end{array}$ \\
\hline $\begin{array}{l}\text { Age } \\
\text { - Younger than } 35 \text { years }\end{array}$ & $\begin{array}{l}\text { - in relationship with } \\
\text { length of job tenure }\end{array}$ & \\
\hline $\begin{array}{l}\text { - Older than } 35 \text { years } \\
\text { Nationality: Immigrant status }\end{array}$ & $\begin{array}{l}\text { - in relationship with } \\
\text { labor market position }{ }^{35}\end{array}$ & $\begin{array}{l}-\quad 43 \\
-\quad 35\end{array}$ \\
\hline Educational level & & \\
\hline - Higher & $\begin{array}{l}+\quad \text { in relationship with } \\
\text { labor market position } 35\end{array}$ & + \\
\hline - Lower secondary vocational & $\begin{array}{l}+\quad \text { versus primary } \\
\text { education } 27\end{array}$ & \\
\hline - Senior secondary vocational & $\begin{array}{l}+\begin{array}{l}\text { versus primary } \\
\text { education }\end{array}{ }^{27} \\
\end{array}$ & \\
\hline
\end{tabular}


Table 1. Continued

\begin{tabular}{|c|c|c|c|}
\hline \multirow{2}{*}{$\begin{array}{l}\text { Predictor } \\
\text { - Senior general } \\
\text { secondary/pre-university } \\
\text { Health }\end{array}$} & \multicolumn{2}{|c|}{ Intervention } & Return to work \\
\hline & + & $\begin{array}{l}\text { versus primary } \\
\text { education }{ }^{27}\end{array}$ & \\
\hline $\begin{array}{l}\text { - Better health at beginning of } \\
\text { sickness absence }\end{array}$ & + & 35 & \\
\hline - Had same complaints before & + & 46 & \\
\hline - Psychological diagnosis & + & $\begin{array}{l}\text { versus musculoskeletal } \\
27\end{array}$ & $-\quad 43$ \\
\hline & - & 35 & \\
\hline $\begin{array}{l}\text { - Musculoskeletal complaints } \\
\text { for longer than one year }\end{array}$ & & & $-\quad 43$ \\
\hline $\begin{array}{l}\text { - Cardiovascular diseases } \\
\text { for longer than one year }\end{array}$ & & & $-\quad 43$ \\
\hline - Chronic pain & & & $-\quad 43$ \\
\hline - Brain damage & & & $-\quad 43$ \\
\hline - Musculoskeletal diseases & & & $-\quad 43$ \\
\hline - More serious complaints & & & $-\quad 3543$ \\
\hline Attitude & & & $+/-\quad 43$ \\
\hline Self efficacy & & & $+/-43$ \\
\hline Flexibility & & & $+/-43$ \\
\hline Coping style & & & $+/-\quad 43$ \\
\hline Motivation & & & $+/-\quad 43$ \\
\hline \multicolumn{4}{|l|}{ Firm size } \\
\hline - 10-49 employees & + & $\begin{array}{l}\text { versus } 100 \text { employees } \\
\text { or more }^{27}\end{array}$ & \\
\hline - More than 50 employees & & & 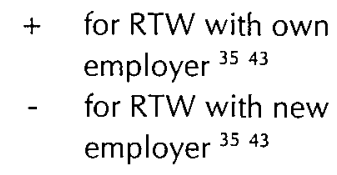 \\
\hline \multicolumn{4}{|l|}{ Industry } \\
\hline - Agriculture/fishery & & $\begin{array}{l}\text { versus manufacturing } \\
\text { industry } 27 \\
35\end{array}$ & \\
\hline - Transport & - & $\begin{array}{l}\text { versus manufacturing } \\
\text { industry } 27\end{array}$ & \\
\hline - Manufacturing industries & - & 35 & $+\quad 43$ \\
\hline - Construction & - & 35 & $+\quad 43$ \\
\hline - Other sectors & + & $\begin{array}{l}\text { versus manufacturing } \\
\text { industry } 27\end{array}$ & \\
\hline - Retail trade & & & $-\quad 43$ \\
\hline - Service & & & $+\quad 43$ \\
\hline - Hotel and catering industry & & & $-\quad 43$ \\
\hline - Government & & & $-\quad 43$ \\
\hline
\end{tabular}


- Private sector

Contractual working hours:

More than 8 hours and less

than 33 hours

Job tenure: Longer

Absence history:

More sickness absence

Occupational level: Higher

Duration: Longer

Residential area: urbanized

Labor shortage

Disability management

programs: available

Work adjustments

Occupational workload:

low physical load

Interventions $+\quad$ in relationship with gender ${ }^{35}$

$-\quad 27$

$+\quad 43$

$-\quad 43$

$+\quad 3637$

$-\quad 27$

- In relationship with taking on the sick role ${ }^{9}$

$+\quad 46 \quad-\quad 202122$

$+\quad 43$

- 43

$+\quad 43$

$+\quad 43$

$+\quad 35$

$?$

Summarizing, the aim of the present study is twofold: (1) to investigate the relationship between the probability of receiving an intervention by the occupational physician and the probability of return to work (RTW) of sick workers; (2) to explore the use of simultaneous modelling of the intervention and RTW process.

\section{Methods}

\section{Design}

The system of figure 1 is expressed in two simultaneous equations: one for both the dependent variables. Analyses are performed at population level using data from a major longitudinal survey on work incapacity and return to work in the Netherlands (Project Evaluatie Stelselherziening, 1991-1994) ${ }^{47}$. The first measurement (approximately 11 months after the first day of illness) is used in the present study. We analyze the correlation of (the timing of) the first contact with this physician and (the timing of) RTW. 
$104 \mid$ Chapter 4

\section{Sample and instruments}

The data are obtained by means of a questionnaire. The subjects are all workers who reported themselves sick in November 1990 and whose cases were reported to the medical administration service (GMD) nine months thereafter. The sample includes all those that were interviewed at baseline, 11 months after they first reported sick. This includes people who had returned to work as well as people who had not returned (yet). Information about their sickness absence process up to the 11th month was gathered retrospectively. Missings were excluded casewise. In total, analyses were performed on 2586 cases ( 980 females and 1606 males). The dependent variables are 'intervention' and 'RTW' (return to work). The variables are operationalized in the following way:

- Intervention: first contact with occupational physician

- Timing of intervention: probability of first contact with an occupational physician during the interval $[t, t+d t]$, where $t$ indicates the time in months

- RTW: working/not working approximately 11 months after first day of illness

- Timing of RTW: probability of first RTW during the interval $[t, t+d t]$

- Predictors: (1) Predictors of the probability of receiving intervention; (2) Predictors of the probability of RTW.

\section{Analyses}

Two types of analyses are performed. Since we have a pair of binary dependent variables, a bivariate probit model is appropriate ${ }^{48}$. This kind of model allows for correlation between the error terms of the two dependent variables. With the bivariate probit, we estimate the correlation $(\rho)$ between the probability of intervention and the probability of RTW. The model is specified as:

Intervention $^{*}=\beta_{1}^{\prime} x_{1}+\varepsilon_{1}$

$R T W^{*}=\beta_{2}^{\prime} x_{2}+\varepsilon_{2}$

Where:

Intervention $=1$ if Intervention $*>0,0$ otherwise.

RTW $=1$ if $R T W^{*}>0,0$ otherwise.

$E\left[\varepsilon_{1}\right]=E\left[\varepsilon_{2}\right]=0$ 
$\operatorname{Var}\left[\varepsilon_{1}\right]=\operatorname{Var}\left[\varepsilon_{2}\right]=1$

$\operatorname{Cov}\left[\varepsilon_{1}, \varepsilon_{2}\right]=\rho$

The stochastic component is described by two latent continuous variables which follow the bivariate normal distribution $\left(\phi_{2}\right)^{\text {a }}$.

Then:

$$
\operatorname{Pr}(\text { Intervention }=1, R T W=1)=\phi_{2}\left(\beta_{1} x_{1}, \beta_{2} x_{2}, \rho\right)
$$

There are four possible states: (1) worker who received an intervention, but did not return to work; (2) worker who did not receive an intervention, but returned to work; (3) worker who received an intervention and returned to work; and (4) worker who did not receive an intervention and did not return to work. The cumulative density functions (CDF's) of these four possibilities are estimated simultaneously by means of Maximum Likelihood. The hypothesis is tested that the correlation coefficient $\rho$ equals zero (Chi-square distribution with one degree of freedom).

To investigate the effect of duration, the elapsed time until the intervention $(t i)$ and the elapsed time until the worker returns to work $\left(t_{2}\right)$ are modeled with a bivariate hazard model. This allows us to investigate the joint distribution of both dependent variables ${ }^{49}$. We postulate the following equations for the possible outcomes:

Survivor function (no intervention and no RTW):

$S\left(t_{1}, t_{2}\right)=\exp \left(1-\lambda_{1} t_{1}-\lambda_{2} t_{2}-\exp \left(\lambda_{12}\left(\lambda_{1} t_{1}+\lambda_{2} t_{2}\right)\right)\right)$

Hazard 1 (intervention, no RTW):

$h_{1}\left(t_{1} t_{2}\right)=\lambda_{1}\left(1+\lambda_{12} \exp \left(\lambda_{12}\left(\lambda_{1} t_{1}+\lambda_{2} t_{2}\right)\right)\right)$

a For two standard-normally distributed $\varepsilon$ s, their joint density is:

$\phi\left(\varepsilon_{1}, \varepsilon_{2}\right)=\frac{1}{2 \pi \sigma_{\varepsilon_{1}} \sigma_{\varepsilon_{2}} \sqrt{1-\rho^{2}}} \exp \left[-\frac{1}{2}\left(\frac{\varepsilon_{1}{ }^{2}+\varepsilon_{2}{ }^{2}-2 \rho \varepsilon_{1} \varepsilon_{2}}{1-\rho^{2}}\right)\right]$

where $\rho$ is a correlation parameter denoting the extent to which the two $\varepsilon$ s covary. 
$106 \mid$ Chapter 4

Hazard 2 (no intervention, RTW):

$h_{2}\left(t_{1} t_{2}\right)=\lambda_{2}\left(1+\lambda_{12} \exp \left(\lambda_{12}\left(\lambda_{1} t_{1}+\lambda_{2} t_{2}\right)\right)\right)$

Joint hazard $(1,2)$ (both intervention and RTW):

$h_{12}\left(t_{1} t_{2}\right)=\lambda_{1}+\lambda_{2}+\exp \left(\lambda_{12}\left(\lambda_{1} t_{1}+\lambda_{2} t_{2}\right)\right) \times\left(\lambda_{12} \lambda_{1}+\lambda_{12} \lambda_{2}+\lambda^{2}{ }_{12} \lambda_{1} \lambda_{2}\right)$

Where: $\lambda_{12}$ is a measure of association between intervention and RTW, and $\lambda_{1}$ and $\lambda_{2}$ are specified as:

$\lambda_{i}(t)=\exp \left(X^{\prime} \beta_{i}\right) i=1,2$

$\lambda_{1}$ is the instantaneous probability of the observed individuals receiving an intervention during the interval $[t, t+d t]$, given that the individuals have not yet received an intervention. $\lambda_{2}$ is the instantaneous probability of the observed individuals RTW during the interval $[t, t+d t]$, given that the individuals have not yet returned to work. The parameter $\lambda_{12}$ measures dependence between $\lambda_{1}$ and $\lambda_{2}$. Again, the equations are estimated by Maximum Likelihood.

Table 2. Frequencies of intervention and return to work cases in the sample.

\begin{tabular}{|c|c|c|c|c|c|c|}
\hline \multirow{2}{*}{ Intervention } & & & Return to work & No & Yes & Total \\
\hline & \multirow[t]{4}{*}{ No } & Count & & 301 & 279 & 580 \\
\hline & & $\%$ within intervention & & 51.9 & 48.1 & 100.0 \\
\hline & & $\%$ within return to work & & 21.2 & 23.9 & 22.4 \\
\hline & & $\%$ of total & & 11.6 & 10.8 & 22.4 \\
\hline & \multirow[t]{4}{*}{ Yes } & Count & & 1117 & 889 & 2006 \\
\hline & & $\%$ within intervention & & 55.7 & 44.3 & 100.0 \\
\hline & & $\%$ within return to work & & 78.8 & 76.1 & 77.6 \\
\hline & & $\%$ of total & & 43.2 & 34.4 & 77.6 \\
\hline & \multirow[t]{4}{*}{ Total } & Count & & 1418 & 1168 & 2586 \\
\hline & & $\%$ within intervention & & 54.8 & 45.2 & 100.0 \\
\hline & & $\%$ within return to work & & 100.0 & 100.0 & 100.0 \\
\hline & & $\%$ of total & & 54.8 & 45.2 & 100.0 \\
\hline
\end{tabular}




\section{Results}

First, the frequencies of intervention and RTW are shown in table 2. This table shows that the cases are approximately equally distributed over the four possible states, which is a good starting point for further analysis.

Table 3. Parameter estimates for the bivariate probit and the bivariate hazard model ${ }^{b}$.

\begin{tabular}{|c|c|c|c|c|}
\hline \multirow[t]{2}{*}{ Parameter } & \multicolumn{2}{|c|}{ Bivariate probit } & \multicolumn{2}{|c|}{ Bivariate hazard } \\
\hline & $\begin{array}{l}\text { Intervention } \\
\text { (st. error) }\end{array}$ & $\begin{array}{l}\text { RTW } \\
\text { (st. error) }\end{array}$ & $\begin{array}{l}\text { Intervention } \\
\text { (st. error) }\end{array}$ & $\begin{array}{l}\text { RTW } \\
\text { (st. error) }\end{array}$ \\
\hline \multirow[t]{2}{*}{ Gender: Female } & -0.041 & -0.133 & $-0.223^{* *}$ & -0.365 \\
\hline & $(0.094)$ & $(0.087)$ & $(0.072)$ & $(0.264)$ \\
\hline \multirow[t]{2}{*}{ Age (years) } & $0.740 \mathrm{E}-02 *$ & $-0.022 * *$ & $-0.520 \mathrm{E}-02 *$ & $-0.054^{* *}$ \\
\hline & $(0.303 \mathrm{E}-02)$ & $(0.280 \mathrm{E}-02)$ & $(0.223 \mathrm{E}-02)$ & $(0.827 E-02)$ \\
\hline \multirow[t]{2}{*}{ Nationality: Dutch } & 0.130 & $0.314^{*}$ & $-0.170^{*}$ & 0.025 \\
\hline & $(0.099)$ & $(0.097)$ & $(0.068)$ & $(0.247)$ \\
\hline \multicolumn{5}{|l|}{$\begin{array}{l}\text { Educational qualifications } \\
\text { (reference category: primary } \\
\text { education) }\end{array}$} \\
\hline \multirow[t]{2}{*}{ - Lower vocational } & $0.278^{* *}$ & $0.167^{* *}$ & $0.279 * *$ & -0.246 \\
\hline & $(0.073)$ & $(0.067)$ & $(0.053)$ & $(0.192)$ \\
\hline \multirow[t]{2}{*}{ - Junior general secondary } & -0.023 & $0.388 * *$ & -0.011 & $0.482 *$ \\
\hline & $(0.105)$ & $(0.099)$ & $(0.080)$ & $(0.228)$ \\
\hline \multirow[t]{2}{*}{ - Senior secondary vocational } & 0.118 & $0.270^{* *}$ & 0.118 & -0.069 \\
\hline & $(0.088)$ & $(0.080)$ & $(0.063)$ & $(0.233)$ \\
\hline \multirow{2}{*}{$\begin{array}{l}\text { - Senior general secondary or pre- } \\
\text { university }\end{array}$} & 0.190 & $0.446 * *$ & 0.166 & 0.378 \\
\hline & $(0.158)$ & $(0.136)$ & $(0.126)$ & $(0.392)$ \\
\hline \multirow[t]{2}{*}{ - Higher vocational } & $0.369 \mathrm{E}-02$ & $0.449 * *$ & -0.026 & 0.316 \\
\hline & $(0.134)$ & $(0.118)$ & $(0.099)$ & $(0.329)$ \\
\hline \multirow[t]{2}{*}{ - University } & 0.100 & 0.410 & 0.017 & -0.906 \\
\hline & $(0.265)$ & $(0.227)$ & $(0.182)$ & $(1.180)$ \\
\hline \multirow[t]{2}{*}{ Breadwinner } & -0.016 & $0.308 * *$ & -0.044 & $0.516^{*}$ \\
\hline & $(0.084)$ & $(0.077)$ & $(0.062)$ & $(0.241)$ \\
\hline \multicolumn{5}{|l|}{$\begin{array}{l}\text { Diagnosis (reference category: } \\
\text { musculoskeletal) }\end{array}$} \\
\hline \multirow[t]{2}{*}{ - Psychological } & 0.160 & -0.019 & $0.212 * *$ & $-0.580^{*}$ \\
\hline & $(0.084)$ & $(0.075)$ & $(0.055)$ & $(0.240)$ \\
\hline \multirow[t]{2}{*}{ - Cardiovascular } & 0.021 & 0.018 & -0.139 & -0.159 \\
\hline & $(0.129)$ & $(0.122)$ & $(0.104)$ & $(0.312)$ \\
\hline
\end{tabular}

b $*$ significant at $5 \%$ level; $* *$ significant at $1 \%$ level. 
$108 \mid$ Chapter 4

Table 3. Continued

\begin{tabular}{|c|c|c|c|c|}
\hline \multirow[t]{2}{*}{ Parameter } & \multicolumn{2}{|c|}{ Bivariate probit } & \multicolumn{2}{|c|}{ Bivariate hazard } \\
\hline & $\begin{array}{l}\text { Intervention } \\
\text { (st. error) }\end{array}$ & $\begin{array}{l}\text { RTW } \\
\text { (st. error) }\end{array}$ & $\begin{array}{l}\text { Intervention } \\
\text { (st. error) }\end{array}$ & $\begin{array}{l}\text { RTW } \\
\text { (st. error) } \\
\end{array}$ \\
\hline \multirow[t]{2}{*}{ - Accidents } & $0.510 \mathrm{E}-02$ & $0.160 \mathrm{E}-02$ & -0.123 & -0.464 \\
\hline & $(0.129)$ & $(0.118)$ & $(0.098)$ & $(0.342)$ \\
\hline \multirow[t]{2}{*}{ - Other } & -0.049 & 0.032 & $-0.114^{*}$ & -0.127 \\
\hline & $(0.069)$ & $(0.065)$ & $(0.052)$ & $(0.176)$ \\
\hline Had same complaints & -0.064 & $-0.251 * *$ & -0.058 & -0.275 \\
\hline before $(1=$ yes; $0=$ no $)$ & $(0.063)$ & $(0.057)$ & $(0.046)$ & $(0.163)$ \\
\hline Previous absence record (weeks) & $\begin{array}{l}0.126 \mathrm{E}-02 \\
(0.327 \mathrm{E}-02)\end{array}$ & $\begin{array}{l}-0.013 * * \\
(0.318 \mathrm{E}-02)\end{array}$ & $\begin{array}{l}0.232 \mathrm{E}-03 \\
(0.231 \mathrm{E}-02)\end{array}$ & $\begin{array}{l}-0.022^{*} \\
(0.010)\end{array}$ \\
\hline $\begin{array}{l}\text { Management position } \\
(1=\text { yes; } 0=\text { no })\end{array}$ & $\begin{array}{l}-0.035 \\
(0.059)\end{array}$ & $\begin{array}{l}-0.054 \\
(0.054)\end{array}$ & $\begin{array}{l}-0.339 * * \\
(0.047)\end{array}$ & $\begin{array}{l}-0.185 \\
(0.159)\end{array}$ \\
\hline \multicolumn{5}{|l|}{$\begin{array}{l}\text { Occupational workload (reference } \\
\text { category: high physical workload, } \\
\text { low mental workload, and } \\
\text { unfavorable working conditions) }\end{array}$} \\
\hline - Low physical workload, high & 0.104 & 0.079 & 0.070 & 0.101 \\
\hline $\begin{array}{l}\text { mental workload and favorable } \\
\text { working conditions }\end{array}$ & $(0.094)$ & $(0.086)$ & $(0.067)$ & $(0.010)$ \\
\hline \multirow{2}{*}{$\begin{array}{l}\text { - Moderate physical workload, } \\
\text { high mental workload and } \\
\text { favorable working conditions }\end{array}$} & $0.393^{* *}$ & -0.139 & $0.243^{*}$ & -0.606 \\
\hline & $(0.148)$ & $(0.120)$ & $(0.956)$ & $(0.464)$ \\
\hline - Moderate/high physical & 0.101 & -0.150 & 0.020 & -0.319 \\
\hline $\begin{array}{l}\text { workload, moderate mental } \\
\text { workload and favorable working } \\
\text { conditions }\end{array}$ & $(0.086)$ & $(0.079)$ & $(0.061)$ & $(0.216)$ \\
\hline \multirow{2}{*}{$\begin{array}{l}\text { - Very high physical workload, } \\
\text { low mental workload and } \\
\text { unfavorable working conditions }\end{array}$} & 0.065 & 0.114 & 0.021 & -0.164 \\
\hline & $(0.118)$ & $(0.105)$ & $(0.074)$ & $(0.282)$ \\
\hline \multirow{2}{*}{$\begin{array}{l}\text { Permanent employment contract } \\
(1=\text { yes; } 0=\text { no })\end{array}$} & 0.159 & $0.461 * *$ & $-0.168^{*}$ & -0.230 \\
\hline & $(0.122)$ & $(0.114)$ & $(0.068)$ & $(0.335)$ \\
\hline \multirow[t]{2}{*}{ Contractual working hours } & $0.223 E-02$ & $-0.314 \mathrm{E}-03$ & $-0.015^{* *}$ & -0.034 \\
\hline & $(0.337 \mathrm{E}-02)$ & $(0.304 \mathrm{E}-02)$ & $(0.251 \mathrm{E}-02)$ & $(0.872 \mathrm{E}-02)$ \\
\hline \multirow[t]{2}{*}{ Monthly pay (mean in euros) } & $0.405 \mathrm{E}-05$ & $-0.150 \mathrm{E}-04$ & $0.221 \mathrm{E}-05$ & $-0.290 \mathrm{E}-05$ \\
\hline & $(0.698 \mathrm{E}-05)$ & $(0.789 \mathrm{E}-05)$ & $(0.105 E-04)$ & $(0.346 E-04)$ \\
\hline \multicolumn{5}{|l|}{$\begin{array}{l}\text { Firm size (reference category: } 100 \\
\text { employees or more) }\end{array}$} \\
\hline \multirow[t]{2}{*}{ - less than 10 employees } & 0.012 & $-0.268 * *$ & $0.567 \mathrm{E}-02$ & -0.424 \\
\hline & $(0.086)$ & $(0.079)$ & $(0.060)$ & $(0.227)$ \\
\hline \multirow[t]{2}{*}{$-10-<49$ employees } & 0.141 & $-0.193 * *$ & $0.129 *$ & $-0.538 * *$ \\
\hline & $(0.074)$ & $(0.066)$ & $(0.050)$ & $(0.189)$ \\
\hline \multirow[t]{2}{*}{ - $50-<99$ employees } & 0.066 & -0.073 & 0.023 & -0.021 \\
\hline & $(0.091)$ & $(0.081)$ & $(0.069)$ & $(0.227)$ \\
\hline
\end{tabular}




\begin{tabular}{|c|c|c|c|c|}
\hline \multicolumn{5}{|c|}{$\begin{array}{l}\text { Industry (reference category: } \\
\text { manufacturing industries) }\end{array}$} \\
\hline \multirow{2}{*}{ - Agriculture/fishery } & -0.422 & $-0.714^{* *}$ & $-0.738^{* *}$ & -0.778 \\
\hline & $(0.228)$ & $(0.266)$ & $(0.202)$ & $(0.638)$ \\
\hline \multirow[t]{2}{*}{ - Construction } & 0.094 & -0.042 & 0.083 & -0.243 \\
\hline & $(0.118)$ & $(0.105)$ & $(0.077)$ & $(0.291)$ \\
\hline \multirow[t]{2}{*}{ - Trade } & 0.117 & -0.024 & 0.081 & $-0.558^{*}$ \\
\hline & $(0.095)$ & $(0.089)$ & $(0.065)$ & $(0.259)$ \\
\hline \multirow[t]{2}{*}{ - Transport } & $-0.361 * *$ & $0.498 \mathrm{E}-02$ & $-0.472 * *$ & $0.516^{*}$ \\
\hline & $(0.103)$ & $(0.102)$ & $(0.096)$ & $(0.208)$ \\
\hline \multirow[t]{2}{*}{ - Banking/insurance } & 0.033 & -0.053 & -0.017 & -0.131 \\
\hline & $(0.119)$ & $(0.110)$ & $(0.084)$ & $(0.297)$ \\
\hline \multirow[t]{2}{*}{ - Other sectors } & $0.575 * *$ & 0.160 & $0.323 * *$ & $-0.730^{*}$ \\
\hline & $(0.105)$ & $(0.089)$ & $(0.067)$ & $(0.286)$ \\
\hline \multirow[t]{3}{*}{ Job tenure (months) } & $-0.105 E-$ & $0.165 \mathrm{E}-$ & $-0.116 \mathrm{E}-$ & $0.377 \mathrm{E}$ \\
\hline & $02 * *$ & $02 * *$ & $02 * *$ & $02 * *$ \\
\hline & $(0.332 \mathrm{E}-03)$ & (0.307E-03) & $(0.248 \mathrm{E}-03)$ & $(0.818 \mathrm{E}-03)$ \\
\hline$\rho$ & $\begin{array}{l}-0.188 \mathrm{E}-02 \\
(0.044)\end{array}$ & . & . & . \\
\hline$\lambda_{12}$ & . & . & $\begin{array}{l}-0.094 \\
(0.177)\end{array}$ & . \\
\hline
\end{tabular}

Table 3 shows the results of the bivariate probit and the bivariate hazard estimations. We are primarily interested in the association between the intervention and RTW: the $\rho$ (in the probit model) and $\lambda_{12}$ (in the hazard model). The effects of the covariates are also estimated. Since we have two dependent variables, there are four possible combinations of significant positive and negative effects of the covariates: (1) positive in the intervention equation, negative in the RTW equation $(+,-) ;(2)$ positive in both equations $(+,+)$; (3) negative in the intervention equation, positive in the RTW equation $(-,+)$; and (4) negative in both equations $(-,-)$. The first possibility $(+,-)$ means that the explanatory variables have a positive effect on the probability of intervention, but a negative effect on RTW. This can indicate two things: difficult cases are called in first, or the intervention generates little positive effect on RTW. If both coefficients are positive $(+,+)$, this can either reveal characteristics that denote the easy cases (i.e. the 'easy' cases are dealt with first), or characteristics that promote RTW. The third possibility $(-,+)$ points towards characteristics that foster 'self-management' in workers: they lower the probability of receiving an intervention but increase RTW anyway. Finally, if both coefficients are negative, this indicates characteristics that generate the 
110|Chapter 4

neglected and prospectless workers (see table 4 for a summary of possible interpretations).

Table 4. Possible interpretations of the effects: + positive influence; - negative influence.

\begin{tabular}{cll}
\hline $\begin{array}{l}\text { Coefficients in } \\
\text { intervention equation }\end{array}$ & $\begin{array}{l}\text { Coefficients in RTW } \\
\text { equation }\end{array}$ & Interpretation \\
\hline+ & - & Difficult cases first, or little effect of \\
& & intervention \\
+ & + & Easy cases first, or effect of intervention \\
- & + & 'self-managing' \\
- & - & Prospectless and neglected \\
\hline
\end{tabular}

Relationship between the probability of intervention and RTW

The results from the bivariate probit estimations show that the correlation coefficient $\rho$ between the probability of receiving an intervention from the occupational physician and the probability of return to work of the worker is not statistically significant.

The effects of the characteristics on both dependent variables can also be seen in table 3. Significant effects are found for age, educational qualifications and job tenure. Age is positively related to the probability of receiving an intervention, but negatively related to RTW (+,-). So the older the worker, the sooner he will be called by the occupational physician, but the lower his chances of RTW. People with lower vocational educational qualifications have a higher probability of being called by the physician and a higher probability of RTW $(+,+)$ than the reference category of people with primary education only. Workers with a longer job tenure have lower chances of receiving an intervention and higher chances of RTW $(-,+)$.

Relationship between the timing of the intervention and the timing of RTW The bivariate hazard model enables us to examine the joint distribution of the waiting times of the intervention and the RTW variable. Table 3 shows that the timing of the intervention is not significantly correlated with the timing of RTW (the parameter $\lambda_{12}$ is not statistically significant). The effect of the covariates can also be derived from table 3 . In figures 2 and 3 we illustrate some of these effects. The probability of intervention and RTW in each month can be calculated and represented graphically (probability density functions). Because the effects of having psychological complaints and different age groups are significant, we 
illustrate the effects of both variables. The probability density functions for "typical" workers with psychological complaints ("psych") and "typical" workers with musculoskeletal complaints ${ }^{d}$ ("musc") (keeping all other variables at the median values for people with that diagnosis) are represented in figure 2 . Three probability density functions are calculated per subgroup: the probability that the worker does receive an intervention but does not return to work ("intervention, no $\mathrm{rtw}^{\prime}$ ), the probability of no intervention and no RTW ("no intervention, no rtw") and the probability of not receiving an intervention but returning to work anyway ("no intervention, $\mathrm{rtw}^{\prime}$ ).

The same is calculated for "typical" younger eand older f workers and represented in figure 3.

'A typical worker with psychological complaints in this sample is a man of 40 years of age, has only primary educational qualifications, the dutch nationality, has had the same complaints before, does not have a management position, works in the manufacturing industry, has a job tenure of 90 months, has a previous absence record of 1 week, a monthly salary of 952.94 euros, a high physical workload, low mental workload and unfavorable working conditions, a permanent employment contract for 38 hours a week, works in a large firm (more than 100 employees) and is a breadwinner.

d A typical worker with musculoskeletal complaints in this sample is a man of 41 years of age, has only primary educational qualifications, the dutch nationality, has had the same complaints before, does not have a management position, works in the manufacturing industry, has a job tenure of 72 months, has a previous absence record of 2 weeks, a monthly salary of 907.56 euros, a high physical workload, low mental workload and unfavorable working conditions, a permanent employment contract for 38 hours a week, works in a large firm (more than 100 employees) and is a breadwinner.

${ }^{\mathrm{e}}$ A typical young worker in this sample is a woman of 20 years of age, has only primary educational qualifications, the dutch nationality, has musculoskeletal complaints, has had the same complaints before, does not have a management position, works in the manufacturing industry, has a job tenure of 11 months, a previous absence record of 3 weeks, a monthly salary of 471.93 euros, a high physical workload, low mental workload and unfavorable working conditions, has a permanent employment contract for 40 hours a week, works in a large firm (more than 100 employees) and is not a breadwinner.

f A typical older worker in this sample is a man of 50 years of age, has only primary educational qualifications, the dutch nationality, has musculoskeletal complaints, has had the same complaints before, has a management position, works in the manufacturing industry, has a job tenure of 144 months, does not have a previous absence record, has a monthly salary of 998.32 euros, a high physical workload, low mental workload and unfavorable working conditions, a permanent employment contract for 38 hours a week, works in a large firm (more than 100 employees) and is a breadwinner. 
$112 \mid$ Chapter 4

Figure 2. Probability density functions for typical workers with psychological complaints and typical workers with musculoskeletal complaints.
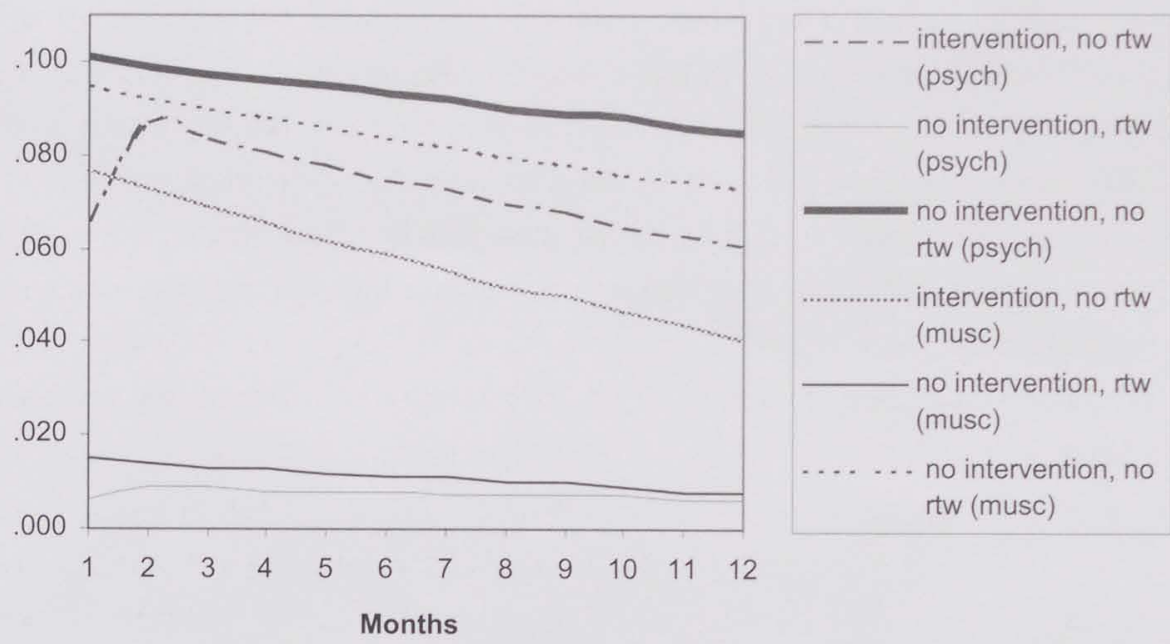

Figure 3. Probability density functions for typical young workers (age 20) and typical older workers (age 50).

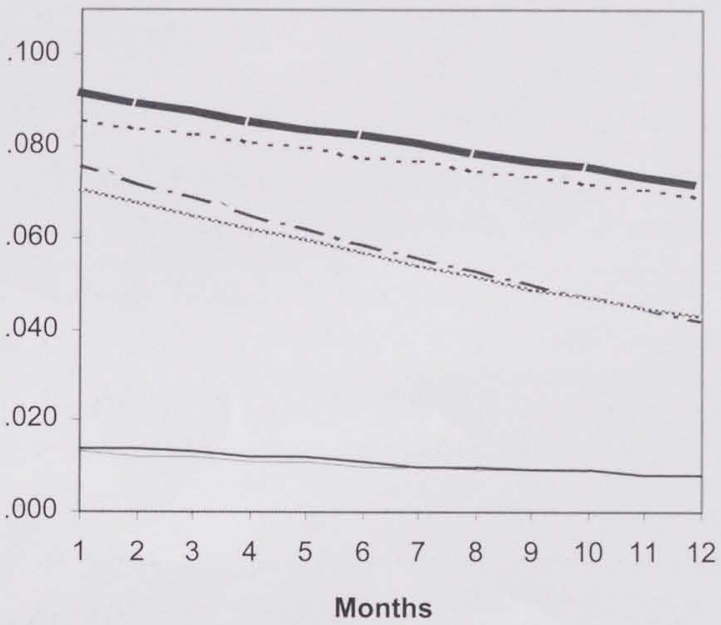
-...- intervention, no rtw (age 20)
- no intervention, rtw (age 20)
$=$ no intervention, no rtw (age 20) intervention, no rtw (age 50)
no intervention, rtw (age 50)
...... no intervention, no rtw (age 50)




\section{Discussion}

Relationship between the probability of intervention and RTW

Since the error terms of the intervention and RTW equations are not significantly related, there is no evidence for endogeneity bias when the effect of the intervention by the occupational physician is considered. The fact that there is no significant correlation is remarkable. RTW of sick workers is stated to be an important task of the occupational physician ${ }^{33}$. Yet it seems that the intervention does not provide the incentive to return to work quicker. We have to be careful with the interpretation of this finding, however. We said beforehand that a large effect was not to be expected, because the intervention can be seen as the beginning of the path towards RTW, rather than a RTW intervention in itself. Given the design of our study, we cannot make firm statements regarding the effectiveness of interventions by occupational physicians. We do not have actual control on the type of intervention offered by the physicians. It concerns many physicians with different approaches. By linking the intervention to the outcome RTW, implicitly other interventions along the way are included which also affect RTW. Another factor that keeps us from statements about the effectiveness is the fact that we could not control the timing of the intervention. Besides the selection behavior of the physician, other processes may play a role (e.g., jurisdictional, economic).

In this perspective it is also important to note that, at the time of the data collection (the beginning of the '90's), the context in which these interventions took place was not as focused upon RTW as it is now. In recent years, people have become aware of the magnitude of the problem and attitudes towards RTW have changed. Nevertheless, this awareness does not explain the absence of the expected effect (i.e. a positive correlation between intervention and RTW), because the goal of the intervention at that time clearly was to return the worker to the workplace ${ }^{23}$. New legislation was introduced in the late ' 90 's to reduce the inflow into the disability benefit system and encourage RTW. The focus of attention shifted towards the first year of absence, because it seemed that a more intensive management of sick workers, especially during the first period of absence, would generate a higher RTW rate and fewer work days lost ${ }^{20,21,50}$. Despite the measures that were taken, however, the inflow risk into disability nowadays is about the same as it was in the beginning of the ' 90 's $1.7 \%$ of the working population entered the disability 
$114 \mid$ Chapter 4

benefit system in 1993 and $1.7 \%$ in 2000) ${ }^{51}$. The outflow risk has even decreased $\left(9.4 \%\right.$ in 1993 versus $8.6 \%$ in 2002) ${ }^{51,52}$. Further outflow is mainly into old age pension. The disabled population is still growing. Solving the problem (i.e. returning more people back to work) apparently does not seem to be a matter of changing attitudes alone. It seems that the interventions that are undertaken need to be targeted more effectively, i.e. we need to target the right people at the right time. One has to wonder how the intervention strategy can become more effective. There are three possible reasons for the fact that it does not work: (1) the wrong group is targeted, (2) the timing is wrong, or (3) the intervention is not effective in itself. Our analyses provide us with some leads to examine the first possibility. The occupational physician may do better in aiming his intervention strategy at another group of workers. To achieve an 'optimal' intervention strategy, a first step is to identify characteristics that foster both the probability of RTW and the probability of receiving an intervention, and identify groups of workers that need more help (are more urgent) and groups that are self-managing and need less help. This is what we do next.

\section{Identification of target groups}

Factors that predict both the probability of intervention and the probability of RTW are interesting, for they can guide the actions of the physician. An example. Characteristics that foster a higher chance of RTW, despite a low chance of intervention, indicate self-management of workers with that characteristic. This is, for example, the case with workers with a longer job tenure in this study. While a longer job tenure gives a smaller chance of being called by the occupational physician, it fosters RTW of the worker $(-,+)$. It seems that workers with a longer job tenure have a greater self-managing capacity. This could be related to the fact that they have more credit with the company. When the physician has to make a selection of who to call first, these 'self-managing' workers may be less urgent to call for an interview. The physician will do better in targeting those workers for which the intervention is more advantageous (the 'weak' or 'difficult' cases).

Besides job tenure, other factors that influence both the probability of receiving an intervention by the occupational physician and the probability of RTW in our study are age and educational qualifications. Age is positively related to the chance of intervention, but negatively to the probability of RTW $(+,-)$. The finding that older workers have a lower chance of RTW has been reported before ${ }^{43}$. Our 
estimates of the probability of receiving an intervention with the probit and hazard model seem to be conflicting: the probit shows a positive estimate (older workers are more likely to be called in), while the hazard shows a negative estimate (younger workers are more likely to be called in). When we look at the probability density functions for younger and older workers over time (illustrated in figure 3), we see that the lines of older and younger workers who do not return to work are crossing around the 10th month of absence. This indicates that at first, younger workers are more likely to be called in, while by the time of month 12 they will have been caught up by the older workers. It appears that the 'prospectless' young workers are then left waiting. Though an older age increases the chance of being called by the occupational physician, this does not seem to have a beneficial effect on RTW. We explained before that this could indicate either (1) that older workers are seen as 'difficult' cases and are called in first, but still have a low probability of RTW, or (2) that there is little effect of the intervention. Given the negative relationship with RTW, we can conclude that for older workers either the timing of the intervention is wrong or a different intervention is needed.

Another parameter that influences both the probability of intervention and of RTW is having vocational educational qualifications instead of primary education only. Having vocational educational qualifications influences the chance of intervention and the chance of RTW positively $(+,+)$. This can indicate two things. First, these positive effects could reflect the effect of the intervention: those that are called in quicker, return to work quicker as well. With this, workers with a vocational education background have a higher chance to be called by the occupational physician than workers with only primary education, and therefore have a higher chance of RTW. Second, it could also indicate selection by physicians: they could call those workers first, who have good prospects of RTW (the 'easy' cases). These workers would also do well without the intervention. To understand the influence of vocational qualifications, we can infer in whose interest the selection takes place. Working in the public sector, the occupational physician needs to weigh the individual's needs and the public interest (i.e. lower social security costs) ${ }^{25}$. It is stated, however, that the physician is primarily oriented towards the individual's needs ${ }^{25}$. He needs to be objective (for the assessment), but is also concerned with the well-being of the worker and acts as his counselor. He will therefore call in those workers, whom he believes may benefit from the intervention. Having vocational instead of primary educational qualifications makes someone more 
employable. It is known that workers with a higher education have a higher chance of RTW ${ }^{43}$. Chances of success (i.e. RTW) therefore seem to play a role in the selection.

\section{Whom to target?}

The occupational physician might do better in calling those workers first with a low probability of RTW. In table 3 we see that this concerns workers with the following characteristics: older workers, workers with primary education only, non-breadwinners, workers with psychological complaints, people who experienced the same complaints before, people with a longer previous absence record, workers with a temporary employment contract, workers in small firms, in agriculture, trade, and transport sectors, and workers with a short job tenure. The intervention will not be advantageous by definition for workers with these characteristics, though. For some workers a different intervention may be advisable. This concerns, for example, workers who experience a relatively high chance of being called for an intervention by the occupational physician, but still experience a low probability of RTW. It could also be the case that the timing of the intervention does not work out well.

The relationship between the timing of the intervention and the timing of RTW We examined the relationship between the timing of the intervention and the timing of RTW by means of a hazard model. It is important to note that the bivariate hazard model estimations cannot be directly compared to those of the probit model. Firstly, the probit assumes a standard normal distribution of the errors, while the hazard model is based on an exponential distribution. Secondly, the models are not comparable because the hazard is estimated without intercepts. Identification problems prevented us to estimate the hazard with the intercepts. Although this adjustment does not impair a comparison of the covariate effects within the same model, it does prevent conclusions about the true size of the effects and therefore a comparison with the probit estimations. Nevertheless, it can be expected that the effects of the covariates are similar in both models. In our estimations this is largely the case, which supports the effects we already found in the probit equation.

When combining the information in figure 2, it can be concluded that the typical worker with psychological complaints has a lower probability to return to work 
than the typical worker with musculoskeletal complaints, and that this disadvantage increases over time. That is, both the probability of "intervention, no RTW" and the probability of "no intervention, no RTW" is higher for the psychological subgroup. As time passes, the group that still has to return to work (i.e. those still absent) will increasingly be made up of people with psychological complaints.

\section{Conclusions}

The results of this study show that the probability of a worker being contacted by the occupational physician is not correlated with the probability of RTW. Neither is the timing of both events correlated. Our analyses do not indicate that the intervention by the occupational physician provides incentives for sick workers to return to work quicker. There are three possible reasons for the fact that the intervention strategy is ineffective: (1) the wrong group is targeted, (2) the timing is wrong, or (3) the intervention is ineffective in itself. We examined the first possibility and identified characteristics that significantly predict both the probability of receiving an intervention and the probability of RTW. On the basis of these characteristics, several groups of workers were identified, which have different needs of intervention. Using these results the intervention strategy can be targeted more precisely to these groups of workers.

Much of the current understanding of the RTW process is based on studies of limited scope and often low methodological quality ${ }^{7}$. A review by Krause et al (2001) ${ }^{7}$ on determinants of duration of disability and RTW after work-related injury and illness reveals that a systematic review of the RTW literature is complicated because it needs to cover a wide range of diseases and conditions, requiring different treatment and rehabilitation strategies. Evidence on the effectiveness of these strategies is scattered and scarce ${ }^{7,15}$. Krause et al (2001) state that the generalizability of research findings needs to be improved. They state that one of the challenges for future research lies in studying the importance of factors across different disability phases, health conditions, and settings, using crossdisciplinary research methods ${ }^{7}$. The study of RTW in general may reveal common determinants across diseases or outcome definitions ${ }^{7}$. This paper offers a framework in which this can be studied. Analyses at population level provide a 
$118 \mid$ Chapter 4

general picture of existing relationships between aspects of intervention strategies that determine the effectiveness (like timing and selection) and RTW. Selection and timing (or duration) aspects in intervention strategies have hardly been addressed in previous RTW studies. We believe this study is complementary to other studies on the effectiveness of interventions, because these commonly focus more on the content but have a limited scope. By modelling the probability of intervention and RTW as simultaneous equations, the endogeneity problem can be overcome. The simultaneous equation framework is potentially useful for many other settings that are similarly endogenous in nature ${ }^{53}$ and in which performing an experiment is not possible. In the field of RTW it can be used to gather more information on how to target intervention strategies. 


\section{References}

1. LISV. Ontwikkeling arbeidsongeschiktheid. Jaaroverzicht WAO, WAZ en Wajong 2000. Amsterdam: Landelijk Instituut Sociale Verzekeringen; 2001 Oktober 2001.

2. Vos EL, de, Wevers CWJ. Aan de slag met een arbeidshandicap: internationale ervaringen: Landelijk Instituut Sociale Verzekeringen; 1998.

3. Einerhand MGK, Knol G, Prins R, Veerman T\}. Sickness and invalidity arrangements. Facts and figures from six European countries. Den Haag: Ministerie van Sociale Zaken en Werkgelegenheid; 1995.

4. Shrey DE, Hursh $\mathrm{CH}$. Workplace Disability Management: International Trends and Perspectives. Journal of Occupational Rehabilitation 1999;9(1):45-59.

5. Knol HK, Beljaars WLMM, Bruins-Slot JHW, Noordermeer A, Tijink HJA. Handboek Reïntegratie. Maarssen: Elsevier/De Tijdstroom; 2000.

6. Dembe AE. The Social Consequences of Occupational Injuries and IIInesses. American Journal of Industrial Medicine 2001;40:403-417.

7. Krause N, Frank JW, Dasinger LK, Sullivan TJ, Sinclair SJ. Determinants of Duration of Disability and Return-to-Work After Work-Related Injury and IIIness: Challenges for Future Research. American Journal of Industrial Medicine 2001;40:464-484.

8. Bloch FS, Prins R. Who Returns to Work and Why? A six-Country study on Work Incapacity \& Reintegration. New Brunswick NJ: Transaction Publishers; 2001.

9. Frank J, Sinclair S, Hogg Johnson S, Shannon H, Bombardier C, Beaton D, et al. Preventing disability from work-related low-back pain. New evidence gives new hope-if we can just get all the players onside. Canadian Medical Association Journal 1998;158(12):1625-31.

10. Karjalainen K, Malmivaara A, Tulder MWV, Roine R, Jauhiainen M, Hurri $H$, et al. Multidisciplinary Biopsychosocial Rehabilitation for Subacute Low Back Pain among Working Age Adults. The Cochrane Library 2003(1).

11. Beek AJvd, Frings-Dresen MHW, Elders LAM. Effectiviteit van werkaanpassingen bij werkhervatting na klachten aan het bewegingsapparaat. TBV 2000;8(5):137-143.

12. Elders LAM, Beek AJvd, Burdorf A. Return to work after sickness absence due to back disorders - a systematic review on intervention strategies. Int Arch Occup Environ Health 2000;73(5):339-348.

13. Bouter LM, Dongen MCIMv. Epidemiologisch onderzoek. Opzet en interpretatie. Houten: Bohn Stafleu van Loghum; 1991.

14. Swanborn PG. Evalueren. Het ontwerpen, begeleiden en evalueren van interventies: een methodische basis voor evaluatie-onderzoek. Amsterdam: Boom; 1999.

15. Staal JB, Hlobil H, Tulder MWV, Köke AJA, Smid T, Mechelen WV. Return-to-Work Interventions for Low Back Pain. A Descriptive Review of Contents and Concepts of Working Mechanisms. Sports Medicine 2002;32(4):251-276. 
$120 \mid$ Chapter 4

16. Smulders PGW, Veerman T). Handboek Ziekteverzuim. Gids voor de bedrijfspraktijk. Den Haag: Delwel; 1990.

17. Franche RL, Krause N. Readiness for Return to Work Following Injury or Illness: Conceptualizing the Interpersonal Impact of Health Care, Workplace, and Insurance Factors. Journal of Occupational Rehabilitation 2002;12(4):233-256.

18. Habeck RV, Hunt HA, Tol Bv. Workplace factors associated with preventing and managing work disability. Rehabilitation Counseling Bulletin 1998:Counseling-Bulletin.

19. Vallacher RR, Nowak A, editors. Dynamical Systems in Social Psychology. London: Academic Press, Inc; 1994.

20. Shrey DE. Worksite disability management model for effective return-to-work planning. Occupational Medicine: state of the art reviews 2000;15(4):789-801.

21. Akabas SH, Gates LB, Galvin DE. Disability Management. A Complete System To Reduce Costs, Increase Productivity, Meet Employee Needs, And Ensure Legal Compliance. New York: AMACOM; 1992.

22. Crook J, Moldofsky $H$. The probability of recovery and return to work from disability as a function of time. Quality of Life Research 1994;3(suppl. 1):s97-s109.

23. Boer WELd. Beoordeling, begeleiding en preventie in de sociale verzekeringsgeneeskunde. Medisch Contact 1988;51/52:1597-1600.

24. Schröer CAP. Ziekteverzuim wegens overspanning: een onderzoek naar de aard van overspanning, de hulpverlening en het verzuimbeloop. Maastricht: Universiteit Maastricht; 1993.

25. Croon NHT. Bijdrage van de verzekeringsarts in de publieke sector aan de arbeidsparticipatie van mensen met een verminderde belastbaarheid. In: Willems JHBM, Croon NHT, Koten J-W, editors. Handboek Arbeid en Belastbaarheid. Houten: Bohn Stafleu van Loghum; 1997.

26. Dougherty C. Introduction to Econometrics. Oxford: Oxford University Press; 2002.

27. Joling C, Groot W, Janssen PPM. Waiting for the Doctor. Gender differences in the timing of an intervention by the occupational physician. Journal of Occupational Rehabilitation 2003;13(1):45-61.

28. Bollen KA. Structural Equations with Latent Variables. Chapel Hill, North Carolina: Wiley-Interscience; 1989.

29. Wittenboer Gvd. Formele interventiemodellen. Amsterdam: Universiteit van Amsterdam; 1992.

30. Buijs J. Innovatie en interventie. Deventer: Kluwer; 1984.

31. Meershoek A. Weer aan het werk. Verzekeringsgeneeskundige verzuimbegeleiding als onderhandeling over verantwoordelijkheden. Maastricht: Maastricht University; 1999. 
32. KNMG. Richtlijnen inzake het omgaan met medische gegevens. In. Utrecht; 1992. p. 17-19.

33. Kaiser CP. Het verzekeringsgeneeskundig handelen en de verzuimduur. Maastricht: Universiteit Maastricht; 1992.

34. Vinke $H$, Andriessen S, Heuvel SGvd, Houtman ILD, Rijnders S, Vuuren CVv, et al. Vrouwen en reïntegratie. Hoofddorp: TNO Arbeid; 1999.

35. Gründemann RWM, Nijboer ID. WAO-intrede en werkhervatting. Amsterdam: Universiteit van Amsterdam; 1998.

36. Beek KWHv. To be hired or not to be hired, the employer decides. Relative chances of unemployed job-seekers on the dutch labor market. Den Haag: Universiteit van Amsterdam; 1993.

37. Glebbeek AC. Perspectieven op Joopbanen. Groningen: Rijksuniversiteit Groningen; 1993.

38. Griffin WA. Assessing State Changes in Microsocial Interaction: An Introduction to Event-History Analysis. In: Mordechai Gottman J, editor. The Analysis of Change. Mahwah, New Jersey: Lawrence Erlbaum Associates Publishers; 1995. p. 309-337.

39. Heckman Jj. Statistical Models for Discrete Panel Data. In: Manski CF, McFadden DL, editors. Structural Analysis of Discrete Data and Econometric Applications. Cambridge: MIT Press; 1981.

40. Faucett J. Chronic low back pain: early interventions. Annual review of nursing research 1999;17:155-82.

41. Vendrig AA. Prognostic Factors and Treatment-Related Changes Associated with Return to Work in the Multimodal Treatment of Chronic Back Pain. Journal of Behavioral Medicine 1999;22(3):217-232.

42. Giezen AM, Bouter LM, Nijhuis FIN. Prediction of return-to-work of low back pain patients sicklisted for 3-4 months. Pain 2000;87:285-294.

43. Lierop BAGv. Reïntegratie na scholing. De brug tussen arbeidsongeschiktheid en arbeidsparticipatie. Maastricht: Universiteit Maastricht; 2001.

44. Delft MLE. Sociale atlas van de vrouw. Den Haag: Sociaal en Cultureel Planbureau; 1991.

45. Brinkgreve C, Waals Fvd. Vrouwen en gezondheidszorg. In: Aakster CW, Groothoff JW, editors. Medische Sociologie. Sociologische perspectieven op ziekte en zorg. Groningen: Wolters-Noordhoff; 1998.

46. Schroër CAP. Ziekteverzuim wegens overspanning: een onderzoek naar de aard van overspanning, de hulpverlening en het verzuimbeloop. Maastricht: Universiteit Maastricht; 1993.

47. Molenaar-Cox PGM, Fiseler JG, Stelt HGvd, Smaal M, Kers WC. Databoek PES3. Amsterdam: GAK/GMD; 1995. 
122 Chapter 4

48. Jones AM. Health Econometrics. In: Culyer AJ, Newhouse JP, editors. Handbook of Health Economics. Amsterdam: Elsevier Science B.V.; 2000.

49. Lawless JF. Statistical Models and Methods for Lifetime Data. New York: John Wiley \& Sons, Inc.; 1982.

50. Shrey DE. Disability management in industry: the new paradigm in injured worker rehabilitation. Disability and rehabilitation 1996;18(8):408-14.

51. LISV. Trendrapportage Arbeids(on)geschiktheid 2001. Amsterdam: Landelijk Instituut Sociale Verzekeringen; 2001.

52. UWV. Kroniek van de Sociale Verzekeringen 2003. Amsterdam: Uitvoering Werknemersverzekeringen; 2003.

53. Lowry $M$, Shu S. Litigation risk and IPO underpricing. Journal of Financial Economics 2002;65:309-335. 


\section{Chapter 5}

\section{How can we optimize Disability Management intervention strategies?}

Provisionally accepted as:

Joling C, Groot W, Janssen PPM. Duration dependence in sickness absence. How can we optimize Disability Management intervention strategies? Journal of Occupational and Environmental Medicine. 
124 Chapter 5 


\section{Abstract}

This study aims to investigate the presence and type of duration dependence in sickness absence. We address the following questions: (1) What are the effects of an intervention by the occupational physician, worker characteristics and socioeconomic factors on the sign and the significance of duration dependence effects; and (2) How to adjust the timing of an intervention to different groups of workers? Analyses are performed at population level using data from a major longitudinal survey on work incapacity and return to work in the Netherlands. We estimate a range of semiparametric (piecewise hazard) and parametric (Weibull) models of constant and variable duration dependence. We find evidence for the presence of variable duration dependence. The intervention under study has no significant effect on duration dependence, while the age of a worker and his previous absence record have a positive effect. The results are not consistent with the prevailing early intervention principle of Disability Management. Variable duration dependence models can provide valuable insights for policy questions related to the timing and the use of interventions in a population of sick workers. 
$126 \mid$ Chapter 5 


\section{Introduction}

Previous research on the return to work (RTW) process of absent workers indicates that duration dependence affects RTW ${ }^{1-3}$. This means that the elapsed time of absence from work determines the chance of returning to work within a specific period of time. Duration of absence plays an important role in the RTW process. The RTW process is shaped by individual, social, organizational and economic factors which may be variable and which are likely to interact ${ }^{1-5}$. The role of duration is reflected in the fact that some predictors of RTW manifest themselves after the onset of the process, some may change throughout the process, sometimes predictors have a different impact in different phases of the process, or that the direction of the effect is reversed ${ }^{3}$. During sickness absence, interventions take place to accelerate the return to work. Duration dependence of predictors may change the direction as well as the size of the effect of these interventions. This implies that the timing of RTW interventions is crucial for their success. The optimal timing of interventions remains difficult to determine, however, because as yet, we do not have a clear picture of the duration dependence during the RTW process. It may be constant or variable over time, as well as variable across workers and is influenced by observed worker characteristics and unobserved worker heterogeneity ${ }^{6.9}$.

Particularly within the framework of Disability Management, interventions take place quickly after the worker has called in sick (so-called 'early intervention' principle) ${ }^{10}$. It is assumed that this early intervention accelerates the return to work of the worker. This assumption is based on the observation that the longer someone stays away from work, the more difficult it becomes to return to the workplace (i.e. negative duration dependence) ${ }^{10-12}$. The interaction between the timing of interventions and the probability of return to work has however not been investigated. Early intervention can also aggravate the situation ${ }^{13}$ and lead to high and needless costs.

Research that has been done on the influence of time on RTW has revealed many time-dependent predictors ${ }^{3}$. To study the effect of duration most studies adopt a proportional hazards model (e.g., Cox regression) ${ }^{14-18}$. In a proportional hazards model, the probability distribution of durations of work absence is described by a location parameter, specified as a regression function of observed worker characteristics, and a set of shape parameters, describing the duration dependence 
$128 \mid$ Chapter 5

and assumed to be constant ${ }^{6}$. The assumption of proportionality in the proportional hazard models implies that duration dependence is identical across workers. There are, however, indications that duration dependence during the RTW process is variable, and differs by observable and non-observable characteristics ${ }^{6}$. This means that duration dependence effects of predictors may vary in direction and intensity, and the relative ordering of the conditional probabilities can change over the duration of absence ${ }^{6}$. The presence of variable duration dependence would mean that RTW intervention strategies may have to differ across time as well as across workers ${ }^{19}$. Early interventions could, for example, be targeted to the types of workers most likely to be subject to negative duration dependence ${ }^{6,19}$.

This study aims to explore duration dependence with one specific intervention that takes place during the first year of absence. We study the impact of the timing of an intervention by the occupational physician on RTW'. Our study concerns the following questions: (1) What are the effects of the intervention, worker characteristics and socio-economic factors on the sign and the significance of duration dependence effects; and (2) How to adjust the timing of an intervention to different groups of workers?

\section{Duration dependence during the return to work process}

Several predictors of return to work have been found to interact with time. The length of work absence is the result of many influences other than the direct physical effects of injury ${ }^{3,20-23}$. A recent extensive review by Krause et al (2001) on predictors of the duration of work disability shows that predictors on individual level (individual (human capital) characteristics, individual task level job characteristics), organizational level (e.g., size of firm and type of employer) and societal level (e.g., litigation and economic incentives) may shorten or lengthen the duration of absence ${ }^{3}$. Economic studies found evidence for the hypotheses that the decision to return to work after a period of absence is influenced by the available wages, disability benefits, and the workers' tastes for wealth, health and leisure ${ }^{20,}$ 21,23 .

The values of these predictors may fluctuate over time, but because of analytical reasons, many studies postulate that their effect on the probability of RTW at any 
point in time (the hazard rate) remains constant (constant duration dependence). In other words, it is implicitly assumed that a unit change in predictor $X$ brings about the same amount of 'risk' during the whole sickness absence period. As stated in the introduction, there are indications that the assumption of constant duration dependence during the RTW process is not justified ${ }^{6}$. The effects of both timeinvariant and time-varying predictors can fluctuate over time ${ }^{24}$. The effects can also vary between workers. In their study, Butler et al (2001) showed that workers' responses to elapsed duration vary significantly with their characteristics and with economic incentives to return to work ${ }^{6}$. Another study by Johnson and Ondrich (1990) on the duration of post-injury absences from work also showed that the process of adjusting to the effects of injury varies among workers ${ }^{20}$. Nevertheless, most studies do not account for possible variation across workers (the no heterogeneity assumption $\left.{ }^{24}\right)$. The presence of variable duration dependence during the RTW process remains largely unexplored. This is partly due to the fact that this requires analytical models that are more difficult to apply and more difficult to estimate than the semi-parametric hazard models (e.g., Cox' proportional hazards model). Testing hypotheses about the effect of time on the hazard rate is difficult, because unmeasured sources of heterogeneity usually contaminate that effect ${ }^{25}$. Unobserved heterogeneity is however just one possible source of misspecification of the hazard rate. There are more possible sources of misspecification. Blossfeld and Rohwer (2002) state that in empirical social research we almost never have sufficient a priori reasons to decide for one specific hazard rate model ${ }^{9}$. It is therefore considered the best strategy to estimate a variety of different models in order to find robust estimation results ${ }^{9}$. Recently, new specifications of existing hazard models have been derived, which allow an investigation of variability in duration dependence across time as well as across workers. In this study, we estimate six different models to explore duration dependence during the RTW process.

\section{Methods}

\section{Design}

We analyze the conditional probability of RTW during the first year of absence by means of different hazard rate models. Analyses are performed at population level 
$130 \mid$ Chapter 5

using data from a major longitudinal survey on work incapacity and return to work in the Netherlands (Project Evaluatie Stelselherziening, 1991-1994) ${ }^{26}$. The first measurement (approximately 11 months after the first day of illness) is used in the present study.

\section{Sample and instruments}

The data were obtained by means of a questionnaire. The subjects are all employees that reported themselves sick in November 1990 and whose cases were reported to the medical administration service (GMD) nine months thereafter. The sample includes all those that were interviewed at baseline, 11 months after they first reported sick. This includes people who had returned to work as well as people who had not returned (yet). Missings were excluded casewise. In total, analyses were performed on 2586 cases.

The variables are operationalized in the following way:

- Intervention: first contact with occupational physician

- RTW: working/not working approximately 11 months at the latest after first day of illness

- Timing of RTW: probability of first RTW during the interval $[\mathrm{t}, \mathrm{t}+\mathrm{dt}]$

- Predictors: predictors of the probability of RTW

\section{Analyses}

In this study, we estimate a range of semiparametric (piecewise hazard) and parametric (Weibull) models of constant and variable duration dependence. These models are briefly explained below. For an extensive description of the estimation method see Butler et al ${ }^{6}$. Using two goodness-of-fit measures, the model that provides the best fit to the data is selected and its estimation results are described.

\section{Piecewise hazard models}

Two types of piecewise hazard models are estimated: (1) with constant duration dependence (i.e. Piecewise Constant Hazard Rate model); and (2) with variable duration dependence (Extended Piecewise Hazard Rate model - cf. Butler et al (2001)). Interaction terms are included (intervention*duration) to see whether the effect of the intervention fluctuates with time. 
The piecewise constant hazard model divides the duration into $M$ intervals (in our case 11 months) with interval boundaries $\mathrm{Co}^{\mathrm{C}} \mathrm{Cr}, \mathrm{C2}, \mathrm{C} 3 . . . \mathrm{Cm}$. The hazard rate for the ith individual on the mth interval is given by ${ }^{6}$ :

$$
\lambda_{i m}(t)=\exp \left(X_{i} \theta\right) \exp \left(h_{m}\right), c_{m-1} \leq t<c_{m}, M \quad m=1,2, \ldots . M
$$

Where the $h_{m}$ represent the transition rates from each interval. The $\exp \left(X_{i} \theta\right)$ function allows for worker differences in the transition rate. The transition rate refers to the propensity of individuals to change states in a state space ${ }^{9}$. In our case this refers to the propensity of returning to work, and we call this the RTW rate. In the second model, following Butler et al (2001), the proportional hazards assumption of constant duration dependence is relaxed to estimate a model in which duration dependence effects vary with workers' observed characteristics:

$\lambda_{i m}(t)=\exp \left(X_{i} \theta\right) \exp \left(h_{m}+\tau X_{i} \gamma\right)$

Where $\tau$ is a discrete proxy for the duration $t$.

\section{Weibull models}

To study the changes in the RTW rate over time (i.e. duration dependence), we estimate different Weibull models. Weibull models are flexible and adaptable to a wide variety of models of durations ${ }^{8}$. The hazard rate $h(i)$, probability density function $f(i)$ and the distribution function $F(i)$ of the Weibull model are denoted by:

$$
\begin{aligned}
& h_{i}(t)=\exp \left(\mathrm{X}_{i}^{\prime} \beta\right) \alpha t^{\alpha-1} \\
& f_{i}(t)=\exp \left(\mathrm{X}_{i}^{\prime} \beta\right) \alpha t^{\alpha-1} \exp \left(-\exp \left(\mathrm{X}_{i}^{\prime} \beta\right) t^{\alpha}\right) \\
& F_{i}(t)=\exp \left(-\exp \left(\exp \mathrm{X}_{i}^{\prime} \beta\right) t^{\alpha}\right)
\end{aligned}
$$

In constant duration dependence models, the shape parameter $\alpha$ is a constant and the location parameter is specified by a regression function of observed worker characteristics, $\exp \left(X_{i}^{\prime} \beta\right)$. The parameter $\alpha$ represents the duration dependence. The hazard function of the Weibull distribution increases monotonically if $\alpha>1$ (positive duration dependence), decreases if $\alpha<1$ 
$132 \mid$ Chapter 5

(negative duration dependence) and is constant if $\alpha=1$ (constant duration dependence). It is assumed that variables $X_{i}$ affect the hazard rate logaritmically, i.e. the same amount of duration $t$, leads to a smaller change in $\log \left(X_{i}\right)$ Coefficients with positive signs indicate variables that are positively correlated with the RTW rate, while coefficients with negative signs indicate variables that are negatively correlated with the RTW rate. Positive duration dependence increases as the values of the variables increase.

In this study we also estimate variable duration dependence models in which the shape parameter $\alpha$ is also linked to a vector of observed worker characteristics: $\alpha_{i}=\exp \left(X_{i} \phi\right)$. The signs of the coefficients $\phi$, that determine the shape parameter indicate the effect of individual characteristics on duration dependence ${ }^{6}$.

\section{Goodness-of-fit measures}

Goodness-of-fit of the different models is assessed with Likelihood Ratio tests and the

Schwarz Bayesian Information Criterion (BIC). The LR test can be used to test constraints on a model ${ }^{27}$. It assesses the constraint by comparing the log likelihood of the unconstrained model to the log likelihood of the constrained model:

$$
\text { LRstatistic }=-2\left(\log L_{\text {constrained }}-\log L_{\text {full }}\right)
$$

The outcome of this test is $\Pi^{2}$ distributed with degrees of freedom equal to the number of independent constraints. The null hypothesis is that the effect of the constrained variable(s) equals zero. If the constraint(s) significantly reduce(s) the likelihood of the model, the null hypothesis is rejected.

The Schwarz BIC is a measure to assess the overall fit of a model. It allows for a comparison of nested and non-nested models, so we can compare the piecewise and the Weibull models.

The Schwarz BIC is defined as:

$$
B I C=-2 \log \cdot L(\hat{\theta})+p \log n
$$

Where $L(\hat{\theta})$ is the maximum likelihood function for the model, $p$ is the number of free parameters in the model, and $n$ is the sample size. Even if neither model $A$ 
nor model B is the "true" model, the BIC is designed to choose the model that will, on average, give better out-of-sample predictions ${ }^{27}$. The model with the smaller $\mathrm{BIC}$ is preferred ${ }^{27}$. How strong the preference is depends on the magnitude of the difference. The guideline is: absolute difference (interpretation of the evidence): 0 2 (weak), 2-6 (positive), 6-10 (strong), > 10 (very strong).

\section{Unobserved heterogeneity}

In parametric hazard rate models like the Weibull, the usual way in treating the error term is based on the assumption that there is a time-invariant unobserved constant specific for each individual ${ }^{9}$. Furthermore it is assumed that this unobserved constant can be represented as the realization of a random variable, identically distributed for all individuals and independent of observed covariates ${ }^{9}$. This random variable is to capture both individual heterogeneity and deviations from the supposed shape of duration dependence ${ }^{9}$. The RTW rate then depends on a vector of observed covariates $X i$ and on a scalar stochastic term, $v$, which is not observed ${ }^{9}$. The underlying rate is assumed to be parametrically given according to a Weibull distribution, while the stochastic term, $v$, follows a gamma distribution $\left(1, \sigma^{2}\right)$. The following model is known as the model of Lancaster ${ }^{28}$. The distribution function $F\left(t \mid X_{i}, v\right)$ is given by:

$$
F\left(t \mid \mathrm{X}_{\mathrm{i}}, v\right)=1-\left[1+\sigma^{2} \mu I(t)\right]^{-\sigma^{-2}}
$$

Where: $\mu=\exp \left(X_{i} \beta\right)$ and $I(t)=t^{\alpha}$.

The hazard function $h\left(t \mid X_{i}, v\right)$ is denoted by:

$$
h\left(t \mid X_{i}, v\right)=\mu \psi_{2}(t)[F(t \mid x, v)]^{\sigma^{2}}
$$

Where: $\psi_{2}(t)=\alpha t^{\alpha-1}$.

Accordingly the density function is given by:

$$
f\left(t \mid X_{i}, v\right)=\mu \psi_{2}(t)\left(\left[1+\sigma^{2} \mu I(t)\right]^{-\sigma^{-2}}\right)^{\sigma^{2}}
$$

A potential problem in all mixture models is a misspecification of the error term. Parameter estimates can be highly sensitive to the assumed parametric form of the 
$134 \mid$ Chapter 5

error term ${ }^{9}$. A misspecification puts the reliability of the estimates at stake. It is not necessarily better to include an error term in a model, because misspecification of the hazard rate by neglecting the error term might be replaced by misspecification of the parametric distribution of the error term ${ }^{9}$. The value of mixture models does therefore not lie in separating an error term from a true RTW rate, but rather in broadening the range of models that can be used to look for robust estimation results ${ }^{9}$.

Summarizing, six different models are estimated:

1. Piecewise hazard model with constant duration dependence (i.e. Piecewise Constant Hazard Rate model);

2. Piecewise hazard model with variable duration dependence (Extended Piecewise Hazard Rate model - cf. Butler et al ${ }^{6}$ );

3. Weibull model with constant duration dependence;

4. Weibull model with variable duration dependence (cf. Butler et al ${ }^{6}$ );

5. Weibull model with constant duration dependence and a gamma mixture (cf. Lancaster ${ }^{28}$ );

6. Weibull model with variable duration dependence and a gamma mixture (cf. Butler et al ${ }^{6}$ ).

Using the LR tests and the Schwarz B.I.C., the model with the best fit is chosen. The results are described next.

\section{Results}

The results of the goodness-of-fit tests of all models are reported in figure 1 . We use LR tests to compare the nested models and Schwarz B.I.C. tests to compare non-nested models. In the first step, LR tests show that the variable models are preferred over the constant models. The second step, comparing the piecewise variable model with the Weibull variable model, shows that the piecewise variable model is strongly preferred. Finally, in the last step, the piecewise variable is compared to the Weibull mixture model and the evidence of the Schwarz B.I.C. is again in favor of the piecewise variable model. Concluding, the piecewise variable hazard model proves to have the best fit. The estimation results of this model are 
given in table 1. The estimates of the piecewise constant model are also given for comparison.

Figure 1. Choice of best model using LR and Schwarz B.I.C. goodness-of-fit measures

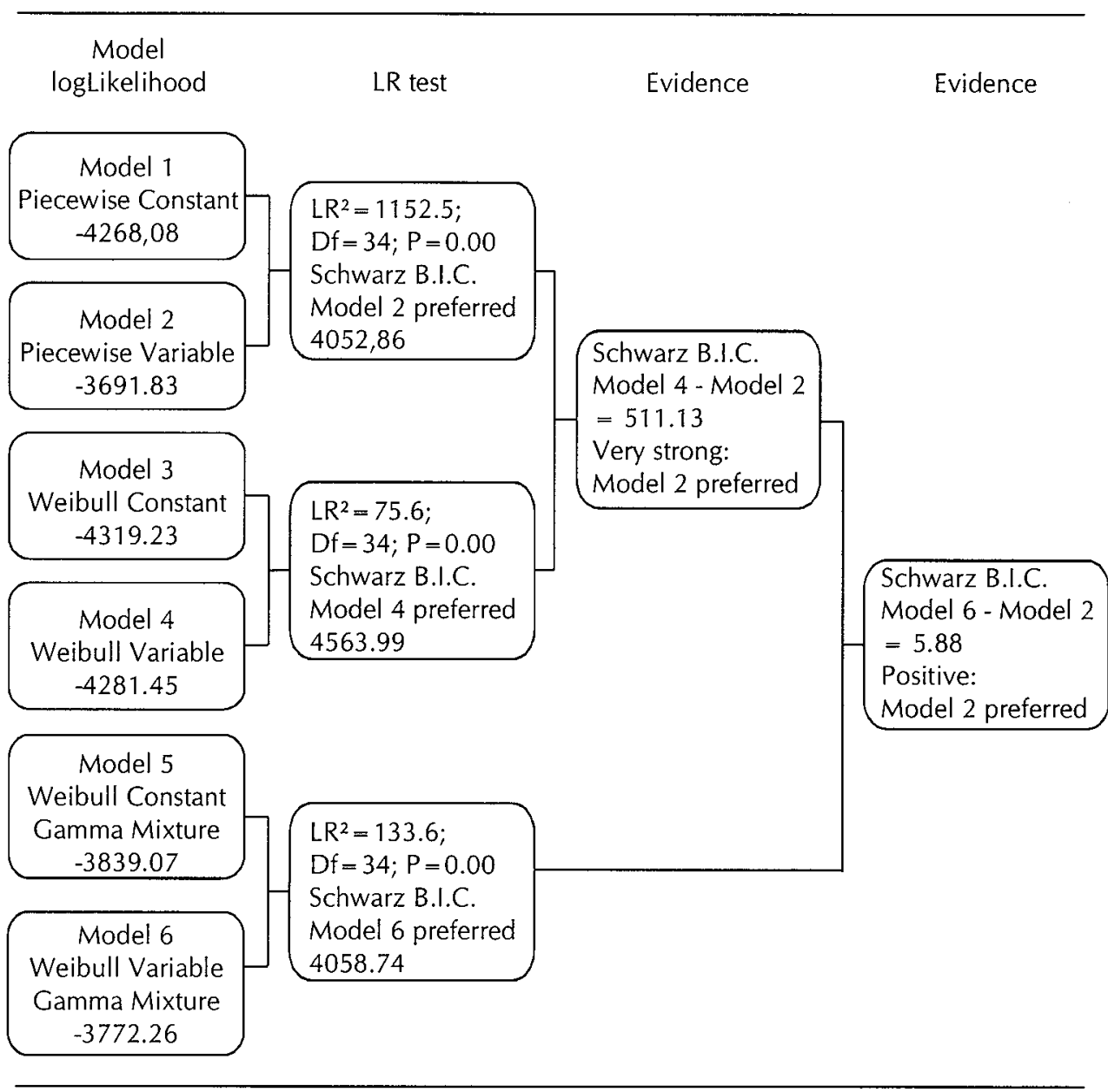


$136 \mid$ Chapter 5

Table 1. Parameter Estimates Piecewise Constant and Piecewise Variable Hazard Model ${ }^{\text {a }}$

\begin{tabular}{llll}
\hline Parameters & $\begin{array}{l}\text { Constant } \\
\text { Model }\end{array}$ & \multicolumn{2}{l}{ Variable Model } \\
\cline { 2 - 4 } & Location & Location & Shape \\
& Parameter & Parameter & parameter \\
& Estimate & Estimate & Estimate \\
& (St. Error) & (St. Error) & (St. Error) \\
\hline Age & $-0.023^{* *}$ & $-0.038^{* *}$ & $0.004^{* *}$ \\
Female & $(0.004)$ & $(0.009)$ & $(0.001)$ \\
& -0.126 & -0.242 & 0.033 \\
Dutch nationality & $(0.114)$ & $(0.274)$ & $(0.037)$ \\
& $0.418^{* *}$ & 0.362 & -0.009 \\
& $(0.135)$ & $(0.303)$ & $(0.045)$
\end{tabular}

Educational qualifications (ref. primary

educational qualifications):

- Lower vocational educational qualifications

$\begin{array}{lll}0.192^{*} & 0.163 & -0.012 \\ (0.088) & (0.213) & (0.029) \\ 0.364^{* *} & 0.470 & -0.061 \\ (0.118) & (0.274) & (0.040) \\ 0.301^{* *} & 0.367 & -0.029 \\ (0.100) & (0.232) & (0.031) \\ 0.581^{* *} & 0.872^{* *} & -0.060 \\ 0.154 & (0.328) & (0.046) \\ 0.473^{* *} & 0.647^{*} & -0.067 \\ (0.143) & (0.311) & (0.043) \\ 0.473 & 0.434 & 0.001 \\ (0.247) & (0.578) & (0.083)\end{array}$

Diagnosis (ref. musculoskeletal):

- Psychological diagnosis

$\begin{array}{lll}-0.029 & -0.111 & 0.002 \\ (0.093) & (0.217) & (0.030) \\ -0.013 & -0.153 & -0.005 \\ (0.139) & (0.322) & (0.045) \\ 0.005 & -0.093 & -0.004 \\ (0.144) & (0.341) & (0.047) \\ 0.015 & -0.059 & -0.008 \\ (0.081) & (0.194) & (0.027)\end{array}$

Had same complaints before

$-0.241 * *$

$-0.323 * \quad 0.040$

- Cardiovascular diagnosis

(0.069)

(0.158)

(0.022)

Management position

$-0.018$

$-0.244 \quad 0.035$

(0.074)

(0.154)

(0.021)

a $*$ significant at $5 \%$ level; ${ }^{* *}$ significant at $1 \%$ level 
Industry (ref. manufacturing industries)

- Agriculture/fishery

$-1.144 *$

$-2.693$

0.347

(0.469)

(4.162)

(0.573)

- Construction

$-0.117$

$-0.463$

0.029

(0.131)

(0.330)

(0.043)

- Trade

$-0.063$

$-0.265$

0.021

- Transport

(0.109)

(0.253)

(0.036)

0.020

0.072

$-0.003$

(0.120)

(0.245)

(0.035)

- Banking/insurance

$-0.027$

$-0.081$

0.029

(0.125)

(0.280)

(0.040)

- Other sectors

0.176

0.049

$-0.014$

(0.109)

(0.248)

(0.037)

Job tenure

$0.174 \mathrm{E}-02 * * \quad 0.003 * *$

$-0.212 \mathrm{E}-03$

Previous absence record

$$
(0.370 \mathrm{E}-03)
$$

(0.001)

(0.123E-03)

$-0.016^{* *}$

$-0.027^{*}$

0.003 *

(0.004)

$(0.012)$

(0.001)

Workload (ref. high physical, low mental

workload and unfavorable working

conditions):

- Low physical, high mental workload, 0.118 favorable working conditions

$(0.102)$

0.180

0.016

- Moderate physical, high mental workload,-0.105

(0.224)

$(0.032)$

favorable working conditions

(0.146)

$-0.239$

0.037

- Moderate/high physical, moderate mental-0.142

(0.353)

(0.050)

workload, favorable working conditions

(0.100)

$-0.217$

0.019

- Very high physical, low mental workload,0.154

(0.240)

(0.034)

unfavorable working conditions

(0.130)

0.162

$-0.003$

Permanent employment contract

$0.623 * *$

(0.314)

$(0.041)$

0.421

$-0.068$

Breadwinner

$(0.187)$

(0.480)

(0.066)

$0.366^{* *}$

$0.548 *$

$-0.050$

Monthly pay (euros)

(0.101)

(0.258)

(0.033)

$-0.391 \mathrm{E}-04$

$-0.422 \mathrm{E}-04$

$0.172 \mathrm{E}-05$

(0.406E-04)

$(0.816 \mathrm{E}-03)$

(0.125E-04)

Firm size (ref. $>100$ employees):

- <10 employees

$\begin{array}{lll}-0.270^{* *} & -0.271 & 0.028 \\ (0.101) & (0.231) & (0.032) \\ -0.178^{*} & -0.275 & 0.032 \\ (0.081) & (0.187) & (0.026) \\ -0.048 & -0.181 & 0.030 \\ (0.097) & (0.242) & (0.033)\end{array}$

$-10-<49$ employees

$-0.178^{*}$

$-0.275$

0.032

$-50-<99$ employees

$-0.048$

(0.242)

(0.033) 
$138 \mid$ Chapter 5

Table 1. Continued

\begin{tabular}{|c|c|c|c|}
\hline \multirow[t]{2}{*}{ Parameters } & \multirow{2}{*}{$\begin{array}{l}\text { Constant } \\
\text { Model }\end{array}$} & \multicolumn{2}{|c|}{ Variable Model } \\
\hline & & $\begin{array}{l}\text { Location } \\
\text { Parameter } \\
\text { Estimate } \\
\text { (St. Error) }\end{array}$ & $\begin{array}{l}\text { Shape } \\
\text { parameter } \\
\text { Estimate } \\
\text { (St. Error) }\end{array}$ \\
\hline Contractual working hours & $\begin{array}{l}0.003 \\
(0.005)\end{array}$ & $\begin{array}{l}-0.005 \\
(0.012)\end{array}$ & $\begin{array}{l}0.001 \\
(0.001)\end{array}$ \\
\hline Intervention & $\begin{array}{l}-0.714^{* *} \\
(0.203)\end{array}$ & $\begin{array}{l}-0.861 * * \\
(0.269)\end{array}$ & $\begin{array}{l}0.023 \\
(0.045)\end{array}$ \\
\hline Intercept month 1 & $\begin{array}{l}-4.738^{* *} \\
(0.476)\end{array}$ & & $\begin{array}{l}-4.159 * * \\
(0.611)\end{array}$ \\
\hline Interaction intervention $*$ month 1 & $\begin{array}{l}-0.116 \\
(0.509)\end{array}$ & & $\begin{array}{l}-0.111 \\
(0.535)\end{array}$ \\
\hline Intercept month 2 & $\begin{array}{l}-4.289 * * \\
(0.474)\end{array}$ & & $\begin{array}{l}-3.731^{* *} \\
(0.598)\end{array}$ \\
\hline Interaction intervention * month 2 & $\begin{array}{l}0.677^{*} \\
(0.332)\end{array}$ & & $\begin{array}{l}0.719 * \\
(0.335)\end{array}$ \\
\hline Intercept month 3 & $\begin{array}{l}-4.272 * * \\
(0.472)\end{array}$ & & $\begin{array}{l}-3.726^{* *} \\
(0.584)\end{array}$ \\
\hline Interaction intervention * month 3 & $\begin{array}{c}0.782 * \\
(0.347)\end{array}$ & & $\begin{array}{l}0.822 * \\
(0.347)\end{array}$ \\
\hline Intercept month 4 & $\begin{array}{l}-3.840^{* *} \\
(0.449)\end{array}$ & & $\begin{array}{l}-3.307^{* *} \\
(0.555)\end{array}$ \\
\hline Interaction intervention * month 4 & $\begin{array}{c}0.790^{*} \\
(0.319)\end{array}$ & & $\begin{array}{l}0.831^{* *} \\
(0.315)\end{array}$ \\
\hline Intercept month 5 & $\begin{array}{l}-3.369 * * \\
(0.434)\end{array}$ & & $\begin{array}{l}-2.846^{* *} \\
(0.537)\end{array}$ \\
\hline Interaction intervention * month 5 & $\begin{array}{c}0.667^{*} \\
(0.286)\end{array}$ & & $\begin{array}{l}0.707^{*} \\
(0.284)\end{array}$ \\
\hline Intercept month 6 & $\begin{array}{l}-3.081^{* *} \\
(0.429)\end{array}$ & & $\begin{array}{l}-2.560^{* *} \\
(0.531)\end{array}$ \\
\hline Interaction intervention * month 6 & $\begin{array}{l}0.768^{* *} \\
(0.276)\end{array}$ & & $\begin{array}{l}0.804^{* *} \\
(0.284)\end{array}$ \\
\hline Intercept month 7 & $\begin{array}{l}-3.043^{* *} \\
(0.431)\end{array}$ & & $\begin{array}{l}-2.505^{* *} \\
(0.527)\end{array}$ \\
\hline Interaction intervention $*$ month 7 & $\begin{array}{l}0.721^{* *} \\
(0.260)\end{array}$ & & $\begin{array}{l}0.746^{* *} \\
(0.272)\end{array}$ \\
\hline Intercept month 8 & $\begin{array}{l}-3.097^{* *} \\
(0.438)\end{array}$ & & $\begin{array}{l}-2.522^{* *} \\
(0.539)\end{array}$ \\
\hline Interaction intervention $*$ month 8 & $\begin{array}{l}0.788 * * \\
(0.289)\end{array}$ & & $\begin{array}{l}0.812^{* *} \\
(0.306)\end{array}$ \\
\hline
\end{tabular}




\begin{tabular}{lll}
\hline Intercept month 9 & $-2.690^{* *}$ & $-2.069 * *$ \\
Interaction intervention * month 9 & $(0.427)$ & $(0.538)$ \\
Intercept month 10 & 0.487 & 0.543 \\
& $(0.280)$ & $(0.296)$ \\
Interaction intervention * month 10 & $-2.623^{* *}$ & $-1.846 * *$ \\
& $(0.435)$ & $(0.617)$ \\
Intercept month 11 & $0.637^{*}$ & 0.684 \\
& $(0.285)$ & $(0.367)$ \\
Interaction intervention * month 11 & $-2.979 * *$ & -1.862 \\
& $(0.452)$ & $(0.955)$ \\
Number of observations & 0.620 & 0.711 \\
Schwarz B.I.C. & $(0.325)$ & $(0.803)$ \\
LogLikelihood & 2586 & 2586 \\
\hline
\end{tabular}

\section{Duration dependence effects}

To get a picture of the duration dependence effects during the RTW process of the sick workers, the survival and hazard functions are depicted in figures 2 and 3. In these figures we can see that the probability of remaining absent over time decreases as a function of time, within the first year of absence. When the piecewise constant model and the piecewise variable model are compared, and given that the variable model provides the best fit for the data, it seems that the constant model overestimates the probability of RTW (figure 2).

Figure 2. Probability of remaining absent over time: Piecewise Constant Hazard Model and Piecewise Variable Hazard Model (survivor functions)

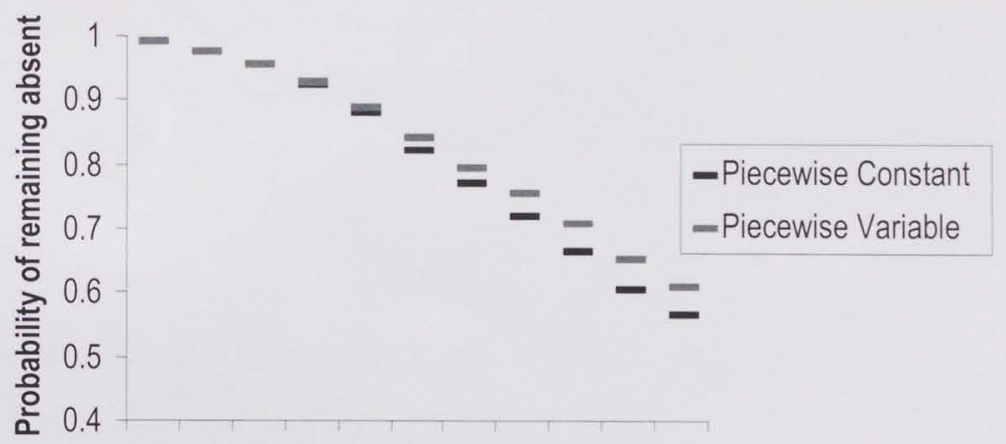

Nov Dec Jan Feb Mar Apr Jun Jul Aug Sep Oct 
$140 \mid$ Chapter 5

Figure 3. Conditional probability of RTW (RTW rate) in each month: Piecewise Constant Hazard Model and Piecewise Variable Hazard Model (hazard functions)

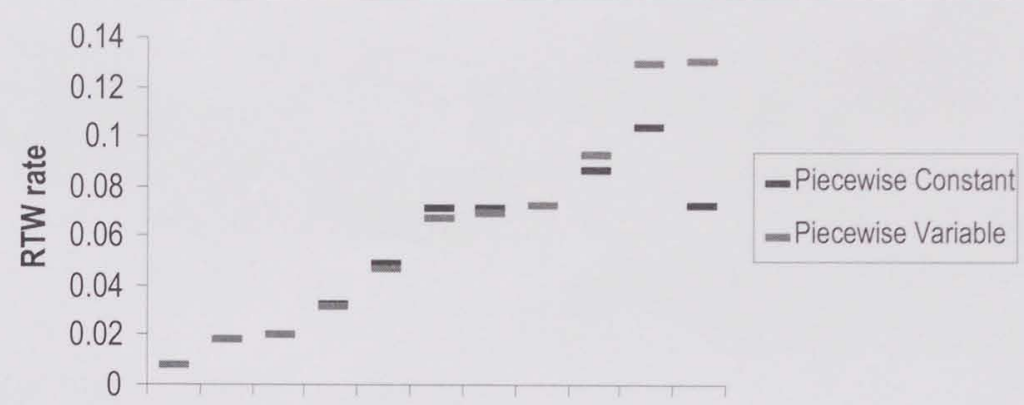

Nov Dec Jan Feb Mar Apr Jun Jul Aug Sep Oct

Month

The hazard function denotes the instantaneous probability of returning to work in a given time period, given that a worker has not yet returned to work in a previous time period. The hazard increases over time roughly in three steps. Particularly, in month 3, 6 and 9 the hazard increases. More specific effects can be seen in table 1.

Coefficients with a positive (negative) sign indicate that as the variable increases, duration dependence becomes more (less) positive, i.e. the RTW rate increases (decreases) and sickness absence duration decreases (increases) because of the duration dependence response ${ }^{6}$. Duration dependence was included in the piecewise variable hazard model by interaction variables between duration and worker characteristics. Age and previous absence record prove to have a significant effect on duration dependence (i.e. the shape of the hazard function). Age has a positive effect on duration dependence, meaning that older workers have an increasing RTW rate and decreasing durations of absence over time. A longer previous absence record has a positive effect on duration dependence as well. More weeks of previous absence increase the RTW rate over time.

\section{Effect of the intervention on the RTW rate}

The intervention has a negative effect on the RTW rate. The significant interaction terms between the intervention and duration that were included in the piecewise models, show that the effect of the intervention fluctuates over the different time periods. While the intervention significantly influences the location parameter, the 
shape parameter is not significantly affected. The intervention does not influence duration dependence.

\section{Effect of worker characteristics on the RTW rate}

Several characteristics significantly affect the RTW rate (location parameter) in the piecewise model. Negative effects on the RTW rate (i.e. an increase in the variable decreases the RTW rate) are found for age, having had the same complaints before, previous absence record, workers in relatively small firms (less than 50 employees), and for the intervention by the occupational physician. Positive effects are for instance found for educational qualifications. Having lower vocational, junior general secondary, senior secondary vocational, senior general secondary or pre university qualifications, or having higher vocational educational qualifications significantly increases the RTW rate compared to having primary educational qualifications only (the reference category). Other positive effects on the RTW rate are generated by having the Dutch nationality, a longer job tenure, a permanent employment contract and being a breadwinner.

\section{Discussion and conclusions}

In this study, we found evidence for the presence of variable duration dependence. The shape of the hazard function is significantly affected by the age of a worker and his previous absence record. Our results also show that the effect of the intervention is negative. Furthermore, several characteristics are identified that significantly influence the location parameter of the RTW rate. This RTW rate shows an interesting pattern. First of all, one can discern a seasonal influence. During the summer months the RTW rate stabilizes. Secondly, we see that at the end of the first year of absence, RTW probabilities increase substantially. This may be a consequence of the fact that, in the Dutch social security system, disability certification is due after 52 weeks of sickness absence. After these 52 weeks of waiting time (in which the worker receives sickness benefits), the health and work status of the worker are assessed for disability benefit purposes. So the end of the sickness benefits goes together with an increase in the probability of returning to work. 
$142 \mid$ Chapter 5

Variable duration dependence models can provide useful information for Disability Management (DM) policy questions. Besides yielding the net effect of predictors and interventions on the RTW rate, the differentiation between location and shape parameters of the RTW rate yields specific knowledge on duration dependence effects and enables specific targeting of interventions. Designing an appropriate intervention strategy for sick workers implies making decisions about what kind of intervention is undertaken for whom and when. Up to now, there is a limited knowledge base upon which these decisions can be made ${ }^{19}$. The effectiveness of many DM interventions and their 'optimal' timing remains unknown ${ }^{19}$. Necessarily, assumptions have to be made about what interventions to apply at what time during the sickness absence. DM strategies explicitly focus on early interventions 10,11 , under the assumption of the presence of negative duration dependence during sickness absence. Though there are indications that the probability of RTW decreases as a function of time ${ }^{12}$, the actual pattern of the duration dependence itself has hardly been investigated. Our study shows positive duration dependence for some groups of workers. Knowing the probability patterns and duration dependence of different groups of workers in different settings can form a starting point for future intervention strategies. The presence of positive duration dependence in our study, for example, raises the question whether interventions are cost-effective and necessary, and if so, whether it may be better to intervene 'late' instead of 'early' for older workers and workers with a longer previous absence record. The intervention by the occupational physician in this study can be seen as the beginning of the path towards RTW, as we argued in an earlier study ${ }^{19}$. In the present study we find that those workers that are selected by the occupational physician have a lower probability of RTW (significant negative effect on the location parameter). The timing of the intervention, and thus the initiation of the path towards RTW, however, does not matter significantly (no significant effect on the shape parameter). This is remarkable, given the assumptions that underlie the 'early intervention' principle in Disability Management practices. One intervenes early in the sickness absence process with the objective to facilitate or accelerate the RTW process (i.e. change the shape of the RTW probability function).

Allowing for variable duration dependence in a model makes it possible to discern groups of workers with different intervention needs. DM policy and interventions can be aimed at both location and shape aspects of the RTW probability function. 
Do we, for example, want to influence the magnitude of the risk (i.e. the location parameter), or the shape of the risk function over time?

If one wants to use this type of (variable) hazard models, an important point of concern has to be addressed. As we explained in the introduction, estimation of the shape of the hazard function may be difficult. One has to be aware of the risk of model misspecification, and thus unreliable estimates ('spurious' results) '. Findings may be a consequence of unobserved heterogeneity, instead of being the result of an underlying causal process ${ }^{9}$. Spurious results might be defined by the fact that they heavily depend on a specific type of model ${ }^{9}$. A multiple model estimation strategy overcomes this problem. In order to find robust parameter estimates, it is considered to be the best strategy to estimate a range of different models and possible shapes of the transition rate (in our case RTW rate) and assess their fit ${ }^{9}$. Piecewise models are useful when there is no clear idea about the form of the duration dependence ${ }^{9}$, but a combination of these semi-parametric with parametric models is still preferred. We believe that knowledge gathered by means of variable hazard models can help us to make decisions about how to design DM intervention strategies. The results can be used to target interventions at the right people and at the right time. 
144 |Chapter 5

\section{References}

1. Franche RL, Krause N. Readiness for Return to Work Following Injury or Illness: Conceptualizing the Interpersonal Impact of Health Care, Workplace, and Insurance Factors. Journal of Occupational Rehabilitation 2002;12(4):233-256.

2. Habeck RV, Hunt HA, Tol Bv. Workplace factors associated with preventing and managing work disability. Rehabilitation Counseling Bulletin 1998:Counseling-Bulletin.

3. Krause N, Frank JW, Dasinger LK, Sullivan TJ, Sinclair SJ. Determinants of Duration of Disability and Return-to-Work After Work-Related Injury and IIIness: Challenges for Future Research. American Journal of Industrial Medicine 2001;40:464-484.

4. Smulders PGW, Veerman TJ. Handboek Ziekteverzuim. Gids voor de bedrijfspraktijk. Den Haag: Delwel; 1990.

5. Vallacher RR, Nowak A, editors. Dynamical Systems in Social Psychology. London: Academic Press, Inc; 1994.

6. Butler RJ, Baldwin ML, Johnson WG. The effects of worker heterogeneity on duration dependence: low-back claims in workers compensation. The Review of Economics and Statistics 2001;83(4):708-716.

7. Griffin WA. Assessing State Changes in Microsocial Interaction: An Introduction to Event-History Analysis. In: Mordechai Gottman J, editor. The Analysis of Change. Mahwah, New Jersey: Lawrence Erlbaum Associates Publishers; 1995. p. 309-337.

8. Blossfeld HP, Hamerle A, Mayer KU. Event History Analysis. Hillsdale, New Jersey: Lawrence Erlbaum Associates Inc.; 1989.

9. Blossfeld HP, Röwer G. Techniques of event history modeling: new approaches to causal analysis. 2nd ed. Mahwah, NJ: Lawrence Erlbaum; 2002.

10. Shrey DE. Worksite disability management model for effective return-to-work planning. Occupational Medicine: state of the art reviews 2000;15(4):789-801.

11. Akabas SH, Gates LB, Galvin DE. Disability Management. A Complete System To Reduce Costs, Increase Productivity, Meet Employee Needs, And Ensure Legal Compliance. New York: AMACOM; 1992.

12. Crook J, Moldofsky $\mathrm{H}$. The probability of recovery and return to work from disability as a function of time. Quality of Life Research 1994;3(suppl. 1):s97-s109.

13. Frank J, Sinclair S, Hogg Johnson S, Shannon H, Bombardier C, Beaton D, et al. Preventing disability from work-related low-back pain. New evidence gives new hope-if we can just get all the players onside. Canadian Medical Association Journal 1998;158(12):1625-31.

14. Dasinger LK, Krause N, Deegan LJ, Brand RJ, Rudolph L. Duration of Work Disability After Low Back Injury: A comparison of Administrative and Self-Reported Outcomes. American Journal of Industrial Medicine 1999;35:619-631. 
15. Krause N, Dasinger LK, Deegan LJ, Brand RJ, Rudolph L. Alternative Approaches for Measuring Duration of Work Disability After Low Back Injury Based on Administrative Workers' Compensation Data. American Journal of Industrial Medicine 1999;35:604-618.

16. Krause N, Dasinger LK, Deegan LJ, Rudolph L, Brand RJ. Psychosocial Job Factors and Return-to-Work After Compensated Low Back Injury: A Disability Phase-Specific Analysis. American Journal of Industrial Medicine 2001;40:374-392.

17. Dasinger LK, Krause N, Thompson PJ, Brand RJ, Rudolph L. Doctor Proactive Communication, Return-to-Work Recommendation, and Duration of Disability After a Workers' Compensation Low Back Injury. Journal of Occupational and Environmental Medicine 2001;43(6):515-525.

18. Joling C, Groot W, Janssen PPM. Waiting for the Doctor. Gender differences in the timing of an intervention by the occupational physician. Journal of Occupational Rehabilitation 2003;13(1):45-61.

19. Joling C, Janssen PPM, Groot W. Modelling return-to-work intervention strategies. A method to help target interventions. Journal of Occupational Rehabilitation $2004 ; 14(1): 43-62$.

20. Johnson WG, Ondrich J. The Duration of Post-Injury Absences from Work. The Review of Economics and Statistics 1990;72(4):578-586.

21. Meyer BD, Viscusi WK, Durbin DL. Workers' Compensation and Injury Duration: Evidence from a Natural Experiment. American Economic Review 1995;85(2):322-340.

22. Johnson WG, Baldwin ML, Butler RJ. Back Pain and Work Disability: The Need for a New Paradigm. Industrial Relations 1998;37(1):9-34.

23. Curington WP. Compensation for Permanent Impairment and the Duration of Work Absence: Evidence from four Natural Experiments. Journal of Human Resources 1994;29(3):888-910.

24. Willett JB, Singer JD. Investigating Onset, Cessation, Relapse, and Recovery: using Discrete-Time Survival Analysis to Examine the Occurrence and Timing of Critical Events. In: Mordechai Gottman J, editor. The Analysis of Change. Mahwah, New Jersey: Lawrence Erlbaum Associates; 1995.

25. Allison PD. Event History Analysis. Regression for Longitudinal Event Data. Beverly Hills, California: Sage Publications, Inc; 1984.

26. Molenaar-Cox PGM, Fiseler JG, Stelt HGvd, Smaal M, Kers WC. Databoek PES3. Amsterdam: GAK/GMD; 1995.

27. Scott Long J. Regression Models for Categorical and Limited Dependent Variables. Thousand Oaks, California: Sage Publications, Inc.; 1997.

28. Lancaster $T$. Econometric methods for the duration of unemployment. Econometrica 1979;47(4):939-956. 
$146 \mid$ Chapter 5 
Chapter 6

\section{General Discussion}


$148 \mid$ Chapter 6 


\section{Introduction}

In this chapter, the contribution of this study to our knowledge about and insight in the impact of interventions on sickness absence is discussed. The main findings are briefly summarized in the next section. This is followed by a discussion of the strengths and weaknesses of our conceptualization of the problem of intervention in the sickness absence process (section 3). This chapter concludes with policy implications of the research findings.

\section{Main Findings}

In Chapter 1 of this thesis, a conceptual framework to model intervention in the sickness absence process was formulated. In successive chapters, this framework was elaborated upon. Each chapter had a different focus. In Chapter 2 we focused upon the selection for a physiotherapy intervention. For this purpose we analyzed a sample of workers from Great Britain. Chapters 3, 4 and 5 concerned sick workers in the Dutch social security context. The British and Dutch samples are not comparable. They are used to investigate different issues. In the Dutch sample, we studied the role of elapsed duration in the selection for a particular intervention (Chapter 3), the relationship between the probability of intervention and the probability of RTW (Chapter 4), and the presence and type of duration dependence in sickness absence (Chapter 5).

We started by studying selection effects with return to work (RTW) interventions. Because the interventions under study took place in a non-experimental context, we expected that the selection of people for these interventions was not random. Selection effects with interventions during sickness absence could influence the estimates of the disability risk. For instance, if some people do not qualify for certain interventions, they can fall behind in the RTW process and experience a higher disability risk. In the separate studies of this thesis, it was shown that selection effects are present in two different interventions that take place during sickness absence, i.e. physiotherapy interventions and the first intervention by the occupational physician. In Chapter 2 we investigated determinants of the probability of receiving a physiotherapy intervention. Having had a physiotherapy treatment the year before the interview appeared to increase the probability of 
$150 \mid$ Chapter 6

receiving another treatment significantly. Some sort of dependence upon this treatment was observed. We referred to this as medicalization. A minor selection effect was found for people with higher educational qualifications: they appeared to have a greater probability of receiving physiotherapy.

We also studied possible selection effects with the first intervention by the occupational physician. It was investigated whether the relatively high inflow risk into disability for women, compared to that for men, is reflected in a disadvantage in the probability of being called by the occupational physician during sickness absence. The estimates showed that for both men and women the probability of receiving an intervention decreases as time passes. The duration dependence is strongly negative for women, while for men there appears to be no duration dependence. This means that as time progresses in the sickness absence process, womens' chances decrease relative to those of men. Women seem to have characteristics which favor the probability of being called by the occupational physician and consequently have a shorter expected duration. Gender differences appear to have their origins in underlying characteristics, instead of in a gender difference in treatment. Selection effects were found for educational qualifications, diagnosis, firm size, industry, occupational workload and job tenure. These variables are mostly related to the labor market position of the worker. People with a better labor market position appear to be more likely to be called by the occupational physician.

A second important aspect that was investigated in this study, was the presence of endogeneity in the relationship between the selection for interventions and the probability of RTW. We could not prove a significant relationship between the intervention by the occupational physician and the probability of RTW. However, in the simultaneous modelling framework, other variables in the equation proved to be significantly related to both the intervention and RTW. On the basis of the direction of the effect of these endogenous variables (positive or negative), several groups of workers could be identified, who differ in the probability - and perhaps also in the need - of an intervention. In the simultaneous framework, a longer job tenure appeared to give a smaller probability of being called by the occupational physician, but it fostered RTW of the worker $(-,+)$. It seems that workers with a longer job tenure have a greater self-managing capacity. Besides job tenure, other factors that influence both the probability of receiving an intervention by the occupational physician and the probability of RTW in our study were age and 
educational qualifications. Age is positively related to the probability of intervention, but negatively to the probability of RTW (+,-). Having vocational educational qualifications instead of primary education only, influences the probability of intervention and the probability of RTW positively $(+,+)$.

Previous studies, as well as practical experiences with Disability Management, indicated that time plays an important role in the RTW process. Our study confirms the importance of the elapsed duration in sickness absence. The role of the elapsed time in sickness absence was expressed by duration dependence on the probability of intervention and the probability of RTW. We found evidence for the presence of duration dependence on the probability of receiving an intervention by the occupational physician, as well as on the probability of RTW. Moreover, we found that the duration dependence effects differ between workers (variable duration dependence). The shape of the hazard function was significantly affected by the age of a worker and his previous absence record. Both variables have a positive influence, i.e. older workers and workers with a longer previous absence record have an increasing RTW rate and decreasing durations of absence over time. Furthermore, several characteristics were identified that significantly influence the location parameter of the RTW rate.

The presence of duration dependence ${ }^{a}$ has important consequences for future intervention strategies. Interventions can influence the location and the shape of the RTW probability function. Decisions about the optimal timing of interventions can be made by looking at the shape of the RTW probability function over time, for different groups of workers. Inefficient timing of interventions leads to needless costs and a diverging disability risk. In the case of negative duration dependence during sickness absence, early intervention seems beneficial, whereas with positive duration dependence it seems better to intervene later on, if at all.

a That is, 'true' duration dependence, as opposed to 'spurious' duration dependence (a methodological artefact). The difference between the two is explained later on. 
$152 \mid$ Chapter 6

\section{Strengths and weaknesses}

Our conceptualization of intervention in the sickness absence process has certain strengths, but also some limitations. The consequences of the chosen level of analysis and the conceptualization are discussed below.

\section{Level of analysis}

We explicitly chose to analyze individual behavior at the population level. As we argued in Chapter 4, analyses at population level can provide a general picture of relationships that exist between aspects of intervention strategies that determine the effectiveness of these interventions (like selection and timing), and RTW. Other approaches to these problems (e.g., Randomized Clinical Trials (RCTs)) usually use a broader conceptualization but have a more limited scope. The generalizability of the research findings of RCTs to settings and populations that are different from those in which the trial occurred, is frequently difficult ${ }^{1}$. Previous studies on interventions during sickness absence were able to explain their effectiveness, or the lack of it, for specific groups of people in particular settings. The studies concern very specific and divergent groups of subjects. For example, it concerns people with chronic work-related upper extremity disorders ${ }^{2}$, acute low back pain patients ${ }^{3}$, or directors of day-care centers susceptible to stress and burnout ${ }^{4}$. Moreover, the effects are specific to a particular setting, e.g., nurses in a hospital setting ${ }^{5}$. The generalizability of research findings is also hampered by the fact that there is heterogeneity in interventions. Frequently, packages of separate interventions are carried out at the same time, lumped together as 'multidisciplinary' or 'multimodal' interventions ${ }^{2,6-9}$. Furthermore, a comparison of findings of different studies is difficult because there is a wide variability in outcome measures ${ }^{10}$.

Explanations for the success of interventions in clinical trials or related studies, generally do not provide any insight into how one must intervene in the future ${ }^{11}$. Clues about future intervention strategies can merely be found if effect $X$ in context $Y$ repeatedly leads to the same effects, and under conditions that ensure the same result is feasible in the future ${ }^{11}$. Studies at population level are helpful in this respect, because they are better suited to answer policy questions. A RCT will answer a clinician's question: what is the expected outcome if I give a particular treatment to a patient with certain characteristics relative to not giving that 
treatment? '. Analyses at population level will typically answer a policymaker's question: what is the expected outcome if somewhat more or somewhat less of a treatment is used in a population? '. In this sense, findings from studies at population level complement findings from RCTs. At the population level, probability patterns can be drawn, which not only provide empirically relevant information about the population under study, they also provide leads for future intervention strategies.

\section{Conceptualization of intervention in the sickness absence process}

We stated in Chapter 2 that in the literature, the process of intervention during sickness absence is not conceptualized unambiguously. For example, in research on interventions for workers with musculoskeletal complaints, many authors have assumed a straightforward chain of events, in which complaints are followed by sickness absence, while recovery and RTW are seen as identical ${ }^{12-14}$. The chain of events is, however, not as straightforward as that. A worker can, for instance, still be in ill health when he returns to work (sickness presenteeism, "zero injuries effect $\left.^{\prime \prime b}{ }^{15}\right)$. Another situation that occurs is that workers are 'objectively' in good health but do not return to work ("medical paradox"c ${ }^{16}$ ).

In our study, we conceptualized RTW as being a change of state, i.e. a transition from not working to working, for an individual in a particular time period. What we observe is the probability pattern of this state and changes in the RTW pattern over time. Transitions from one state to the other are made when a theoretical threshold is crossed 15, 17. Thresholds for sickness absence are, for instance, denoted by concepts like "disposition to be present" and "need to be absent" ${ }^{15}$. The transition from sickness absence to RTW is believed to be reached when the hypothetical "RTW threshold" is crossed ${ }^{17}$. We are not able to explain why a certain threshold is crossed, we only observe that it is crossed, and assess the circumstances under which this is likely to happen (for instance, whether it concerns women, or older workers more frequently). The way in which the probability of RTW evolves over time can be expressed by the duration

\footnotetext{
${ }^{b}$ The zero injuries effect refers to occupational injuries that do not lead to the taking of sick leave (Aronsson, Gustafson \& Dallner, 2000).

c The medical paradox refers to a discrepancy between the expectations of work resumption according to scientific medical criteria and the actual work resumption rates and the the behavior of the patient (Bloch \& Prins, 2001).
} 
$154 \mid$ Chapter 6

dependence of the process. In general, duration dependence may arise for conceptually distinct reasons ${ }^{18,19}$ : (1) the observed duration dependence may be spurious, that is, it may be the consequence of unobserved heterogeneity; (2) duration dependence may be seen as the result of a diffusion process, reflecting the changing relationship of a set of interdependent individual units in a system over time; or (3) duration dependence may be seen as an expression of a causal process. In the latter case, measures of time serve as proxies for time-varying causal factors, which are difficult to observe directly ${ }^{19}$, such as the intensity of the sickness absence situation. The second option (diffusion) is based on the idea that some sort of contagion, infection or simply social pressure drives the process under study ${ }^{19}$. Spurious duration dependence is a methodological phenomenon. It can be the consequence of unobserved heterogeneity ${ }^{18,19}$.

The presence of 'true' duration dependence (option 2 or 3), has important consequences for intervention strategies. The role of interventions during sickness absence is conceptualized by distinguishing two possible states in which individuals can be found at any point in time: (1) the worker has not (yet) experienced the intervention, or (2) the worker has experienced the intervention under study. The period of time that a worker has spent in a state, and the state transition of experiencing the intervention (i.e. from 1 to 2) can influence the probability of RTW. The influence of the intervention is given by the shift of the RTW probability profile, as a consequence of experiencing the intervention. $A$ positive effect shifts the probability function upward, a negative effect shifts it downward.

The decision to initiate an intervention is influenced by certain selection mechanisms. It was hypothesized in an earlier study by Gründemann and Nijboer, for example, that labor market mechanisms influence the qualification for interventions within a company ${ }^{20}$. For medical and paramedical interventions that a patient himself can initiate, it is known that individual experiences with the intervention in the past will influence future decisions of initiation ${ }^{21,22}$. With our conceptualization, we cannot disentangle the exact mechanisms behind the selection decision. What we evaluate is the result of the intervention decision on RTW. We do, however, have indications which underlying mechanisms are concerned, by looking at the characteristics that foster qualification for the intervention. Characteristics that foster selection for the intervention in Chapter 3 
were, for instance, mostly related to the labor market position of the worker (e.g., educational qualifications and job tenure).

We argued that the relationship between interventions and RTW could be endogenous in nature. Endogeneity refers to a certain amount of circularity between two processes ${ }^{23}$. In our case, it was assumed that the intervention affects the RTW probability, but at the same time prospects of RTW were likely to influence the selection for an intervention. The presence of endogeneity was conceptualized by estimating the intervention and RTW equations simultaneously. The values of endogenous variables in both equations are determined by the interaction of the relationships in the model ${ }^{23}$.

\section{The risk of model misspecification}

Covariate estimates are sensitive to the set of covariates incorporated in the model. Changing a set of covariates (i.e. omitting certain variables) will lead to changes in the duration dependent shape of the hazard function ${ }^{18,}{ }^{19}$. What can be done to minimize the risk of misspecification? One way to deal with unobserved heterogeneity is to incorporate an error term in the model specification (i.e. the mixture approach). This error term is supposed to capture both individual heterogeneity and deviations from the supposed shape of duration dependence ${ }^{19}$. Parameter estimates of mixture models can, however, be highly sensitive to the assumed parametric form of the error term ${ }^{19,24}$. One has to assume a particular distribution for this error term, while by definition, it is impossible to know the distribution of factors that are not observed ${ }^{19}$. It is therefore argued that the mixture approach possibly only shifts the problem to another level: misspecification of the transition rate by neglecting the error term might be replaced by misspecification of the parametric distribution of the error term ${ }^{19}$. As a solution to this problem, a semi-parametric specification of the error term was suggested by Heckman and Singer ${ }^{24}$. However, their semi-parametric specification appeared to be strongly dependent on the choice of the duration dependence distribution ${ }^{25}$.

In their discussion of duration models, Blossfeld and Röhwer ${ }^{19}$ state that, at least in sociological research, there is almost never enough theoretical and empirical evidence to choose one distribution over the other, and just to make more or less arbitrary distributional assumptions about unobserved heterogeneity will not lead 
$156 \mid$ Chapter 6

to better models. The best strategy seems to be to estimate a series of models with different specifications, and observe whether the estimates are stable or not ${ }^{19}$.

\section{Policy implications}

The findings from this study should be viewed as a complement to findings from clinical trials for obtaining more valid empirical estimates for Disability Management (DM) policy use. We gained insight into the use two interventions during sickness absence. In our British sample, indications were found towards medicalization of musculoskeletal complaints and dependence upon physiotherapy treatments. Over the past few decades, our society has reclassified a growing array of uncomfortable and undesirable aspects of life - among which musculoskeletal symptoms - that were seen as inescapable and inevitable concomitants of daily life in the past, as diseases for which we increasingly seek treatment ${ }^{26}$. We have to wonder whether this is desirable, because medicalization not only fosters somatization of the complaints, it also leads to a disproportional high and inefficient use of (para)medical services ${ }^{26}$. This adds substantially to the overall costs of medical care ${ }^{26}$.

In our sample of long-term absent workers in the Netherlands, women were found to have characteristics that favor the probability of being called by the occupational physician. The women concerned were on average younger than the men, better educated, they more frequently had a psychological diagnosis (where men more frequently had a musculoskeletal one), they more frequently worked in small companies, and they mainly worked in the trade and services sectors. Although their characteristics made the women in our sample more likely to be called by the occupational physician, this was not reflected in their disability risk. Women experience a higher disability risk. This suggests that women at least need better targeted and more effective interventions during sickness absence to enhance their RTW probabilities. The same goes for other high risk groups, like youngsters, that now also appear to be falling behind (as we noted in the introduction).

This study provides some starting points to optimize RTW intervention strategies. First, by investigating the relationship between interventions and RTW in a particular situation, like we did in Chapter 4, groups of people can be 
distinguished that differ in the probability - and perhaps also in the need - of receiving an intervention. It can be indicated which workers would benefit most from the intervention and which workers have more self-managing capacity and are less urgent. Moreover, we can discern which workers do not seem to benefit from the intervention. For these workers, the timing of the intervention is ineffective, or perhaps they need a different intervention to increase their RTW chances. By studying duration dependence patterns of different groups of workers, we can gather information about the optimal timing of interventions. If negative duration dependence is observed in a population, there may be a need of early intervention, whereas if positive duration is observed, the question is whether we need to intervene at all. In our sample, a positive duration dependence during sickness absence was observed. An older age and a longer previous absence record appeared to have a positive influence on duration dependence. In other words, these factors increase the probability of RTW as time passes. Duration dependence is influenced by the context of social security arrangements. In the Netherlands, after 52 weeks of absence disability certification is due. Part of this disability certification is a medical examination. Our findings indicate that the certification has some sort of deterrent effect: we see that the RTW probabilities at the end of the sickness absence period suddenly increase. Possibly, for some longterm absent workers the prospect of being labeled as 'disabled' is a strong incentive to RTW. It could be that the medical examination has a deterrent effect and fosters RTW.

The location parameter of the RTW probability function (i.e. the magnitude of the 'risk') is influenced by a multitude of factors (see table 3 in Chapter 4). Some of these factors can be influenced by interventions, like for instance occupational workload. Others that can not be influenced, like for example the age of a worker, can been taken into account when targeting intervention strategies.

The RTW profile is affected by changes in attitudes and behavior of workers, employers and those implementing the social security policy. During the 90s, the social security context changed but this did not seem to result in a behavioral change of workers and employers ${ }^{27}$. Despite the far-reaching privatization of the sickness and disability risk that has taken place in the 90 s, in the beginning of the twenty-first century employers still showed reactive instead of pro-active behavior with respect to the problem of work incapacity ${ }^{27}$. However, in 2003, a turnaround seems to have taken place. Provisional numbers over 2003 show a decreased 
$158 \mid$ Chapter 6

inflow risk, and for the first time in years, the volume of beneficiaries is also decreasing ${ }^{28}$. This could be the effect of the tightening up of the social security administration practice, and the intensification of Disability Management activities during the first year of absence that were enforced by law in $2002^{d}$. Question is how long this effect will last. Previous changes all had only temporary effects. A further restriction of the eligibility criteria for the disability benefit system is still to be launched. The RTW profile is changing now. The intensification of Disability Management activities increases the probability of receiving interventions during sickness absence. The idea of early intervention finds increasing support. We argued in this thesis however, that in some cases early intervention may not be desirable, because it does not improve the situation (or may even aggravate it) or because it leeds to high and needless costs. Gathering insight into duration dependence patterns and the impact of interventions during sickness absence can help us optimize RTW intervention strategies.

\footnotetext{
${ }^{d}$ Wet Verbetering Poortwachter (2002).
} 


\section{References}

1. McClellan MB, Newhouse JP. Health Services Research: Overview of the Special Supplement Issue. Health Services Research 2000;35(5-2):1061-1070.

2. Feuerstein $M$, Callan Harris S, Hickey P, Dyer D, Armbruster W, Carosella AM. Multidisciplinary rehabilitation of chronic work-related upper extremity disorders. Longterm effects. 1993;35(4):396-403.

3. Gatchel RJ, Polatin PB, Noe C, Gardea M, Pulliam C, Thompson J. Treatment- and Cost-Effectiveness of Early Intervention For Acute Low-Back Pain Patients: A One-Year Prospective Study. Journal of Occupational Rehabilitation 2003;13(1):1-9.

4. Kushnir T, Milbauer V. Managing Stress and Burnout at Work: A Cognitive Group Intervention Program for Directors of Day-Care Centres. Pediatrics 1994;94(6):1074-1076.

5. Cooper JE, Tate RB, Yassi A, Khokhar ). Effect of an early intervention program on the relationship between subjective pain and disability measures in nurses with low back injury. Spine 1996;21(20):2329-36.

6. Pfingsten $M$, Hildebrandt J, Leibing E, Franz C, Saur P. Effectiveness of a multimodal treatment program for chronic low-back pain. Pain 1997;73(1):77-85.

7. Heikkilae $H$, Heikkilae E, Eiseman M. Predictive factors for the outcome of a multidisciplinary pain rehabilitation programme on sick-leave and life satisfaction in patients with whiplash trauma and other myofascial pain: a follow-up study. Clinical Rehabilitation 1998;12(6):487-496.

8. Karjalainen K, Malmivaara A, Tulder MWV, Roine $R$, Jauhiainen $M$, Hurri $H$, et al. Multidisciplinary Biopsychosocial Rehabilitation for Subacute Low Back Pain among Working Age Adults. The Cochrane Library 2003(1).

9. Karjalainen $K$, Malmivaara A, Tulder MWV, Roine $R$, Jauhiainen $M$, Hurri $H$, et al. Multidisciplinary biopsychosocial rehabilitation for neck and shoulder pain among working age adults. The Cochrane Library 2000(4).

10. Krause N, Frank JW, Dasinger LK, Sullivan TJ, Sinclair SJ. Determinants of Duration of Disability and Return-to-Work After Work-Related Injury and IIIness: Challenges for Future Research. American Journal of Industrial Medicine 2001;40:464-484.

11. Wittenboer Gvd. Formele interventiemodellen. Amsterdam: Universiteit van Amsterdam; 1992.

12. Zigenfus GC, Yin J, Giang GM, Fogarty WT. Effectiveness of Early Physical Therapy in the Treatment of Acute Low Back Musculoskeletal Disorders. Journal of Occupational and Environmental Medicine 2000;42(1):35-39.

13. Cherkin DC, Deyo RA, Battié M, Street J, Barlow W. A Comparison of Physical Therapy, Chiropractic Manipulation, and Provision of an Educational Booklet for the Treatment of Patients with Low Back Pain. New England Journal of Medicine 1998;339(15):1021-1029. 
$160 \mid$ Chapter 6

14. Skargren El, Öberg BE, Carlsson PG, Gade M. Cost and Effectiveness Analysis of Chiropractic and Physiotherapy Treatment for Low Back and Neck Pain. Spine 1997;22(18):2167-2177.

15. Aronsson G, Gustafson K, Dallner M. Sick, but yet at work. An empirical study of sickness presenteeism. Journal of Epidemiology and Community Health 2000;2000(54):502509.

16. Bloch FS, Prins R. Who Returns to Work and Why? A six-Country study on Work Incapacity \& Reintegration. New Brunswick NJ: Transaction Publishers; 2001.

17. Smulders PGW, Veerman TJ. Handboek Ziekteverzuim. Gids voor de bedrijfspraktijk. Den Haag: Delwel; 1990.

18. Zorn CJW. Modeling Duration Dependence. Political Analysis 2000;8(3):367-380.

19. Blossfeld HP, Röwer G. Techniques of event history modeling: new approaches to causal analysis. 2nd ed. Mahwah, NJ: Lawrence Erlbaum; 2002.

20. Gründemann RWM, Nijboer ID. WAO-intrede en werkhervatting. Amsterdam: Universiteit van Amsterdam; 1998.

21. Mielenz TJ, Carey TS, Dyrek DA, Harris BA, Garret JM, Darter JD. Physical Therapy Utilization by Patients with Acute Low Back Pain. Physical Therapy 1997;77(10):1040-1051.

22. Heckman JJ. Statistical Models for Discrete Panel Data. In: Manski CF, McFadden $\mathrm{DL}$, editors. Structural Analysis of Discrete Data and Econometric Applications. Cambridge: MIT Press; 1981.

23. Dougherty C. Introduction to Econometrics. Oxford: Oxford University Press; 2002.

24. Heckman J, Singer B. A Method for Minimizing the Impact of Distributional Assumptions in Econometric Models for Duration Data. Econometrica 1984;52(2):271-320.

25. Trussell \}, Richards T. Correcting for unmeasured heterogeneity in hazard models using the Heckman-Singer procedure. In: Tuma N, editor. Sociological Methodology 1985. San Francisco CA: Jossey-Bass; 1985. p. 242-276.

26. Barsky AJ, Borus JF. Somatization and Medicalization in the Era of Managed Care. JAMA 1995;274(24):1931-1934.

27. Veerman TJ, Besseling IJM. Prikkels en privatisering: integrerende rapportage evaluatie wetgeving rond ziekteverzuim, WAO en reïntegratie. 's-Gravenhage: Ministerie van Sociale Zaken en Werkgelegenheid; 2001.

28. UWV. Maandoverzicht arbeidsongeschiktheidsuitkeringen (voorlopige cijfers). Januari t/m december 2003. Amsterdam: Uitvoering Werknemersverzekeringen; 2003. 


\section{Summary}

In many European and North American countries incapacity for work is a major socio-economic problem. In the Netherlands, over the last decades, an alarming number of workers has entered the disability benefit system. This study is directed at the optimization of intervention strategies during sickness absence to prevent disability. Chapter 1 starts with a description of the evolution of the social security system in the Netherlands over the last three decades. In the 1950s, 1960s and 1970 s a generous social security policy was pursued in the Netherlands. The unexpected high number of claimants that was attracted, especially by the disability benefit arrangements, led to rapidly increasing costs. From the 1980s on, the social security system has been subject of continuous reorganization and economization. However, the efforts do not appear to have led to the desired effects on the number of disability benefit claimants, the inflow nor the outflow. In the beginning of the twenty-first century, almost one million people received disability benefits, which meant that 1 in 7 workers was disabled.

Over the last couple of years, a far-reaching privatization of the sickness and disability risk has taken place. With this, the importance of a quick return to work (RTW) has increased for workers and employers. Interventions take place during sickness absence to accelerate and facilitate the RTW of sick workers. These increasingly take place early in the sickness absence process. Effective intervention is difficult, however. There is an obvious need for more effective intervention strategies to prevent disability and promote RTW. Important aspects of interventions that take place in a non-experimental context are selection and timing. Furthermore, the elapsed duration plays an important role in the effectiveness of interventions. This study aims to provide more insight into selection and timing aspects of intervention strategies. The following issues are addressed: (a) who is selected for an intervention (selection processes); (b) when does this intervention take place (timing); and (c) what is the effect of this selection and timing on the probability of return to work? Studying these issues can help us answer policy questions about the use of interventions in a population. A conceptual framework to model intervention in the sickness absence process is formulated. This framework is elaborated upon in successive chapters. 
$162 \mid$ Summary

Chapter 2 presents a study of physiotherapy interventions for people with musculoskeletal complaints. We discuss the probability that someone visits a physiotherapist, and look at the probability of recovery of people that received physiotherapy. Physiotherapy is a commonly employed intervention for people with musculoskeletal complaints. However, due to (methodological) limitations in previous research, the effectiveness of physiotherapy interventions has not yet been proven. The aim of this study is twofold. First it is tried to solve some of the methodological problems, of which the most important are selection and endogeneity biases and state dependence. Secondly, the effect of a physiotherapy intervention on recovery from musculoskeletal complaints is investigated. The probability of receiving a physiotherapy intervention is estimated, as well as the probability of recovery as a result of this intervention. A longitudinal design is used. Analyses are performed using secondary data at population level. The analytical framework is provided by a Markov model. We use a logit model to estimate transition probabilities of this Markov model. Results show that experience with physiotherapy in the past is an important predictor for receiving physiotherapy in the future. Other predictors of the probability of receiving an intervention are also identified. Furthermore, the results indicate that the effect of a physiotherapy intervention on recovery is negative. It is concluded that both the latter effect and the effect of intervention experience can partly be explained by medicalization, in spite of a presence of 'severe' cases in the intervention group.

In Chapter 3 we discuss the role of duration in the probability that sick workers are selected for an intervention by the occupational physician. This study aims to answer the question whether the relatively high inflow risk into disability for women, compared to that for men, is reflected in a disadvantage in the probability of being called by the occupational physician during sickness absence. This probability is influenced by sociodemographic, health related and work related factors, as well as by duration of sickness absence. Using a proportional hazards model, the 'risk' of being called by the physician within a certain time period (the so-called hazard rate) is estimated for workers that were called in sick in the Netherlands. Kaplan-Meier curves show a gender difference in hazard rate. Women appear to have a higher chance of being called by the occupational physician (i.e. a shorter waiting time). The influence of the covariates on the hazard rate is estimated using a Weibull model. The Weibull estimations show that 
women experience negative duration dependence, while men's duration dependence is constant. It is concluded that the higher chance women have to be called by the occupational physician is not caused by a gender difference in treatment. Rather, it is the result of a gender difference in underlying characteristics. Underlying characteristics that significantly predict the waiting time for the occupational physician are mostly related to the labor market position of the worker.

In Chapter 4 the relationship between the probability of receiving an intervention by the occupational physician and the probability of RTW of sick workers are analyzed. The aim of this study is twofold: (1) to investigate the relationship between the probability of receiving an intervention by the occupational physician and the probability of return to work (RTW) of sick workers; (2) to explore the use of simultaneous modelling of the intervention and RTW processes. Analyses are performed at population level using data from a major longitudinal survey on work incapacity and return to work in the Netherlands. A bivariate probit model is used to estimate the correlation between the probability of intervention and the probability of RTW. A bivariate hazard model is applied to explore the joint distribution of the waiting times for the intervention and RTW. The results of this study show that the probability of receiving an intervention from the occupational physician is not correlated with the probability of RTW. Neither is the timing of both events correlated. The analyses do not indicate that the intervention by the occupational physician provides incentives for sick workers to return to work quicker.

In Chapter 5 we investigate the presence and type of duration dependence in sickness absence. We address the following questions: (1) What are the effects of an intervention by the occupational physician, worker characteristics and socioeconomic factors on the sign and the significance of duration dependence effects? ; and (2) How to adjust the timing of an intervention to different groups of workers? Analyses are performed at population level using data from a major longitudinal survey on work incapacity and return to work in the Netherlands. We estimate a range of semiparametric (piecewise hazard) and parametric (Weibull) models of constant and variable duration dependence. We find evidence for the presence of variable duration dependence. The intervention under study has no significant 
$164 \mid$ Summary

effect on duration dependence, while the age of a worker and his previous absence record have a positive effect. The results are not consistent with the prevailing early intervention principle of Disability Management. Variable duration dependence models can provide valuable insights for policy questions related to the timing and the use of interventions in a population of sick workers.

This thesis is concluded with a general discussion on the contribution of this study to our knowledge about and insight in the impact of interventions on sickness absence in Chapter 6 . The chosen level of analysis can provide a general picture of relationships that exist between aspects of intervention strategies that determine the effectiveness of these interventions (like selection and timing), and RTW. This approach is especially suitable to answer policy questions regarding the use of interventions in a certain population. RTW probability patterns provide leads for future intervention strategies. In this study, RTW was conceptualized as being a change of state, i.e. a transition from 'not working' to 'working'. For the intervention, two states were defined as well ('received intervention' and 'not received intervention (yet)' $)$. This way, we were able to assess the circumstances under which a state transition is likely. We are not able to explain why a transition takes place, however. The presence of duration dependence in sickness absence has important consequences for intervention strategies. If negative duration dependence is found in a population, early intervention is warranted. If positive duration dependence is observed, however, one has to wonder as to whether there is a need of intervention. Using this information we can optimize the timing of future intervention strategies. 


\section{Samenvatting (Summary in Dutch)}

Arbeidsongeschiktheid vormt een belangrijk probleem in veel Europese en NoordAmerikaanse landen, waaronder Nederland. De afgelopen jaren is het aantal arbeidsongeschikten in Nederland schrikbarend toegenomen. Deze studie is gericht op het optimaliseren van interventiestrategieën tijdens de ziekteverzuimperiode om arbeidsongeschiktheid te voorkomen. We beginnen dit proefschrift met een korte historische schets van het systeem van sociale zekerheid in Nederland. In de jaren '50, '60 en '70 werd in Nederland een ruimhartig sociale zekerheidsbeleid gevoerd. De ongekend hoge instroom in de regelingen leidde echter tot snel stijgende kosten. Vanaf de jaren ' 80 is daarom op verschillende manieren geprobeerd de kosten van met name arbeidsongeschiktheid terug te dringen en de instroom te beheersen. Dit is een moeilijke opgave gebleken. $\mathrm{Na}$ jarenlange inspanningen blijkt het effect op het volume arbeidsongeschikten, en de in- en uitstroom lang niet zo groot als gehoopt. Begin twintigste eeuw bereikte het aantal arbeidsongeschikten de magische grens van één miljoen, wat betekent dat 1 op de 7 werknemers in Nederland in meer of mindere mate arbeidsongeschikt was. De afgelopen jaren heeft een steeds verdergaande privatisering van het ziekte- en arbeidsongeschiktheidsrisico plaatsgevonden. Hiermee is het belang van een snelle reïntegratie na uitval uit het arbeidsproces voor betrokkenen steeds groter geworden. Interventies vinden plaats in de ziekteverzuimperiode om de werkhervatting te vergemakkelijken en te versnellen. In toenemende mate vinden deze interventies vroegtijdig in de ziekteverzuimperiode plaats. Effectieve interventie blijkt moeilijk te zijn. Onderzoeken naar de effectiviteit van interventies kennen verschillende problemen, waardoor er nauwelijks zicht is op de effectiviteit van veel interventies. Er is overduidelijk behoefte aan meer effectieve interventiestrategieën om de werkhervatting van uitgevallen werknemers te versnellen. Belangrijke aspecten van interventiestrategieën zijn selectie en timing. Verder speelt de verstreken duur van het verzuim een belangrijke rol. Deze studie beoogt inzicht te geven in deze aspecten van interventiestrategieën. De volgende kwesties komen aan de orde: (a) wie komen er in aanmerking voor een interventie (selectie); (b) wanneer vindt de interventie plaats (timing); en (c) wat is het effect van deze selectie en timing op de werkhervattingskans? Deze kwesties kunnen ons inzicht verschaffen in de impact van interventies tijdens de ziekteverzuimperiode. We 
$166 \mid$ Samenvatting

introduceren een conceptueel kader om interventie in het ziekteverzuimproces weer te geven. Dit wordt in de opeenvolgende hoofdstukken besproken.

Hoofdstuk 2 beschrijft een studie naar het effect van fysiotherapie interventies bij werknemers met klachten aan het bewegingsapparaat. We onderzoeken wie er fysiotherapie krijgt en kijken naar het effect van deze interventie op de kans dat men herstelt van de klachten. Fysiotherapie is een belangrijke interventie voor mensen met klachten aan het bewegingsapparaat. De effectiviteit ervan is echter omstreden. Het gebrek aan bewijs met betrekking tot de effectiviteit is onder meer een gevolg is van tekortkomingen van de onderzoeken die zijn verricht. Deze studie beoogt een paar belangrijke methodologische problemen te ondervangen waardoor we een uitspraak kunnen doen over het effect van fysiotherapie op de herstelkans. We gebruiken een longitudinaal design en schatten de kans op het krijgen van fysiotherapie, alsmede de kans op herstel als gevolg van deze selectie. Het analytisch kader wordt gevormd door een Markov model. Analyses worden uitgevoerd op populatie niveau met behulp van secundaire data. Het sample betreft Britse werknemers. We gebruiken logit modellen om de overgangskansen van het Markov model te schatten. De resultaten laten zien dat ervaring met fysiotherapie in het verleden de kans op het opnieuw krijgen van fysiotherapie significant verhoogt. Enkele andere voorspellers voor de kans op het krijgen van fysiotherapie worden ook geïdentificeerd. De resultaten geven aan dat het effect van fysiotherapie op de herstelkans negatief is. De bevindingen wijzen in de richting van medicalisering.

In hoofdstuk 3 bespreken we de rol van verstreken duur in de kans op het krijgen van een interventie door de arts van de bedrijfsvereniging. We kijken of de relatief hoge arbeidsongeschiktheidskans van vrouwen wordt weerspiegeld in de kans dat zij worden opgeroepen door deze arts. De kans dat iemand wordt opgeroepen wordt beïnvloed door een aantal factoren, waaronder ook de duur van het verzuim. We gebruiken een proportional hazards model om het 'risico' dat iemand in een bepaalde periode wordt opgeroepen door de arts van de bedrijfsvereniging te schatten. Dit gebeurt op een sample van langdurig zieke Nederlandse werknemers. Kaplan-Meier curves laten een man-vrouw verschil zien in oproepkans. Vrouwen blijken een hogere kans (d.w.z. een kortere wachttijd) te hebben om te worden opgeroepen. De invloed van de covariaten op de hazard 
rate wordt geschat door middel van een Weibull model. De Weibull schattingen laten zien dat vrouwen een negatieve duurafhankelijkheid ondervinden met betrekking tot de kans om opgeroepen te worden, terwijl mannen geen duurafhankelijkheid ondervinden. De oproepkansen van mannen ten opzichte van die van vrouwen nemen dus toe naarmate de tijd vordert. Er wordt geconcludeerd dat de hogere kans van vrouwen om te worden opgeroepen niet wordt veroorzaakt door een man-vrouw verschil in behandeling. Eerder is dit het resultaat van een verschil in kenmerken tussen mannen en vrouwen. Kenmerken die de oproepkans voorspellen zijn voornamelijk gerelateerd aan de arbeidsmarktpositie van de werknemer.

Hoofdstuk 4 beschrijft de relatie tussen de kans op het krijgen van een interventie door de arts van de bedrijfsvereniging en de kans op werkhervatting van uitgevallen werknemers. Omdat deze relatie mogelijk endogeen is gebruiken we een simultaan model om dit te onderzoeken. Analyses worden uitgevoerd op populatieniveau met behulp van secundaire data van langdurig zieke Nederlandse werknemers. Een bivariate probit wordt gebruikt om de correlatie tussen de kans op interventie en de kans op werkhervatting te schatten. Een bivariaat hazard model wordt geschat om inzicht te krijgen in de gezamenlijke verdeling van de wachttijden voor de interventie en de werkhervatting. De resultaten laten zien dat de kans op het krijgen van een interventie door de arts van de bedrijfsvereniging niet is gerelateerd aan de werkhervattingskans. Noch is de timing van beide zaken gerelateerd. De analyses wijzen er dus niet op dat de interventie enig effect heeft op de werkhervatting.

In hoofdstuk 5 onderzoeken we de aanwezigheid van en het type duurafhankelijkheid tijdens de ziekteverzuimperiode. De volgende vragen worden gesteld: (1) Wat is het effect van een interventie door de arts van de bedrijfsvereniging, kenmerken van de werknemer en sociaal-economische factoren op de richting en de grootte van de duurafhankelijke effecten; en (2) Hoe kan men de timing van een interventie aanpassen aan verschillende groepen werknemers? Analyses worden uitgevoerd op populatieniveau. We schatten een reeks parametrische en semi-parametrische modellen met constante en variabele duurafhankelijkheid. Bewijs wordt gevonden voor de aanwezigheid van variabele duurafhankelijkheid. De interventie blijkt geen significant effect te hebben op de 
$168 \mid$ Samenvatting

duurafhankelijkheid tijdens ziekteverzuim, terwijl de variabelen leeftijd en verzuimverleden een positief effect blijken te hebben. Vroegtijdige interventie lijkt in dit geval niet effectief. De vraag rijst of er überhaupt moet worden ingegrepen in het geval van positieve duurafhankelijkheid. We concluderen dat modellen voor variabele duurafhankelijkheid waardevolle inzichten kunnen verschaffen in beleidskwesties over de timing en het gebruik van interventies in een populatie van uitgevallen werknemers.

Dit proefschrift wordt besloten in hoofdstuk 6 met een algemene discussie over de toegevoegde waarde van de bevindingen. Het gekozen analyse niveau geeft inzicht in bestaande relaties tussen aspecten van interventiestrategieën (zoals selectie en timing) en werkhervatting. Deze benadering is uitermate geschikt om beleidsvragen te beantwoorden over het gebruik van interventies in een bepaalde populatie. De patronen van werkhervattingskansen over de tijd voor verschillende groepen werknemers geven aanknopingspunten voor het vormgeven van toekomstige interventiestrategieën. In deze studie is werkhervatting geconceptualiseerd als een transitie van 'niet werken' naar 'werken'. Voor de interventie zijn ook twee toestanden geformuleerd ('geen interventie gehad', en 'wel een interventie gehad'). Op deze manier konden we de omstandigheden waaronder een transitie plaatsvindt in kaart brengen. Deze conceptualisering van interventie in het ziekteverzuimproces geeft ons echter geen inzicht in de onderliggende mechanismen die leiden tot de transitie. De aanwezigheid van duurafhankelijkheid tijdens ziekteverzuim heeft belangrijke consequenties voor interventiestrategieën. Als men negatieve duurafhankelijkheid vindt in een bepaalde populatie, lijkt vroegtijdig ingrijpen op zijn plaats om de werkhervatting te versnellen. Vindt men echter positieve duurafhankelijkheid, dan is het de vraag of men überhaupt wel moet interveniëren. Met behulp van deze informatie kunnen we de timing van toekomstige interventiestrategieën optimaliseren. 


\section{Aftiteling (Acknowledgement)}

Het is een wat gek gevoel dat dit proefschrift nu af is en mijn aio-tijd voorbij. De afgelopen vier jaar waren leerzaam, confronterend, enerverend, vormend, bij vlagen frustrerend, maar vooral ook inspirerend. De mensen die mij direct of indirect hebben geholpen in dit proces wil ik hier graag bedanken. Mijn oprechte dank gaat uit naar:

Mijn promotor Prof. dr. Wim Groot en copromotor Dr. Peter P.M. Janssen, voor hun begeleiding, stimulering en betrokkenheid, voor het vele constructieve commentaar op mijn stukken en voor de kansen die ze me hebben gegeven om me verder te ontwikkelen.

Mijn paranimfen en kamergenootjes Sandy en Regien, voor hun interesse in mijn werk en in de andere dingen die mij bezighouden, steun, vriendschap en gezelligheid.

Dr. Angelique de Rijk, voor haar betrokkenheid, behulpzaamheid en collegialiteit, de gezellige congressen, en omdat zij degene is die mij heeft ingewijd in het (probleemgestuurd) onderwijs.

Dr.Niklas Krause, I wish to thank Dr. Niklas Krause for the inspiring collaboration, his detailed and constructive comments on my work, and his great hospitality during my stay in Berkeley.

De leden van de beoordelingscommissie: Prof. dr. M.P.F. Berger, Prof. dr. J.T.M. van Eijk, Prof. dr. Ph. de Jong, Dr. N. Krause, en Prof. dr. C. de Neubourg, voor de tijd die ze hebben genomen om dit proefschrift te beoordelen, en voor hun waardevolle commentaar en suggesties.

Hilde, voor haar onmisbare hulp bij de financiële afhandeling van mijn reizen.

Jan en Will, voor de technische ondersteuning. 
$170 \mid$ Aftiteling

Denise, Paula, Marike, Christa, Marijke, Ester, Annemiek, Astrid, Corné, Brigitte, Nathalie, mijn zusje Jessica en mijn zwemvrienden uit Maastricht, voor hun vriendschap, steun en interesse in mijn werk, en omdat zij hebben gezorgd voor de nodige afleiding.

Inge, Gladys, Aggie, Rineke, Ab, Isel, Peggy, Carla, Milena, Gonnie, Irma, Sandra, Hanneke, Wil, Arno en alle andere BEOZers, die gezorgd hebben, en nog steeds zorgen voor een goede werksfeer en gezellige lunchpauzes.

Mijn moeder Emmy, omdat ze me altijd heeft gestimuleerd om me te ontwikkelen.

en Fedor, omdat hij me eraan herinnert wat echt belangrijk is.

Lieve mensen, mede dankzij jullie heb ik een goede aio-tijd gehad bij BEOZ en is dit boekje nu uit! Bedankt allemaal!

Catelijne

Maastricht, september 2004. 


\section{Curriculum Vitae}

Catelijne Joling was born on January 13th, 1977 in Ede, the Netherlands. She attended CCNV pre-university school in Harderwijk. After her graduation in 1995, she started her University training at the University of Groningen, Faculty of Psychology, Education and Sociology. She studied Human Movement Sciences, and graduated with a specialization in Work and Health.

In 2000 she enrolled as a PhD student at Maastricht University, Department of Health Organization, Policy and Economics (HOPE / BEOZ). During her PhD training she performed the research which is presented in this thesis. The research performed was part of the Autonomy and Participation program of the Care and Public Health Research Institute (CAPHRI), Netherlands School of Primary Care Research (CARE).

During her time as a PhD student, the author was also involved in teaching activities for the Work and Health program of the Faculty of Health Sciences at Maastricht University. She served on the board of the PhD student Association of Maastricht University (ProVum) in 2001. In 2003, the author visited the University of California at Berkeley, Center for Occupational and Environmental Health, and worked there as a visiting scholar for a period of two months.

Catelijne Joling currently works as Assistant Professor of Work and Health, at the Department of HOPE (BEOZ), Maastricht University. 